\title{
Distribution and Targets of the Relaxin-3 Innervation of the Septal Area in the Rat
}

Francisco E. Olucha-Bordonau ${ }^{1}$, Marcos Otero-García ${ }^{1}$, Ana M Sánchez-Pérez ${ }^{2}$, Ángel

Núñez ${ }^{3}$, Sherie $\mathrm{Ma}^{4,5}$ and Andrew L. Gundlach ${ }^{4,6}$

${ }^{1}$ Departamento de Anatomía y Embriología Humana, Facultad de Medicina, Universidad de Valencia, 46010 Valencia, Spain

${ }^{2}$ Departamento de Fisiología, Facultad de Medicina, Universidad de Valencia, 46010

Valencia, Spain

${ }^{3}$ Departamento de Anatomia, Histología y Neurociencia Facultad de Medicina, Universidad Autónoma de Madrid, 28029 Madrid, Spain

${ }^{4}$ Florey Neuroscience Institutes, ${ }^{5}$ Department of Medicine (Austin Health) and ${ }^{6}$ Department of Anatomy and Cell Biology, The University of Melbourne, Victoria 3010, Australia

*Correspondence to: Francisco E. Olucha-Bordonau

Telephone +34-963983504

Facsimile +34-963864159

Email olucha@uv.es

Running title: Relaxin-3 networks in rat septal area

Number of pages: 51

Number of words in abstract: 250

Number of words in introduction: 1075

Number of words in manuscript: 16590

Number of figures: 19

Number of tables: 5

Key words: relaxin-3 like-immunoreactivity, NI, nucleus incertus: septohippocampal system, hippocampal theta rhythm, stress and emotion

Abbreviations used in text: RLN3, relaxin-3; CRF, corticotropin-releasing factor 
Grant sponsors: The Ministry of Health, Spain; Grant number: ISCIII-FIS PI061816 (to FEOB); National Health and Medical Research Council of Australia; Grant number: 520299 (to SM); Grant number: 277609 and 509246 (to ALG); Johnson \& Johnson Pharmaceutical Research \& Development, LLC, San Diego, USA; Collaborative Research Grant (to ALG).
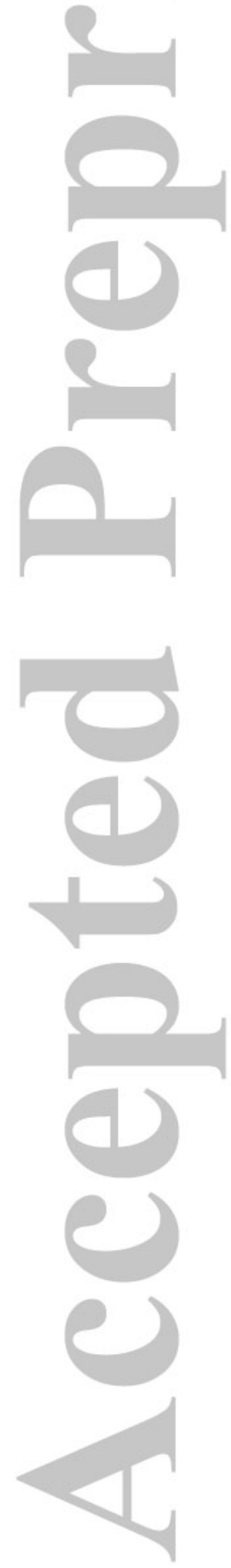


\section{ABSTRACT}

Neural tracing studies have revealed that the rat medial and lateral septum are targeted by ascending projections from the nucleus incertus, a population of tegmental GABA neurons. These neurons express the relaxin-family peptide, relaxin-3; and pharmacological modulation of relaxin-3 receptors in medial septum alters hippocampal theta rhythm and spatial memory. In an effort to better understand the basis of these interactions, we have characterized the distribution of relaxin-3 fibers/terminals in relation to different septal neuron populations identified using established protein markers. Dense relaxin-3 fiber plexuses were observed in regions of medial septum containing hippocampal-projecting choline acetyltransferase (ChAT)-, neuronal nitric oxide synthase (nNOS)- and parvalbumin (PV)- positive neurons. In lateral septum (LS), relaxin-3 fibers were concentrated in the ventrolateral nucleus of rostral LS and the ventral nucleus of caudal LS, with sparse labeling in the dorsolateral- and medialnuclei of rostral LS, dorsal nucleus of caudal LS, and ventral portion nuclei. Relaxin-3 fibers were also observed in the septofimbrial and triangular septal nuclei. In the medial septum, we observed relaxin-3 immunoreactive contacts with ChAT-, PV- and glutamate decarboxylase67-positive neurons that projected to hippocampus; and contacts between relaxin-3 terminals and calbindin- and calretinin-positive neurons. Relaxin-3 co-localized with synaptophysin in nerve terminals in all septal areas, and ultrastructural analysis revealed these terminals were symmetrical and contacted spines, somata, dendritic shafts, and occasionally other axonal terminals. These data predict this GABA/peptidergic projection modulates septohippocampal activity and hippocampal theta rhythm related to exploratory navigation, defensive and ingestive behaviors, and responses to neurogenic stressors.

INDEXING TERMS: nucleus incertus; relaxin-3; septohippocampal system; stress; theta rhythm 


\section{INTRODUCTION}

Arousal neural pathways of the brain are associated with modulation of behavior in accordance with environmental requirements and a key node in the regulation of arousal is the forebrain septal area. Ascending connections from the medial septum to the hippocampus are proposed to provide 'pacemaker' control of hippocampal theta rhythm (Vertes and Kocsis, 1997; Hangya et al., 2009), which may underpin goal-oriented behavior (Vinogradova, 1995) and plastic changes occurring during the formation of cognitive maps (O'Keefe, 1993); whereas descending projections from the lateral septum target a wide variety of subcortical circuits related to visceral and metabolic functions, ranging from aggression, social and sexual behavior to circadian rhythms (Albert and Chew, 1980; Risold and Swanson, 1997a; Veenema and Neumann, 2007).

The septal area plays a central role in controlling hippocampal function, and the importance of the medial septum for 'pacemaking' of hippocampal theta rhythm was noted in early studies (Pestche and Stumpf, 1962; Andersen et al., 1979; Vinogradova, 1995). This view was strengthened by more recent EEG recordings in freely-moving rats that demonstrated that the integrity of the entire medial and lateral septum-hippocampal network is critical for the generation of theta rhythm (Nerad and McNaughton, 2006). There has also been a consensus over many years that the different types of neurons in the septal area play specific roles in generating theta synchrony, with slow-firing cholinergic neurons facilitating hippocampal firing, and parvalbumin GABAergic neurons that innervate GABAergic hippocampal interneurons driving disinhibition of pyramidal or granule cell inhibition, allowing hippocampal synchrony (Freund and Antal, 1988; Freund and Gulyas, 1997; Toth et al., 1997a; Wu et al., 2000), although more recent studies have questioned the relative importance of different neuron populations in awake animals (e.g. Simon et al., 2006).

Neural tract-tracing studies in the rat by our laboratory and others have demonstrated that the septal area is targeted by ascending projections arising from the nucleus incertus (Goto et al., 2001; Olucha-Bordonau et al., 2003). Neurons of the nucleus incertus contain GABA and a range of peptides, such as cholecystokinin, neurotensin, neuromedin B and atrial natriuretic peptide (Kubota et al., 1983; Olucha-Bordonau et al., 2003; Ryan et al., 1995) (see Ryan et al., 2011 for review). Recent studies have revealed that a large population of nucleus incertus neurons express high levels of the peptide, relaxin-3 (RLN3), which is primarily expressed in this region, in addition to smaller adjacent tegmental and midbrain cell groups (Burazin et al., 2002; Bathgate et al., 2003; Tanaka et al., 2005; Ma et al., 2007). The nucleus incertus provides a distinct pattern of ascending projections to raphé nuclei, periaqueductal grey, 
supramammillary nucleus, several hypothalamic nuclei, midline intralaminar nuclei, habenula, amygdala, hippocampus, the septal area and the prefrontal cortex (Goto et al., 2001; Olucha-Bordonau et al., 2003). This pattern of efferents overlaps extensively with the forebrain distribution of RLN3-containing nerve fibers (Tanaka et al., 2005; Ma et al., 2007). The native receptor for RLN3 is G-protein coupled receptor-135 (GPCR135) (Liu et al., 2003) or 'RXFP3' (Bathgate et al., 2006) and the regional topography of RXFP3 in rat brain is largely consistent with the distribution of RLN3-positive fibers (Ma et al., 2007).

The strong connections of the nucleus incertus with a number of brain areas involved in brainstem-diencephalic modulation of hippocampal theta rhythm, such as the median raphé, supramammillary nucleus and the medial septum (Vertes et al., 1993a; Vertes and Kocsis, 1997) lead us to hypothesize a role for the nucleus incertus in theta rhythm activation. We subsequently demonstrated that stimulation of nucleus incertus in urethane-anesthetized rats increased theta and decreased delta activity of the hippocampus, whereas, electrolytic lesion of the nucleus incertus abolished hippocampal theta induced by stimulation of the nucleus reticularis pontis oralis (RPO) (Nunez et al., 2006), a key brainstem generator of hippocampal theta rhythm (Vertes, 1981; Vertes, 1982; Nuñez et al., 1991; Vertes et al., 1993b; Vertes and Kocsis, 1997). The hippocampal area in which field potentials were recorded receives only sparse inputs from the nucleus incertus, and it was concluded that the influence of the nucleus incertus on hippocampal theta rhythm was most likely mediated by its effects within the medial septum and/or other lower brain structures. In fact, the nucleus incertus is presumed to be the major relay station of RPO inputs to the medial septum (and hippocampus), as there are no direct projections from the RPO to hippocampus (Teruel-Marti et al., 2008). Additionally, RPO stimulation results in theta synchronization in the hippocampus and nucleus incertus, at the same frequency and with a high degree of coherence (Cervera-Ferri et al., 2011). Furthermore, because the nucleus incertus is a RLN3 locus in the brain, we hypothesized that RLN3 might contribute to these effects. Consistent with the presence of RLN3 and RXFP3 in the medial septum, injections of a selective RXFP3 agonist peptide (R3/I5; Lui et al., 2005) into this area increased theta activity of the hippocampal field potential in urethane-anesthetized rats, which was significantly attenuated by prior injection of a selective RXFP3 antagonist peptide, R3(B $\Delta 23-27) R / I 5$ (Kuei et al., 2007) (Ma et al., 2009b). R3/I5 infusion into the medial septum also increased hippocampal theta in rats in a familiar home cage environment, whereas R3(B $\Delta 23-27) \mathrm{R} / \mathrm{I} 5$ decreased hippocampal theta in rats exploring a novel enriched context (Ma et al., 2009b). These data support a significant contribution of nucleus incertus and RLN3 inputs to the septum in regulating a fundamental 
brain activity and associated complex behaviors, and therefore characterization of the anatomical and cellular interactions between these inputs and their targets is required.

The goal of the current study, therefore, was to map the distribution of RLN3 positivefibers throughout the rat septum in relation to particular 'landmark' neuron populations. This was achieved in a series of double-labeling experiments using a characterized RLN3 antiserum and antisera for established protein markers expressed by neurons in the septal area. We examined whether RLN3-positive fibers made close contacts with the major septal neuron types in triple- and quadruple-labeling studies combined with confocal microscopy analysis. We also examined the co-localization of RLN3 staining with that for the presynaptic marker, synaptophysin (Jahn et al., 1985) to assess the presence of RLN3 within synapses in the septum. Finally, we conducted ultrastructural analyses of RLN3-positive synapses in the septal area using electron microscopy. The data obtained provide strong anatomical evidence for a role of RLN3 in modulating the activity of specific neurons in the septum that have direct connections with the hippocampus, which may underlie the effects of relaxin-3/RXFP3 signalling on hippocampal theta rhythm and associated complex behaviors.

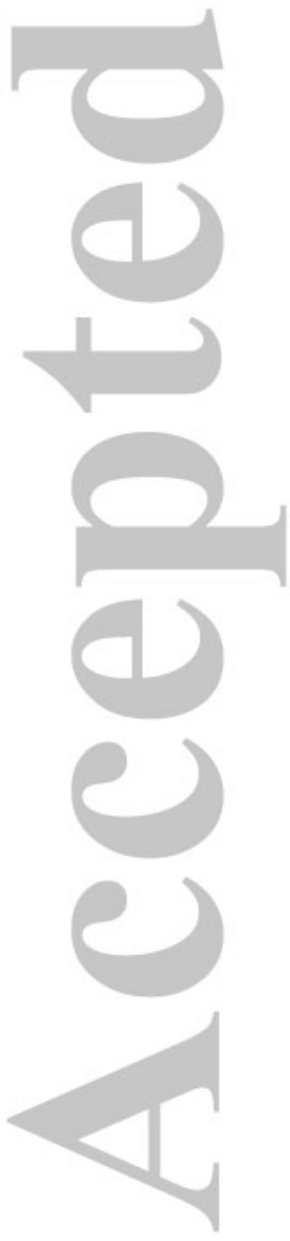




\section{MATERIALS AND METHODS}

Animals

Male Sprague-Dawley rats $(300-400 \mathrm{~g}, \mathrm{n}=22)$ were used in this study. All protocols were approved by the Animal Ethics Committees of the Universitat de València (Spain), Universidad Autónoma de Madrid (Spain), and Howard Florey Institute (Australia). All procedures were in line with directive 86/609/EEC of the European Community on the protection of animals used for experimental and other scientific purposes and the guidelines on animal welfare issued by the National Health and Medical Research Council of Australia. Details of the experimental protocols employed are provided below (see Table 1).

\section{Tracer injections}

Rats were anesthetized with ketamine (Imalgene $55 \mathrm{mg} / \mathrm{kg}$ i.p.) and xylacide (xilagesic $20 \mathrm{mg} / \mathrm{kg}$ i.p.) and trephine holes were drilled in the skull. Anterograde tracer injections into the nucleus incertus were made using $40 \mu \mathrm{m}$ I.D. glass micropipettes (coordinates from bregma: AP $-9.6 \mathrm{~mm}$, ML $0 \pm 0.2 \mathrm{~mm}$ and DV $7.4 \mathrm{~mm}$ ). For anterograde tracing, 15\% miniruby (mR, $10 \mathrm{kD}$ biotinylated dextran amine rhodamine-labeled, Cat No. D-3312, Molecular Probes, Paisley, UK) dissolved in 0.1M PB, pH 7.6 was iontophoretically delivered into the nucleus incertus by passing a positive current of $1 \mu \mathrm{A}, 2 \mathrm{sec}$ on, $2 \mathrm{sec}$ off over 10 min. The micropipette was left in place for an additional $10 \mathrm{~min}$ before withdrawal. Injections of $4 \%$ Fluorogold retrograde tracer dissolved in $\mathrm{dH}_{2} \mathrm{O}$ (FG, 5-hydroxystabilamide (Cat No 80014, Biotium, Hayward, CA, USA), were made into the hippocampus (coordinates from bregma: AP -5.4 mm, ML $5 \mathrm{~mm}$, DV $5 \mathrm{~mm}$ ) and the anterior hypothalamus (coordinates from bregma: AP -1.8 mm, ML $1 \mathrm{~mm}, \mathrm{DV}-8.8 \mathrm{~mm}$ ). Volumes of $0.04-0.08 \mu \mathrm{l}$ of $4 \% \mathrm{FG}$ in $\mathrm{dH}_{2} \mathrm{O}$ were injected using a $40 \mu \mathrm{m}$ I.D. glass micropipette attached to an IM-300 microinjector (Narishige, Tokyo, Japan) over $10 \mathrm{~min}$. After injections, the surgical wound was sutured and rats were injected with Buprex (0.05 mg/kg, i.p., Lab Esteve, Barcelona, Spain) for analgesia.

Rats were then allowed to recover for at least 7 days, prior to further processing.

\section{Brain fixation and sectioning}

For analysis of tracing studies, rats were deeply anesthetized with Nembutal $(150 \mathrm{mg} / \mathrm{kg}$ i.p., Euthalender, Barcelona, Spain) and transcardially-perfused with saline $(250 \mathrm{ml})$ followed by fixative (4\% paraformaldehyde in $0.1 \mathrm{M} \mathrm{PB}, \mathrm{pH} 7.4)$ for $30 \mathrm{~min}(\sim 500 \mathrm{ml})$. Brains were dissected and immersed in the same fixative for $4 \mathrm{~h}$ at $4^{\circ} \mathrm{C}$. They were then incubated in $30 \%$ sucrose in $0.01 \mathrm{M} \mathrm{PBS} \mathrm{pH7.4} \mathrm{for} 48 \mathrm{~h}$ at $4^{\circ} \mathrm{C}$. The brains were cut coronally at the level of the flocculi by using a rat's brain methacrylate matrix in order to obtain reliable sections 
displaying equal orientation. Coronal sections $(40 \mu \mathrm{m})$ were collected using a freezing slide microtome (Leica SM2010R, Leica Microsystems, Heidelberg, Germany). For each brain, 6 series of sections were obtained and collected free-floating in 0.01M PBS.

For electron microscopy, rats were transcardially-perfused with saline $(250 \mathrm{ml})$ followed by fixative ( $4 \%$ paraformaldehyde, $15 \%$ saturated picric acid and $0.2 \%$ glutaraldehyde in $0.1 \mathrm{M} \mathrm{PB}, \mathrm{pH} 7.4)$ for $30 \mathrm{~min}$ ( $\sim 500 \mathrm{ml})$. Brains were dissected and placed into cold 0.1M PB, pH7.4 containing $0.02 \%$ sodium azide. Coronal blocks $(2 \mathrm{~mm})$ were cut with an acrylic brain matrix template and each block was further sectioned at $50 \mu \mathrm{m}$ with a Leica 2000 Vibratome (Leica Microsystems). From each block, 6 series of sections were obtained.

\section{Antibody characterization}

A number of characterized antisera were used in these studies (see Table 2).

The goat polyclonal choline acetyltransferase (ChAT) antiserum (Cat No. AB144P, Chemicon, Temacula, CA, USA) stains a single band of 68-70 kD molecular weight on Western blot analysis of mouse brain lysate (manufacturer's technical data). Its antigen specificity has been determined by preadsorption with the appropriate purified protein. There was no labeling when the antisera dilution was preabsorbed with human placental ChAT (fig 1 in Rico and Cavada, 1998).

The neuronal nitric oxide synthase (nNOS) antibody (Cat No. N2280, Sigma, St Louis, MO, USA) is a mouse IgG1 monoclonal and labels a band of $155 \mathrm{kD}$ by western blot of rat's cortical cultured neurons, which almost disappears when nNOS expression is downregulated (Dhar et al., 2009). We observed a distribution pattern and cellular morphology of nNOSpositive neurons in medial septum similar to that reported earlier (Peng et al., 1994).

The calretinin (CR) antibody (Cat No. 6B3, Swant, Bellinzona, Switzerland) is a mouse monoclonal antibody which recognizes a single band of $29 \mathrm{kDa}$ in Western blots of different vertebrate species including mice and rats (manufacturer's data) and does not produce any specific staining in immunohistochemical studies in CR knockout mice (Schiffmann et al., 1999)

The calbindin (CB-28kD) antibody (Cat No. 300, Swant) is a mouse IgG1 (Celio et al., 1990). It recognizes a single band of $28 \mathrm{kDa}$ in Western blots of different vertebrate species including mice and rats (manufacturer's data). It labels a subpopulation of neurons in normal mouse brain, but not brain sections from CB-28 knockout mice (Airaksinen et al., 1997).

The monoclonal parvalbumin (PV) antibody (Cat No. 235, Swant) was produced by hybridization of mouse myeloma cells with spleen cells from mice immunized with PV 
purified from carp muscles (Celio et al., 1988). It recognized a single $12 \mathrm{kD}$ protein (pI 4.9) on a 2-dimensional immunoblot of rat cerebellar tissue; values identical to those expected for purified PV (Celio et al., 1988); and labeled a subpopulation of neurons in normal brain, but did not stain the brain of PV knockout mice (Raymackers et al., 2003).

The antibody against glutamate decarboxylase-67 (GAD-67), (Cat No. MAB5406, Chemicon) recognizes a single band of $67 \mathrm{kDa}$ on Western blot from rat brain lysate (Fong et al., 2005) (Kay et al., 2011). The signal was reduced in a Western blot of striatum from a heterozygous GAD67 knockout mouse, compared to a wild-type mouse; and immunostaining was also reduced in the central nervous system of this GAD67 mutant (Heusner et al., 2008). The distribution pattern of GAD67 positive neurons we observed in the medial septum was similar to that described by (Bassant et al., 2005).

The tyrosine hydroxylase (TH) antibody (clone TH-2; Sigma) was raised in mouse. Indirect immunoblot analysis of proteins obtained from rat PC-12 pheochromocytoma 12 cells recognizes a single band of approximately $60 \mathrm{kDa}$ corresponding to rat $\mathrm{TH}$ (manufacturer's technical information). The pattern of TH staining in the septal area was identical to that reported earlier (Risold and Swanson, 1997).

The synaptophysin antibody clone SVP-38 (Sigma-Aldrich, St. Louis, MO; S5768) recognizes a 38-kDa molecular weight band in Western blot analysis of presynaptic vesicles (Wheeler et al., 2002; Morris et al., 2005; Flores-Otero et al., 2007). This antibody fails to produce specific immunolabeling in brain tissue from synaptophysin-deficient mice (Eshkind and Leube, 1995).

The polyclonal relaxin 3 (RLN3) antiserum, was raised against a synthetic peptide equivalent to amino acid residues $85-101$ of the pro-RLN3 peptide (Ma et al., 2007). These residues are contained in the $\mathrm{C}$-peptide region and are identical in mouse and human, with one amino acid mismatch from the rat sequence (Bathgate et al., 2002; Burazin et al., 2002). The peptide was conjugated through a C-terminal cysteine to keyhole limpet hemocyanin and injected subcutaneously with Freund's complete adjuvant. Bleeds were tested using dot blotting for immunoreactivity with the peptide epitope and mouse pro-RLN3 (Ma et al., 2007). The antiserum was then purified using an affinity column. No staining was seen in mice in which the relaxin-3 gene had been deleted (Ma et al., 2007; Smith et al., 2010).

Finally, the specificity of the Fluorogold antibody (Biotium) was verified by the presence and absence of labeling in rats injected or not injected with FG, respectively. 


\section{Double immunohistochemistry for RLN3 and CB-28kD, PV, TH, nNOS, ChAT or FG}

For analysis of RLN3 in nerve fibers in relation to other markers of septal neurons, a double-label immunohistochemistry protocol was used. In cases where primary antibodies were raised in different host species (rabbit and mouse), a combination of both antibodies in a single primary antibody incubation was used. In cases where primary antibodies were from the same host species, sequential primary and secondary antibody incubations was separated by overnight rinsing. For single primary antibody incubations, sections were rinsed twice in Tris-buffered 0.05 M saline $\mathrm{pH} 8.0$ (TBS) and transferred to blocking solution (4\% normal donkey serum (NDS), $2 \%$ bovine serum albumin (BSA) and $0.2 \%$ Triton X100 in TBS) for 1 $\mathrm{h}$ at room temperature (RT). Sections were then transferred to incubation media containing 1:2,500 rabbit anti-RLN3 (Ma et al., 2007) and either 1:5,000 mouse anti-PV (Swant), 1:5,000 mouse anti-CB-28kD (Swant), 1:2,500 mouse anti-CR (Swant), 1:10,000 mouse antityrosine hydroxylase (Sigma), 1:500 mouse anti-nitric oxide synthase (Sigma) or 1:1,000 goat anti-ChAT (Chemicon) in TBS containing 2\% NDS, 2\% BSA and 0.2\% Triton X100 for $48 \mathrm{~h}$ at $4^{\circ} \mathrm{C}$. RLN3 and other neuronal markers were then revealed consecutively (see Table 2). For RLN3, sections were rinsed twice in TBS and incubated in biotinylated secondary antibody (1:200 biotinylated donkey anti-rabbit; Cat No. 711-065-152, Jackson Immunoresearch, West Grove, PA USA) for $2 \mathrm{~h}$ at room temperature. Sections were then rinsed twice in TBS and transferred to 1:100 ABC (Vectastain, Cat No. PK-6100; Vector Laboratories, Burlingame, CA, USA). After rinsing $(2 \times$ TBS $)$ the immunolabeling was revealed as a black reaction product by immersing the sections in $0.025 \% \mathrm{DAB}, 0.5 \%$ ammonium nickel sulfate, $0.0024 \%$ $\mathrm{H}_{2} \mathrm{O}_{2}$ in Tris $\mathrm{HCl}$, pH 8.0. Sections were then rinsed for at least $2 \mathrm{~h}$. Septal cell markers were then revealed by incubation in appropriate biotinylated secondary antibody (1:200 biotinylated donkey anti-mouse, Cat No. 715-065-150, Jackson; or 1:200 donkey anti-goat, Cat No. 705-065-147, Jackson) for $1 \mathrm{~h}$. Sections were then rinsed twice in TBS and incubated in 1:100 ABC (Vector) for $1 \mathrm{~h}$. After rinsing $(2 \times \mathrm{TBS})$ the immunolabeling was revealed as a brown reaction project by incubating the sections in $0.025 \% \mathrm{DAB}, 0.0024 \% \mathrm{H}_{2} \mathrm{O}_{2}$ in Tris $\mathrm{HCl}$, pH 7.6. Following several rinses in 0.01M PBS, sections were mounted on chrome alum gelatin-coated slides, air-dried, dehydrated with graded ethanol, cleared with xylene, and coverslipped with DPX (Sigma).

For double-RLN3/FG staining, sections were rinsed twice in 0.05 M TBS, pH 8.0 and transferred to blocking solution (4\% NDS, 2\% BSA and $0.2 \%$ Triton X100 in TBS) for $1 \mathrm{~h}$ at RT. Sections were then transferred to incubation media containing 1:2,500 rabbit anti-RLN3

in TBS containing $2 \% \mathrm{NDS}, 2 \% \mathrm{BSA}$ and $0.2 \%$ Triton $\mathrm{X} 100$ for $48 \mathrm{~h}$ at $4^{\circ} \mathrm{C}$. Sections were 
then rinsed twice in TBS and incubated in biotinylated secondary antibody (1:200 biotinylated donkey anti-rabbit; Jackson). Sections were rinsed twice in TBS and transferred to 1:100 ABC (Vectastain, Cat No. PK-6100, Vector). After rinsing $(2 \times$ TBS), immunolabeling was revealed by immersing the sections in $0.025 \% \mathrm{DAB}, 0.5 \%$ ammonium nickel sulfate, $0.0024 \% \mathrm{H}_{2} \mathrm{O}_{2}$ in Tris $\mathrm{HCl}, \mathrm{pH}$ 8.0. After this first reaction, sections were rinsed overnight at $4^{\circ} \mathrm{C}$. The next day, sections were incubated with rabbit anti-FG (Chemicon) in TBS containing $2 \%$ NDS, $2 \%$ BSA and $0.2 \%$ Triton X100 overnight at RT. The next day, after 24 rinses in TBS, sections were incubated in biotinylated secondary antibody (1:200 biotinylated donkey anti-rabbit; Jackson). Sections were then rinsed $(2 \times$ TBS and transferred to 1:100 $\mathrm{ABC}$ (Vectastain). After rinsing $(2 \times \mathrm{TBS})$, immunolabeling was revealed by immersing the sections in $0.025 \% \mathrm{DAB}, 0.0024 \% \mathrm{H}_{2} \mathrm{O}_{2}$ in Tris $\mathrm{HCl}, \mathrm{pH}$ 7.6. Following several rinses in $0.01 \mathrm{M}$ PBS, sections were mounted on chrome alum gelatin-coated slides, air-dried, dehydrated with graded ethanol, cleared with xylene and coverslipped with DPX (Sigma).

\section{Immunofluorescent detection of neuronal markers in the medial septum}

For detection of medial septal marker proteins, sections were rinsed $2 \times 10 \mathrm{~min}$ and immersed in a blocking media of TBS containing 4\% NDS, 2\% BSA and $0.1 \%$ Triton X-100 for $1 \mathrm{~h}$ at RT. Sections were then incubated in primary antibody solution containing $1: 1,250$ rabbit anti-RLN3 and either 1:2,500 mouse anti-PV (Swant), 1:2,500 mouse anti-CB-28kD (Swant), 1:1,250 mouse anti-CR (Swant), 1:250 mouse anti-nitric oxide synthase (Sigma), 1:500 goat anti-ChAT (Chemicon), 1:1,000 mouse anti-GAD67 (Chemicon) or 1:1,000 mouse anti-synaptophysin (Sigma) in TBS containing 2\% NDS, 2\% BSA and 0.2\% Triton X100 for $48 \mathrm{~h}$ at $4^{\circ} \mathrm{C}$. Sections were then rinsed $(3 \times \mathrm{TBS})$ and incubated in 1:200 FITC-labeled donkey anti-rabbit (Cat No. 711-095-152, Jackson) and 1:200 Texas Red-labeled donkey anti-mouse (Cat No. 715-075-150, Jackson); for quadruple labeling 1:200 Cy5-labeled donkey antimouse (Cat No. 715-175-020, Jackson) or 1:200 Cy5-labeled donkey anti-goat (Cat No. 705175-003, Jackson) in TBS. (Texas Red-labeled secondary antibody was not used in mRinjected cases). Sections were then briefly rinsed in 0.01M PBS and mounted on chrome-alum gelatin-coated slides, air-dried, dehydrated in graded ethanol and coverslipped with DPX.

\section{RLN3 immunocytochemistry for electron microscopy}

Following vibratome sectioning aldehydes were reduced by immersing sections in $1 \%$ $\mathrm{NaBH}_{4}$ in $0.1 \mathrm{M}$ PB for $15 \mathrm{~min}$. Sections were then rinsed $6 \times 5 \mathrm{~min}$ in $0.1 \mathrm{M}$ in PB. Sections were cryoprotected by immersion in a solution of $10 \%$ glycerol, $25 \%$ sucrose in $0.05 \mathrm{M}$ PB at $\mathrm{pH} 7.4$ for $1 \mathrm{~h}$ and passed through 3 cycles of freeze-thawing with liquid nitrogen for 2-3 sec 
to improve reagent penetration into the tissue during the histochemical reactions. Sections were then rinsed in $0.1 \mathrm{M} \mathrm{PB}$ and incubated in blocking solution (4\% NDS, $2 \%$ BSA in $0.1 \mathrm{M}$ PB) for $1 \mathrm{~h}$ at RT. Sections were then transferred to incubation media containing 1:1,250 rabbit anti-RLN3 in PB for $72 \mathrm{~h}$ at $4^{\circ} \mathrm{C}$. After incubation, sections were rinsed twice in $\mathrm{PB}$ and incubated in biotinylated secondary antibody (1:200 biotinylated donkey anti-rabbit, Jackson). Sections were then rinsed twice in PB and incubated in 1:100 ABC (Vectastain). After rinsing $(2 \times \mathrm{PBS})$, sections were revealed with $0.015 \% \mathrm{DAB}, 0.004 \% \mathrm{H}_{2} \mathrm{O}_{2}$ in $0.1 \mathrm{M} \mathrm{PB}$ for $20 \mathrm{~min}$. Sections were then rinsed $4 \times 10 \mathrm{~min}$ in $0.1 \mathrm{M} \mathrm{PB}$. Osmication was performed by immersing sections in $1 \%$ osmium tetroxide (Sigma), $7 \%$ glucose in $0.1 \mathrm{M}$ PB for $1 \mathrm{~h}$ and rinsed $3 \times 10 \mathrm{~min}$ in $0.1 \mathrm{M}$ PB. Inclusion was conducted in graded series of ethanol $(30 \% 2 \times$ $3 \mathrm{~min}, 50 \% 2 \times 10 \mathrm{~min}, 70 \% 2 \times 10 \mathrm{~min}, 2 \%$ uranyl acetate in $70 \%$ ethanol $75 \mathrm{~min}, 70 \% 2 \times$ $3 \mathrm{~min}, 96 \% 2 \times 10 \mathrm{~min}, 100 \% 3 \times 10 \mathrm{~min}$ ). Sections were then immersed in propylene oxide $(2 \times 8 \mathrm{~min})$ and embedded in Durcopan resin (Fluka, Buchs, Switzerland) overnight at RT. On the following day, sections were sandwiched between two acetate sheets and embedded in the resin for $72 \mathrm{~h}$ at $60^{\circ} \mathrm{C}$. Semi-thin sections were obtained with an Ultracut ultramicrotome (Leica Microsystems) and selected areas were re-sectioned into ultrathin sections and examined with a Jeol JEM-1010 electron microscope (Jeol, Tokyo, Japan). Images were captured with a MegaView III digital camera and the AnalySIS software (Olympus, Münster, Germany).

\section{Immunohistochemistry analyses}

DAB immunohistochemistry was studied using a Nikon Eclipse E600 microscope with a DMX2000 digital camera (Nikon, Tokyo, Japan) and maps were constructed using a camera lucida tube attached to a Zeiss Axioskop microscope (Zeiss, Munich, Germany) (Fig. 1). Drawings were made with $20 \times$ and $40 \times$ magnification, scanned and reduced to the final size. As an example, a 40× construction of a map of a section double stained for RLN3 and CB28kD is illustrated in Fig 1A. Photomicrographs of a number of specific areas within the section illustrating the comparative staining are also provided (Fig. 1B-F). Confocal immunofluoresence was analyzed with a laser confocal scan unit TCS-SP2 equipped with argon and helio-neon laser beams attached to a Leica DMIRB inverted microscope (Leica Microsystems). Quadruple scans were made to identify FG, mR/Texas red, FITC and Cy5. Wavelengths for FG excitation were $351 \mathrm{~nm}$ and $364 \mathrm{~nm}$ and for emission 382-487 nm; $\mathrm{mR} /$ Texas red wavelength for excitation was $433 \mathrm{~nm}$ and for emission 560-618 nm; FITC wavelength of excitation was $488 \mathrm{~nm}$ and for emission was $510-570 \mathrm{~nm}$; Cy5 wavelength of 


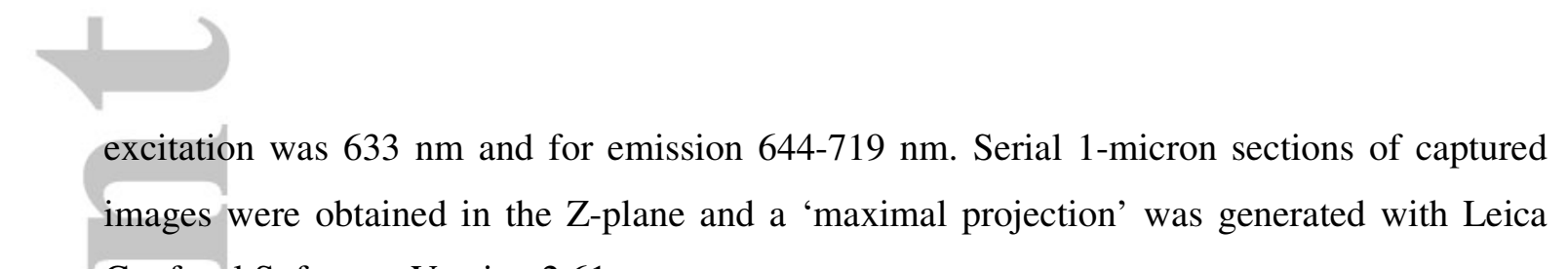
Confocal Software, Version 2.61.
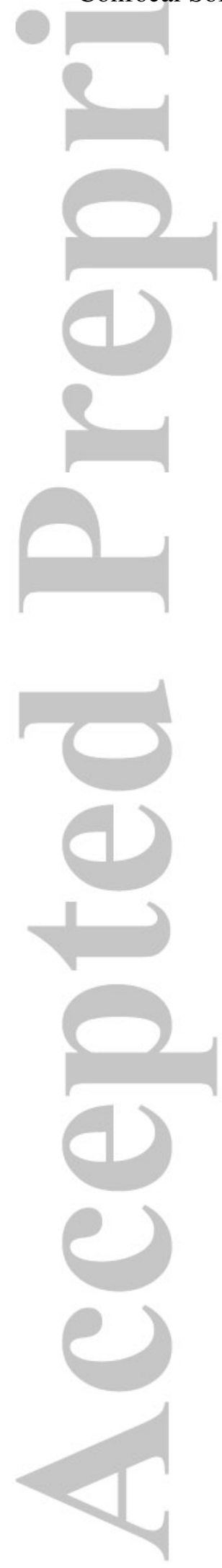


\section{RESULTS}

RLN3-containing nerve fibers were observed in abundance in the medial and lateral septum. In a series of comparative staining experiments, we documented their distribution in the coronal plane relative to retrograde labeling with Fluorogold (FG) from the hippocampus and anterior hypothalamus and anterograde labeling of nucleus incertus projections to the septal area with miniruby (Figs 2-6), as well as to a number of septal neuron populations labeled by protein/enzyme markers (see Figs 4 and 7-15). For neuronal markers we used the calcium-binding proteins, parvalbumin (PV), calbindin-28kD (CB-28kD) and calretinin (CR); and the enzymes, choline acetyltransferase (ChAT), neuronal nitric oxide synthase (nNOS) and tyrosine hydroxylase (TH). We made a semi-quantitative estimation of the density of RLN3 fibres relative to markers for the medial septum (Table 3) and the lateral septum (Table 4). We also assessed the co-localization of RLN3 staining with that for the presynaptic marker synaptophysin to assess the presence of RLN3 within synapses in the septum (Figs 16 and 17). Finally, we performed ultrastructural analyses of RLN3-positive synapses in the septal area using electron microscopy (Fig. 18).

The septal area was divided into five coronal levels according to cytoarchitectonic and external landmarks, and labeling was summarized on maps at each of these levels. Level 1 contained the insula of Calleja magna ( bregma $1.00 \mathrm{~mm}$ ); at level 2, a boundary appeared between the medial septum and the lateral septum ( bregma $0.75 \mathrm{~mm}$ ); at level 3, the ventral division of the lateral septum was evident ( $\sim$ bregma $0.50 \mathrm{~mm}$ ); at level 4 , the fornix appeared at the dorsal tip of the medial septum ( bregma $0.30 \mathrm{~mm}$ ); and at level 5, the fibers of the anterior commissure crossed to the contralateral side ( bregma $0.05 \mathrm{~mm}$ ).

\section{Cytoarchitectonics}

In general, we have adopted the parcellation of the lateral septum described by Risold and Swanson (1997b) and the description of the medial septum and posterior septal area by Jakab and Leranth (1995). Accordingly, the lateral septum is composed of three main portions caudal (LSc), rostral (LSr) and ventral (LSv). In turn, the rostral portion is composed of three nuclei - the dorsolateral (LSr-dl), ventrolateral (LSr-vl) and medial (LSr-m). The caudal division also consists of dorsal (LSc-d) and ventral (LSc-v) nuclei. As there are no clear borders between these nuclei, several neuronal markers were used to establish approximate boundaries. In the original work by Risold and Swanson (1997b), additional subnuclei could be delineated within the dorsolateral and ventrolateral nuclei using the specific markers, calcitonin gene-related peptide or vasopressin. We discovered that $\mathrm{CB}-28 \mathrm{kD}$ and $\mathrm{TH}$ also 
provide landmarks for the basis of further subdivisions. In our descriptions however, we have adopted general divisions of the lateral septal area (Risold and Swanson, 1997b).

The medial septum can be divided cytoarchitectonically into vertical (vMS) and horizontal (hMS) portions. The vMS corresponds to both the medial septum and the vertical limb of the diagonal band and the hMS corresponds to the horizontal limb of the diagonal band. In addition, the medial septum consists of hippocampal-projecting neurons and additional divisions can be delineated using other landmarks. For example, staining for CRimmunoreactivity revealed an "inverted V-shaped" region of neurons and processes capping the dorsolateral part of the medial septum (data not shown).

In the posterior part of the septal area, we observed densely packed CR-positive neurons in the triangular septal nucleus. In addition, rows of CR-labeled neurons appeared between the fimbriafornicis, which we have identified as the septofimbrial nucleus.

\section{Tracer injections}

In order to obtain a better delineation between medial and lateral septum, we made two different retrograde tracer injections: one into the anterior hypothalamic area (Fig. 3A) that mainly labels neurons of lateral septal area (Fig. 3B,C); and the other into the hippocampus (Fig. 3D) that mainly produced retrogradely labelled neurons in the medial septum (Fig. 3E,F). In both cases, large injections were made in order to obtain maximal retrogradelabeling throughout the septal area. For the anterior hypothalamus, the maps constructed (MNC9 case) correspond to an injection centred in the posterior division of the anterior hypothalamic nucleus (Fig. 3A). Diffusion of the tracer also extended rostrally to the anterior hypothalamic nuclei and caudally to the tuber cinereum and anterior levels of the ventromedial hypothalamic nucleus. In cases of tracer diffusion to the anterior hypothalamic nuclei, retrograde labeling in the septal area was observed in rostral and ventral portions of the lateral septum. No retrograde labeling was obtained in the dorsal caudal lateral septal nucleus (Fig. 3C) and only disperse labeling was observed in the septofimbrial nucleus and triangular septal nucleus of the posterior septum. In addition, we observed a band of retrograde labeling in the lateral region of the medial septum (Fig. 3C) that continued ventrally towards the horizontal limb. Hippocampal FG injections were made in the ventralcaudal area (Figs 2A,B and 3D) and others between the dorsal and ventral regions, and included the CA1, CA3 and dentate gyrus. In all cases, retrograde labeling was observed in the vMS (Fig. 3E,F). 


\section{Distribution of nucleus incertus and RLN3-positive afferents throughout the septal area}

The regional pattern of anterograde labeling of nerve axons/terminals in the septal area produced by miniruby injections into the nucleus incertus was similar to that observed after staining for RLN3-immunoreactivity, across all of the five coronal levels assessed (Figs 4 and 5). These distributions overlapped the distribution of ChAT-labeled neurons in the medial septum (Fig. 4) and both the neurons retrogradely-labeled from the ventral hippocampus present in the medial septum (Fig. 5) and the neurons retrogradely-labeled from the anterior hypothalamus that were most abundant in the lateral septum (Fig. 6). At level 1, only dispersed fibers (RLN3 and mR-labeled nucleus incertus fibers) were present in the lateral septal region (Figs 4A and 5A). At levels 2, 3 and 4 the co-occurrence of ChAT and mRlabeled fibers became more evident (Fig. 4B-D), as observed between hippocampal projections and RLN3-positive fibers (Fig. 5B-D). At levels 2 and 3, we observed a band of RLN3-positive fibers that ran parallel to the pial surface in the lateral septum, occupying the ventrolateral rostral lateral septum nucleus ( $\mathrm{LSr}-\mathrm{vl}$ ) and the ventral caudal lateral septum nucleus (LSc-v) (Figs 4B,C and 5B,C). At level 4, two different groups of RLN3- and mRpositive fibers were observed in areas corresponding to the vertical and horizontal portions of the medial septum, with an intervening gap corresponding to the anterodorsal preoptic nucleus (ADP) and basal substantia innominata (SIB) (Figs 4D and 5D). In the lateral septum, the pial band of RLN3/mR-fibers became more evident, spreading through the ventral caudal lateral septum nucleus (LSc-v) (Figs 4D and 5D), which contained dense retrograde-labelling from the anterior hypothalamus (Fig. 6D). At levels 4 and 5, we observed RLN3/mR-fibers running parallel to the fornix within the septofimbrial nucleus (SFi). In addition, some groups of fibers were present in the triangular septal nucleus (TS) (Figs 4D,E, 5D,E and 6D,E).

\section{Coronal level 1 (bregma $+\mathbf{1 . 0 0} \mathbf{~ m m})$}

The most rostral level examined was aligned with the insula of Calleja magna ( bregma $1.00 \mathrm{~mm}$ ), where a narrow cavity is present in the dorsal midline of the medial septum (vMS). The medial septum is clearly differentiated from the lateral septum as it contains a vertical strip of large neurons. The central lateral septum is occupied by the rostral portion, which in turn, contains three nuclei - the medial, dorsolateral and ventrolateral - that are dorsal to the insula of Calleja magna. The dorsal area is occupied by the caudal division of the lateral septum (LSc) and the 'circular' septohippocampal nucleus (Fig. 7A). RLN3-immunoreactive fibers were not observed in the LSc or in the septohippocampal nucleus; and the strongest RLN3-labeling occupied an area containing neurons retrogradely-labeled from the 
hippocampus (Fig. 7B). PV-positive neurons were present in a more restricted region close to the midline (Fig. 7C), whereas CR-positive neurons were concentrated in a peripheral zone of the vMS (Fig. 7F). In contrast CB-28kD cells occupied a more extensive septal region comprising both MS and a narrow band just over the insula of Calleja (Fig 7E).

\section{Coronal level 2 (bregma $+\mathbf{0 . 7 5} \mathbf{~ m m}$ )}

At this level, a clear difference was observed between the cytoarchitectonic configuration of the medial and lateral septum, with a band of TH-positive processes between the two areas that corresponds to the medial rostral lateral septum nucleus ( $\mathrm{LSr}-\mathrm{m})$. Lateral to the septohippocampal nucleus there was a band of loosely packed neurons corresponding to the caudal lateral septum, containing the dorsal (LSc-d) and ventral (LSc-v) nuclei. In the LSc-v, a plexus of RLN3-labeled fibers appeared to run just medial to the ventricular ependymus (Fig. 5B). The trapezoid area between the medial septum, LSc and accumbens shell was occupied by the LSr that contained three near continuous nuclei. The medial nucleus (LSr-m) contained TH-positive processes and was devoid of RLN3-labeled fibers and the dorsolateral nucleus (LSr-dl) also contained sparse RLN3-labeling. In contrast, groups of RLN3 fibers were observed near the accumbens shell in a region corresponding to the LSr-vl nucleus (Fig. $8 \mathrm{D}-\mathrm{F})$.

In the medial septum, a high density of RLN3-labeled fibers was observed in the vertical and horizontal divisions, in areas containing hippocampal-projecting, ChAT-, PV- and nNOSpositive neurons (Fig. 8B-D). There was also an area of dense RLN3-labeling that overlapped a high density of CR-neurons in the dorsal vMS (Fig. 8E). In anterior hypothalamus-injected cases, a band of retrogradely-labeled neurons were located in lateral aspects of the medial septum, where a high density of RLN3-labeling was observed (Fig. 6B).

\section{Coronal level 3 (bregma $+\mathbf{0 . 5 0} \mathbf{~ m m})$}

At this level, we observed groups of neurons and moderate levels of RLN3-positive fibers between the fornix that occupied the dorsal aspects of the septal area between the corpus callosum and the dorsal tip of the medial septum. A high density of RLN3-labeled fibers was observed in the LSc-v nucleus located dorsolateral to the fornix. Lateral to the medial septum, the rostral portion of the lateral septum still contained the LSr-dl, LSr-m and LSr-vl nuclei. The LSr-m nucleus was characterized by TH-positive processes and neurons and scarce RLN3-labeling, as was the LSr-dl nucleus (Fig. 9C). In contrast, the LSr-vl nucleus contained a dense RLN3-plexus and CB-28kD-labeled cells (Fig. 9E). At this level, the LSv also contained scarce CB-28kD cells that formed a band adjacent to the bed nucleus of the stria 
terminalis (BST), running diagonally from the ventral sulcus of the lateral ventricle to the medial septum. Scarce RLN3-labeling was observed in this nucleus.

In contrast to sparse RLN3-labeling in the lateral septum, the medial septum contained uniform labeling in both the vertical and horizontal portions and in areas containing hippocampal projecting-, ChAT-, and PV-neurons (Fig. 9B-D) and nNOS- neurons (data not shown). Similar to labeling at level 2, it was clear that the dorsolateral area containing CR and CB-28kD neurons also contained dense RLN3-labeling (Fig. 9E,F). A band of hypothalamicprojecting neurons was observed in a region between the lateral and medial septum (Fig. 9B).

\section{Coronal level 4 (bregma $+0.30 \mathrm{~mm})$}

A region dorsal to the fornix corresponds to what classical nomenclature refers to as 'the posterior septum' (Jacab and Leranth, 1995). This area contained a central group of CRpositive neurons that correspond to the triangular septal nucleus, and several groups of neurons located between the bundles of the fimbria fornicis that correspond to the septofimbrial nucleus. Capping the septofimbrial nucleus, the LSc appeared divided into dorsal and ventral nuclei (Fig. 10A). Some dispersed RLN3-labeling was observed in the triangular septal nucleus and RLN3-labeled fibers were also concentrated in groups of cells between the fimbrial bundles of the septofimbrial nucleus (Fig. 10D). Few fibers were observed in the LSc-d nucleus, in contrast to the high density present in the LSc-v nucleus. The latter appeared to form a lateral cap to the septofimbrial nucleus and continued ventrally to the dorsal tip of the medial septum. Many labeled fibers were observed to course laterally from the medial septum to the LSc-v and form a denser plexus. The LSv appeared as a band between the LSc-v and the BST and contained only a few dispersed RLN3-labeled fibers (Fig. 6D).

The medial septum at this level appeared split into a dorsal region corresponding to the caudal extension of the vMS, and a ventral region that corresponded to the hMS (Fig. 10A). The vMS contained clusters of hippocampal-projecting (Fig. 5D), and nNOS- (Fig. 10B), PV(Fig. 10E) and ChAT- (data not shown) positive neurons. This area also contained hypothalamic-projecting neurons (Figs 6D and 10C), thus confirming overlap of populations of hippocampal- and hypothalamic-projection neurons in the medial septum. This region also contained a high density of RLN3-labeled fibers. Adjacent to the hMS, we observed two nuclei that correspond to the basal nucleus of the substantia innominata, which contained well-labeled, star-shaped PV and CB-28kD neurons and a low density of RLN3 fibers. The 
anterior dorsal preoptic area located dorsomedially to the hMS also contained a low density of RLN3 positive fibers (Fig. 10 A-D).

\section{Coronal level 5 (bregma $+\mathbf{0 . 0} \mathbf{~ m m})$}

At this level, the septal complex split into two areas - the posterior septum and the hMS. As observed at level 4, in the posterior septum, which is composed of the triangular septal nucleus and septofimbrial nucleus (Fig. 11A), a high density of CR-positive neurons was present in the triangular septal nucleus (Fig. 11B) along with some dispersed, star-shaped PVpositive neurons and scattered hypothalamic-projecting neurons (Fig. 11D). In this area, RLN3-labeled fibers were present amongst clusters of neurons of the septofimbrial nucleus (Fig. 11B-D) and were prominent in the LSc-v nucleus, which contained hypothalamicprojecting neurons (Fig. 11C).

A dense plexus of RLN3-labeled fibers was observed in the hMS amongst hippocampalprojecting, and PV-, nNOS- and ChAT-positive neurons (Fig. 11 E-G). Sparse RLN3-labeled fibers were observed in the basal substantia innominata and anterior dorsal preoptic nucleus (Fig. 11E-G).

\section{Nucleus incertus/RLN3 targeting of identified neurons in the medial septum}

In these studies, we have determined the main targets of nucleus incertus (RLN3) projections within the medial septum, by employing anterograde-tracing analysis following $\mathrm{mR}$ injections into the nucleus incertus combined with RLN3 immunofluorescence; and RLN3 immunofluorescence combined with immunostaining of medial septum neuronal markers. We achieved restricted injections of $\mathrm{mR}$ into the nucleus incertus (Fig. 12A) and anterogradely-labeled fibers in the medial septum were generally found ipsilateral to the injection side with swollen and tufted terminal-like endings. Some of these fibers formed nets encapsulating ChAT-positive neurons (Fig. 12B) that also extended along primary dendrites. PV-positive neurons and processes were encapsulated by terminal-like labeled fibers (Fig. 12C) and some CB-28kD-positive cells were also in close contact with anterogradely-labeled fibers (Fig. 12D). Confocal imaging revealed putative contacts between anterogradely-labeled $\mathrm{mR}$ fibers and PV-positive neurons, some of which were also retrogradely-labeled from the hippocampus (Fig. 12E-G). Confocal images also confirmed the occurrence of putative contacts between CB-28kD and CR-positive somata and/or processes with anterogradelylabeled fibers from the nucleus incertus.

The medial septum displayed the highest concentration of RLN3-positive fibers in all sections examined. Thus, we extended our investigations to determine the types of neurons in 
the medial septum targeted by RLN3 fibers. Confocal analysis of the medial septum following FG injections into the hippocampus and staining for GAD67 and RLN3 revealed many RLN3-positive fiber contacts with GAD67-positive somata or processes. Some of these GAD67-positive neurons also displayed FG-labeling from hippocampal injections (Fig. 13AD). We also observed contacts with PV-positive neurons in the medial septum (Fig. 13E-F).

RLN3 synaptic contacts were generally present on labeled somata and primary dendrites, although contacts with distal dendrites were also observed. In line with earlier reports, CB$28 \mathrm{kD}$ did not co-localize with retrogradely-labeled cells from the hippocampus, although we observed contacts with RLN3 positive-fibers and in many cases, RLN3 fibers contained CB28kD (Fig. 14A-D). FG-labeled, hippocampal-projecting cells did not co-express CR, but some CR-positive neurons received contacts from RLN3-positive terminals and some RLN3positive fibers contained CR (Fig. 14E-H).

In rats that received $\mathrm{mR}$ injections restricted to the nucleus incertus and FG injections in the caudal hippocampus, we employed a quadruple, immunofluorescence-labeling approach. Many mR-labeled fibers contained RLN3 immunofluorescence and over 50\% of FG-labeled neurons contained ChAT immunostaining, with many of these neurons receiving contacts from $\mathrm{mR}$ and $\mathrm{mR} / \mathrm{RLN} 3$-positive terminals (Fig. 15).

\section{Presence of relaxin-3 in synaptic terminals of the septum}

The topography of RLN3-immunopositive fibers in the septum was predominantly in a vertical orientation or slightly angled and running from the medial to the lateral septum. Confocal analysis of double immunofluorescent staining for RLN3 and the presynaptic marker, synaptophysin revealed a strong co-localization of RLN3 and synaptophysin in the medial septum (Fig. 16A-C see supl Fig.1 for red/green color blind). Synaptophysinimmunoreactivity displayed a granular morphology, with unlabeled areas/spaces likely corresponding to neuronal somata or fiber bundles. Co-localization was also detected in the dorsal tip of the vMS between the fornix. Most RLN3-positive fibers in the LSr-dl also displayed synaptophysin immunofluorescence (Fig. 16 D-F, see supl Fig.1 for red/green color blind).

In the posterior septal area, co-localization of synaptophysin and RLN3 immunoreactivity was also observed in the LSc-v nucleus (Fig. 17A-C, see supl Fig.2 for red/green color blind), while in the septofimbrial nucleus, synaptophysin and RLN3 immunoreactivity was colocalized in fibers located in rows between myelinated bundles (Fig. 17D-F, see supl Fig.1 for red/green color blind). 


\section{Ultrastructural analyses of RLN3 terminals in the medial septum}

Earlier we described the ultrastructure of anterogradely-labeled terminals in the medial septum following $\mathrm{mR}$ injections into the nucleus incertus (Ma et al., 2009b). In this study, we examined RLN3-immunostaining in ultrathin sections of the medial septum using electron microscopy. RLN3-positive terminals generally contained 3-7 round, dense vesicles of $\sim 100$ $150 \mathrm{~nm}$ in diameter per section (Fig. 18A-D). The electrodense reaction product of the labeled terminal made it difficult to identify precisely the type of synaptic vesicles, but in all cases they were densely-packed. All RLN3-labeled terminals made symmetric contacts, with a regular synaptic cleft of $20 \mathrm{~nm}$ (Fig. 18A-D). Most RLN3 synapses were on dendritic shafts (Fig. 18C).
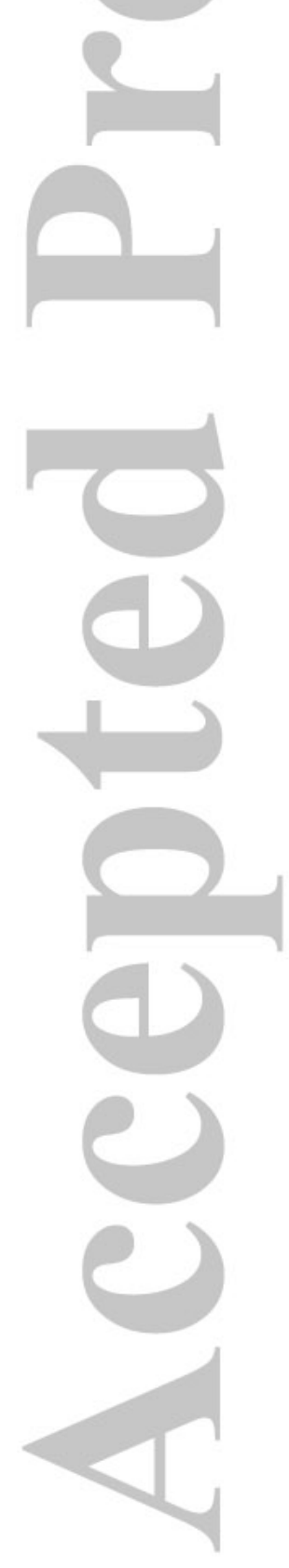


\section{DISCUSSION}

In the current study, we confirmed the topography of the robust RLN3 projections to the medial septum, ventrolateral division of the rostral lateral septum, ventral division of the caudal lateral septum, and the septofimbrial and triangular septal nuclei of the rat. We have also demonstrated the existence of close contacts between RLN3-positive terminals and a range of neuronal types in the septal area, including ChAT-, PV-, CB-28kD-, CR-, and GAD67-positive neurons. Furthermore, we have identified symmetric contacts between RLN3 terminals and several postsynaptic structures. These data suggest RLN3 projections to the septum might contribute to two important functions - modulation of septohippocampal theta rhythm via actions within medial septum, and modulation of different aspects of motivated behaviors such as those related to ingestive and defensive behavior via actions in the ventrolateral division of the rostral lateral septum and/or ventral division of caudal lateral septum. Given the fact that RLN3 positive neurons in the nucleus incertus display CRH-R1 receptors (Bittencourt and Sawchenko 2000), respond to CRH (Tanaka et al., 2005) and are activated by stressors (Banerjee et al., 2010), the nucleus incertus may modulate theta rhythm and motivated behaviors during stress episodes.

Our data are in agreement with those from earlier studies of both anterograde-tracing of projections from the nucleus incertus (Goto et al., 2001; Olucha-Bordonau et al., 2003) and immunostaining of the dense RLN3 innervation of the rat medial septum (Tanaka et al., 2005; Ma et al., 2007). RLN3-positive fibers have also been observed in abundance in the medial septum of the mouse (Smith et al., 2010) and the non-human primate (Ma et al., 2009a), demonstrating the likely relevance of the current findings to the human brain.

\section{Implications for understanding medial septum function}

Comparison with the distribution of staining for different marker proteins within the medial septal area revealed that the highest concentration of RLN3 fibers was present in the dorsal and lateral areas of the medial septum. These regions were enriched in CB-28kD- and CR- containing neurons, but were devoid of PV-positive neurons. In contrast, ChAT-positive neurons were equally distributed throughout the medial septum, as were neurons retrogradelylabeled with FG from the hippocampus. The entire medial septum contained a high density of RLN3-labeling and retrogradely-labeled neurons from the anterior hypothalamus, which contrasts with the lower density observed in the medial division of the rostral lateral septum. We also observed an area of overlapping hippocampal- and hypothalamic- projecting-neurons within the medial septum. 
On the basis of the current findings it is worth considering the possible nature of the influence of RLN3 on neurons in the medial septum and the broader septohippocampal system. There are a number of possible differential effects of nucleus incertus projections on neurons in the medial septum, with a GABA- or a GABA/RLN3-containing projection onto septohippocampal neurons and onto intrinsic CB-28kD and CR neurons and hippocampal and hypothalamic projecting neurons in the lateral aspects of the medial septum. The dorsal area of the medial septum is mainly occupied by intrinsic GABAergic neurons suggesting that the projection to the dorsal area may disinhibit both PV and ChAT projection neurons.

The dorsal area containing CR neurons has been identified as the main target of descending entorhinal projections that specifically target GABA/CR neurons that in turn project to the supramammillary area to target neurons that project back to the medial septum (Leranth et al., 1999). As the supramammillary area is also a prominent target of RLN3 fibers from the nucleus incertus (Ma et al., 2007), it is presumed that the nucleus incertus can modulate the broader septohippocampal system, not only through ascending projections, but also by modulating the entire loop of ascending supramammillary-septo-hippocampal and descending entorhinal-septal-supramammillary projections. Observations that both electrical stimulation of the nucleus incertus (Nunez et al., 2006) and direct injection of an RXFP3 agonist into the medial septal area (Ma et al., 2009b) induce hippocampal theta are suggestive of a synergistic action of GABA and RLN3 on theta rhythm generation.

Another important factor when considering the possible effects of RLN3 on septal function and theta rhythm generation is that 5HT projections arising from the raphe nuclei (Leranth and Vertes, 1999, Vertes et al., 1999) and RLN3 projections arising from the nucleus incertus (Olucha-Bordonau et al., 2003, Tanaka et al., 2005, Ma et al., 2007) both innervate the medial septum; and the median raphe, which is the main source of the 5HT innervation of the medial septum (Leranth and Vertes 1999), also receives projections from the nucleus incertus (Goto et al., 2001, Olucha Bordonau et al., 2003) and projects to the dorsal hippocampus (McKenna and Vertes, 2001). Indeed, a body of evidence indicates that the median raphe is involved in the control of the hippocampal EEG, especially states of hippocampal desynchronization (Vinogradova 1995, Leranth and Vertes 1999). Lesions of the median raphe produce continuous, ongoing theta activity (Yamamoto et al., 1979). And interestingly, median raphe stimulation disrupts the bursting discharge of septal pacemaking neurons, resulting in hippocampal desynchronization (Vertes, 1981, Kitchigina et al., 1999). In addition, pharmacological depletion of 5-HT alters the levels of relaxin-3 mRNA in 
nucleus incertus neurons, presumably via 5-HT-1A receptors expressed by these cells or their inputs (Miyamoto et al., 2008).

Inhibitory circuits are thought to be important in theta rhythm generation. Early anatomical observations revealed that PV/GABAergic septohippocampal neurons contact hippocampal interneurons (Freund and Antal, 1988) and these neurons produce disinhibition of pyramidal cells (Toth et al., 1997b). More recently, it was demonstrated that activation of GABAergic neurons in the medial septum that project to the hippocampus precedes the activation of hippocampal interneurons and the activity of these neurons leads to hippocampal theta rhythm (Hangya et al., 2009). The fact that PV-positive, septohippocampal projection neurons are specifically targeted by RLN3 projections supports the suggested role of the nucleus incertus and RLN3 in generating/modulating theta rhythm.

It is possible that GABAergic CB-28kD and CR neurons in the septal area contribute to hippocampal theta generation and/or modulation. The dorsal area of the medial septum rich in CB-28kD and CR neurons may correspond to layer III of the zoning proposed regarding the 'onion skin-like' organization of the septal complex (Jakab and Leranth 1995). Tracer injections in the MS/LS area where most of these neurons are located result in anterograde labeling in both vertical and horizontal MS (Risold and Swanson, 1997a) raising the possibility of influences of interneurons on septohippocampal neurons. In addition, collaterals from PV neurons of the angular portion of the medial septum project to CB-28kD positive neurons of the MS/LS area (Kiss et al., 1997). Thus, it is likely that intrinsic loops as well as long loops are modulated by RLN3 projections from the nucleus incertus.

RLN3-positive fibers also contact cholinergic septal neurons. In fact, mR-positive fibers from the nucleus incertus form pericellular baskets around the soma of ChAT-positive neurons. ChAT-positive cells are characterized electrophysiologically as slow firing and are thought to contribute to theta by facilitating synchronization (Sotty et al., 2003). It is possible that inhibition of the cholinergic cells may contribute to a sharp transition between irregular activity and theta (but see Simon et al., 2006). Most nNOS-positive neurons are also cholinergic. Although there are no reports on the role of septohippocampal NO transmission in the production of theta rhythm, inhibition of NO transmission impairs the long-term potentiation produced by stimulation, phase-locked to the peak of theta (Holscher, 1999).

Excitatory glutamate neurons in the medial septum may also contribute to theta generation and modulation (Sotty et al., 2003), but as it is difficult to visualize septal glutamate neuronal soma without colchicine enhancement of glutamate transporter staining (Gritti et al., 2006), we have not studied any potential interactions of RLN3 afferents with 
these neurons. Glutamate positive cells are slow, cluster firing units (Sotty et al., 2003) and may contribute to hippocampal theta (Ujfalussy and Kiss, 2006). However, it is worth noting that a large proportion of local CB-28kD and calretinin neurons in the medial septum contain phosphate-activated glutaminase, the synthetic enzyme of glutamate (Gritti et al., 2003).

It is of interest to distinguish two aspects of the nucleus incertus/RLN3 effects on hippocampal theta and function - firstly, the contribution of GABA and RLN3 actions on septal neurons and secondly, any differential effects on different hippocampal regions. As described by Ma et al. (2007), RLN3 co-localizes with GAD (GABA) in most but not all nucleus incertus cells, a finding that raises the possibility of differential effects of GABA and RLN3 on the target area. Although this question has not been addressed experimentally, indirect findings point to an agonistic, facilitatory effect of both transmitters. The stimulation of the nucleus incertus (which should induce GABA and RLN3 release) produces increases in theta rhythm, which are disrupted by lesion of the nucleus incertus (Núñez et al., 2006). In the same way, application of an RLN3 receptor agonist into the septal area results in an increase of theta that is eliminated by the prior injection of an antagonist (Ma et al., 2009b). Regarding any differential effect of nucleus incertus projections on dorsal and ventral hippocampus, the dorsal hippocampus (Núñez et al., 2006, Ma et al., 2009, Cervera-Ferri et al., 2011) does not contain abundant anterograde fibers arising from the nucleus incertus (Goto et al., 2001, Olucha-Bordonau et al., 2003) or RLN3 fibers (Tanaka et al., 2005, Ma et al., 2007), suggesting the effect of the nucleus incertus on this area might be more indirect through the medial septum. Alternatively, the high concentration of RLN3 positive fibers and anterograde fibers arising from the nucleus incertus (Goto et al., 2001, Olucha-Bordonau et al., 2003) in the ventral hippocampus (Tanaka et al., 2005, Ma et al., 2007) supports the idea of an involvement of this projection in modulating anxiety-related behavior, as a major role of ventral hippocampus is related to affective processes (Bannerman et al., 2002, 2004, Yoon and Otto, 2007). Consistent with this idea, the ventral hippocampus is preferentially targeted by the supramammillary nucleus (Haglund et al., 1984).

Using electron microscopy, we have identified that RLN3 terminals display symmetric contacts on soma, dendritic shafts, dendritic spines and axon terminals. These terminals contain dense vesicles and densely-packed synaptic vesicles. These morphologies are near identical to those observed in anterogradely-labeled terminals following tracer injections into the nucleus incertus (Ma et al., 2009b) and these features are characteristic of inhibitory synapses (Gray, 1959, Peters, 1987, DeFelipe et al., 2002). 
Together, the morphological features suggest that the nucleus incertus sends a strong GABA- and RLN3- inhibitory projection to nearly all the elements of the medial septum and drives 'theta-modulating' septohippocampal and intrinsic connections; and long distance hippocampus-septum-supramammillary loops. RLN3/RXFP3 signaling has been shown to affect several aspects of behavior related to theta rhythm. Intra-septal infusion of the selective RXFP3 agonist, R3/I5, induced an increase in hippocampal theta rhythm in a sensory-poor context (the habituated home cage), while the infusion of the RXFP3 antagonist, R3(B $\Delta 23-$ 27)R/I5, into the medial septum decreases hippocampal theta rhythm during exploratory behavior in a novel, enriched environment (Ma et al., 2009b). Similarly, the infusion of the antagonist into the medial septum disrupts performance in the spontaneous alternation task, a test of spatial working memory, in which rats must remember already visited arms in a plus maze in order to explore a novel arm (Ma et al., 2009b).

Clarification of the likely cellular actions of RLN3 signaling within these complex circuits might be facilitated by studies using specific RXFP3 antisera to resolve the precise location of the receptor at the level of individual neurons, if such experimental tools become available. Future studies should also employ in vitro and in vivo electrophysiological studies to characterize actions of RXFP3 activity on different neuron types and pathways within the septum. Indeed, such studies are the goal of our current and future research (e.g. Ma et al., 2009b; Bassant et al., 2005; Simon et al., 2006).

\section{Implications for understanding lateral septum function}

RLN3 fibers were not present in the caudal and ventral portions of the LS as defined by (Risold and Swanson, 1997b), which correspond to the regions known as dorsal and ventral divisions of the LS, according to the classical nomenclature (Jakab and Leranth, 1995). Although RLN3-labeled fibers occurred in all nuclei of the LSr, the highest density was observed in the LSr-vl nucleus, which corresponds to a part of the classical intermediate lateral septum (Jakab and Leranth, 1995), and in the LSc-v. The presence of a projection from the nucleus incertus and RLN3 fibers in the lateral septum has been described in rat (OluchaBordonau et al., 2003; Tanaka et al., 2005; Ma et al., 2007), mouse (Smith et al., 2010) and non-human primate (Ma et al., 2009a), but an accurate identification of the targeted area has not been reported. Here we have identified these areas as the LSr-vl and the LSc-v, according to recently proposed cytoarchitectonic divisions (Risold and Swanson, 1997b).

The LSr-vl has been characterized as the main source of septal projections to the anterior, dorsomedial, ventromedial and dorsal premammillary hypothalamic nuclei and to the 
perifornical area of the hypothalamus. These nuclei, especially the anterior hypothalamic nucleus are part of the hypothalamic system involved in defense mechanisms against predators and social interactions towards conspecifics (Ferris et al., 1990; Risold et al., 1994; Motta et al., 2009). Rats exposed to a context associated with a predator or its cues display Fos activation in the anterior hypothalamic and dorsal premammillary nuclei, as well as the dorsolateral PAG (Cezario et al., 2008). Importantly, all these nuclei receive dense projections from the nucleus incertus (Goto et al., 2001; Olucha-Bordonau et al., 2003) and contain dense plexuses of RLN3 fibers (Tanaka et al., 2005; Ma et al., 2007). A key element in these pathways is the anterior hypothalamic nucleus, which is also densely innervated by the medial amygdala, which relays pheromonal inputs important for the expression of social behaviors in rodents (Halpern, 1987; Canteras et al., 1995). Notably, the medial nucleus contains the densest plexus of RLN3 fibers in the amygdala (Olucha-Bordonau et al., 2009).

It has been reported consistently that lesions of the lateral septum induce a hyperdefensive and transient behavior known as septal rage (Brady and Nauta, 1953; Brady and Nauta, 1955; Albert and Chew, 1980). In the latter work, the location of the lesion appeared restricted to the LSr-vl. As GABA is a primary septal transmitter, it is proposed that the lesion of lateral septum removes GABA inhibition from the hypothalamic centres that drive rage. Following this rationale, the GABAergic/RLN3 projection to the LSr-vl is predicted to alter the level of GABA transmission in the area and produce changes in the level of arousal/'rage' when an animal is under stress. In this respect, it is well documented that CRF and neurogenic stressors activate nucleus incertus neurons (Bittencourt and Sawchenko, 2000; Tanaka et al., 2005; Ryan et al., 2011) and presumably drive arousal and behavioral state changes. An indirect reflection of this concept is the recently described hypoactive phenotype of that RLN3 KO mice (Smith et al., 2011). Specific behavioral studies are now required to investigate the role of nucleus incertus activity and local relaxin-3/RXFP3 signaling in the LS-vl in the control of defensive mechanisms.

The lateral septum may also contribute to the action of the RLN3 system on ingestive behavior. Infusion of urocortin, a CRF family peptide, into the lateral septum induced anorectic effects that may be secondary to stress driven anxiety-like behavior (Bakshi et al., 2007). Notably, the location of the injections in these experiments coincides with the distribution of RLN3-positive fibers in the LSr-vl. Furthermore, a correlation exists between stress and ingestive behavior, which may be partly centered in the LSr-vl, as activation of this region after stress is attenuated by intermittent access to sucrose (Martin and Timofeeva, 2010). 
A consistent ability of RLN3 or RXFP3 agonist peptides to increase food intake in satiated rats has been observed following both icv injection and local injection into several hypothalamic nuclei (McGowan et al., 2005; McGowan et al., 2006; McGowan et al., 2007) (Kuei et al., 2007); and the effect of RXFP3 activation on feeding is blocked by the intracerebroventricular infusion of the antagonists, R3(B $\Delta 23-27) R / I 5$ (Kuei et al., 2007) and R3(1-23R) (Haugaard-Kedström et al., 2011) suggesting a specific RXFP3-mediated action. In this regard, the RLN3 projection to the lateral septum may compensate for any anorectic effect of CRF-like peptides, acting as a feedback regulatory system for controlling food intake after activation of the nucleus incertus by CRF-like peptides. These possibilities can also be tested experimentally with the increased availability of agonist and antagonist peptides selective for RXFP3 (Liu et al., 2005; Kuei et al., 2007; Haugaard-Kedström et al., 2011).

Regarding the strong projection to the LSc-v, we note that this ventral nucleus differs from the dorsal in many aspects. The dorsal nucleus is not targeted by RLN3 fibers, while the ventral nucleus receives a similar density of innervation as the medial septum. The pattern of connections for these areas is also rather different - the dorsal nucleus does not project to the anterior hypothalamus, whereas the ventral nucleus projects profusely to this area, aspects also described in the precise connectivity studies by Risold and Swanson (1997b) and Tulogdi et al. (2010). The main efferents from the LSc-v are directed to the lateral aspects of the medial septum (Risold and Swanson 1997b), which also contains a band of hypothalamic projecting neurons which innervate the "hypothalamic aggression area" (Tulogdi et al., 2010). Again, intrinsic projections within the septal area may provide the structural basis for the interaction between theta rhythm and behaviors such as exploration and aggression.

Furthermore, the RLN3 projection to the septofimbrial and triangular septal nuclei may be important in the brain network that the nucleus incertus is an integral part of. The main efferent projection target of neurons in the septofimbrial and triangular septal nuclei is the medial habenula, which projects to the interpeduncular nuclei (Herkenham and Nauta, 1977) that in turn projects to the nucleus incertus (Goto et al., 2001), thus 'closing the anatomical/functional loop'. This circuit also appears to participate in theta rhythm regulation and associated phenomena, as transection of the fasciculus retroflexus tract connecting the habenula to the interpeduncular nucleus results in reduction of hippocampal theta and REM sleep (high levels of theta characterize REM sleep) (Haum et al., 1992; Valjakka et al., 1998). Furthermore, the septofimbrial nucleus projects strongly to deep layers of the medial septum and the lateral supramammillary nucleus (Risold and Swanson, 1997b), which suggests a contribution of the septofimbrial nucleus to the generation/modulation of theta rhythm. 


\section{Conclusions}

The RLN3 projection to the septal area may mediate/modulate two kinds of processes cognitive processing mediated by the lateral and dorsal areas of the medial septum; and ingestive and defensive processes mediated by the ventrolateral division of the rostral lateral septum (Fig. 19). The RLN3 projection to the medial septum may influence several subsystems including the PV-GABAergic septohippocampal projection, intrinsic connections within the medial septum, cholinergic septohippocampal projections and projections from the medial septum/lateral septum border that belong to a 'long-loop' of connections arising from the entorhinal cortex and terminating on supramammillary nucleus neurons, which in turn project to the medial septum and the hippocampus. It is possible that as a result of activity in these pathways a synchronized wave of activity at theta frequency occurs in the hippocampus. In this regard, it will be important to study the precise role of nucleus incertus GABA/RLN3 inputs and their direct regulation of the hippocampus via actions on local GABA and RXFP3 receptors (Ma et al., 2007).

Our findings suggest that the nucleus incertus GABA/RLN3 system may also modulate descending pathways to the hypothalamus that subserve defensive and ingestive behaviors. Effects on defensive mechanisms may be mediated through actions on reciprocal projections between the lateral septum and the anterior hypothalamic area, as the latter region also receives projections from the medial amygdala and projects to the dorsal premammillary nucleus and the periaqueductal grey, where defensive behavior is driven. Notably, all the components of this system receive projections from the nucleus incertus.

A prominent neurochemical feature of nucleus incertus neurons is their strong expression of CRF type 1 receptors $\left(\mathrm{CRF}_{1}\right)$ (Bittencourt and Sawchenko, 2000; Van Pett et al., 2000). In fact, icv injection of CRF produces c-fos activation in nucleus incertus neurons (Bittencourt and Sawchenko, 2000; Tanaka et al., 2005); and stressors such as a forced swim induce a $\mathrm{CRF}_{1}$-dependent increase in RLN3 expression in nucleus incertus neurons (Banerjee et al., 2010) and stress-induced insomnia and REM sleep deprivation produced c-Fos activation in these neurons (Cano et al., 2008). Therefore, activation of the nucleus incertus by CRF is a likely way to communicate stress-related information to cognitive and emotional centers in the forebrain via nucleus incertus/RLN3 projections. 


\section{ACKNOWLEDGEMENTS}

The authors are indebted to Sonia Priego (SCSIE-UV) and Maria Teresa Mínguez (SCSIE-UV) for their technical assistance with the confocal microscopy and electron microscopy, respectively. The authors wish to thank Ross Bathgate and Geoffrey Tregear (Florey Neuroscience Institutes) for providing the RLN3 antiserum used in these studies.

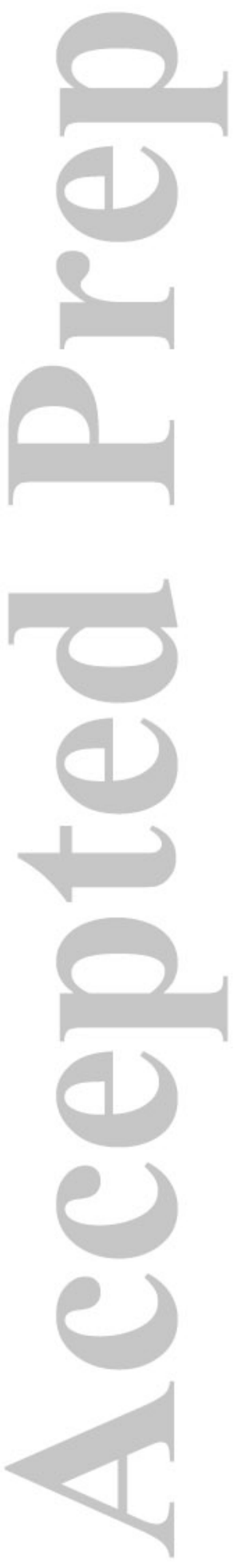




\section{LITERATURE CITED}

Airaksinen MS, Eilers J, Garaschuk O, Thoenen H, Konnerth A, Meyer M. 1997. Ataxia and altered dendritic calcium signaling in mice carrying a targeted null mutation of the calbindin D28k gene. Proc. Natl. Acad. Sci. U. S. A. 94: 1488-1493. .

Albert DJ, Chew GL. 1980. The septal forebrain and the inhibitory modulation of attack and defense in the rat. A review. Behav Neural Biol 30: 357-388.

Andersen P, Bland HB, Myhrer T, Schwartzkroin PA. 1979. Septo-hippocampal pathway necessary for dentate theta production. Brain Res 165: 13-22.

Bakshi VP, Newman SM, Smith-Roe S, Jochman KA, Kalin NH. 2007. Stimulation of lateral septum CRF2 receptors promotes anorexia and stress-like behaviors: functional homology to CRF1 receptors in basolateral amygdala. J Neurosci 27: 10568-10577.

Banerjee A, Shen PJ, Ma S, Bathgate RAD, Gundlach AL. 2010. Swim stress excitation of nucleus incertus and rapid induction of relaxin-3 expression via CRF1 activation. Neuropharmacology 58: 145-155.

Bannerman DM, Deacon RM, Offen S, Friswell J, Grubb M, Rawlins JN. 2002. Double dissociation of function within the hippocampus: spatial memory and hyponeophagia. Behav Neurosci 116: 884-901. .

Bannerman DM, Rawlins JN, McHugh SB, Deacon RM, Yee BK, Bast T, Zhang WN, Pothuizen HH, Feldon J. 2004. Regional dissociations within the hippocampus-memory and anxiety. Neurosci Biobehav Rev 28: 273-283. .

Bassant MH, Simon A, Poindessous-Jazat F, Csaba Z, Epelbaum J, Dournaud P. 2005. Medial septal GABAergic neurons express the somatostatin sst2A receptor: functional consequences on unit firing and hippocampal theta. J Neurosci 25: 2032-2041.

Bathgate RA, Samuel CS, Burazin TC, Layfield S, Claasz AA, Reytomas IG, Dawson NF, Zhao C, Bond C, Summers RJ, Parry LJ, Wade JD, Tregear GW. 2002. Human relaxin gene $3(\mathrm{H} 3)$ and the equivalent mouse relaxin (M3) gene. Novel members of the relaxin peptide family. J. Biol. Chem. 277: 1148-1157. .

Bathgate RAD, Ivell R, Sanborn BM, Sherwood OD, Summers RJ. 2006. International Union of Pharmacology LVII: recommendations for the nomenclature of receptors for relaxin family peptides. Pharmacol Rev 58: 7-31.

Bathgate RAD, Samuel CS, Burazin TCD, Gundlach AL, Tregear GW. 2003. Relaxin: new peptides, receptors and novel actions. Trends Endocrinol. Metab 14: 207-213. 
Bathgate RAD, Samuel CS, Burazin TCD, Layfield S, Claasz AA, Reytomas IG, Dawson NF, Zhao C, Bond C, Summers RJ, Parry LJ, Wade JD, Tregear GW. 2002. Human relaxin gene $3(\mathrm{H} 3)$ and the equivalent mouse relaxin (M3) gene. Novel members of the relaxin peptide family. J Biol Chem 277: 1148-1157. .

Bittencourt JC, Sawchenko PE. 2000. Do centrally administered neuropeptides access cognate receptors? An analysis in the central corticotropin-releasing factor system. J Neurosci 20: $1142-1156$.

Boettger T, Rust MB, Maier H, Seidenbecher T, Schweizer M, Keating DJ, Faulhaber J, Ehmke H, Pfeffer C, Scheel O, Lemcke B, Horst J, Leuwer R, Pape HC, Volkl H, Hubner CA, Jentsch TJ. 2003. Loss of K-Cl co-transporter KCC3 causes deafness, neurodegeneration and reduced seizure threshold. EMBO J 22: 5422-5434.

Brady JV, Nauta WJ. 1953. Subcortical mechanisms in emotional behavior: affective changes following septal forebrain lesions in the albino rat. J Comp Physiol Psychol 46: 339346.

Brady JV, Nauta WJ. 1955. Subcortical mechanisms in emotional behavior: the duration of affective changes following septal and habenular lesions in the albino rat. J. Comp. Physiol Psychol 48: 412-420.

Burazin TCD, Bathgate RAD, Macris M, Layfield S, Gundlach AL, Tregear GW. 2002. Restricted, but abundant, expression of the novel rat gene-3 (R3) relaxin in the dorsal tegmental region of brain. J Neurochem 82: 1553-1557.

Cano G, Mochizuki T, Saper CB. 2008. Neural circuitry of stress-induced insomnia in rats. J Neurosci 28: 10167-10184.

Canteras NS, Simerly RB, Swanson LW. 1995. Organization of projections from the medial nucleus of the amygdala: a PHAL study in the rat. J Comp Neurol 360: 213-245.

Celio MR, Baier W, Scharer L, de Viragh PA, Gerday C. 1988. Monoclonal antibodies directed against the calcium binding protein parvalbumin. Cell Calcium 9: 81-86.

Celio MR, Baier W, Scharer L, Gregersen HJ, de Viragh PA, Norman AW. 1990. Monoclonal antibodies directed against the calcium binding protein Calbindin D-28k. Cell Calcium 11: 599-602.

Cervera-Ferri A, Guerrero-Martínez J, Bataller-Mompeán M, Taberner-Cortes A, MartínezRicós J, Ruiz-Torner A, Teruel-Martí V. 2011.Theta synchronization between the hippocampus and the nucleus incertus in urethane-anesthetized rats. Exp Brain Res 211:177-192. 
Cezario AF, Ribeiro-Barbosa ER, Baldo MV, Canteras NS. 2008. Hypothalamic sites responding to predator threats - the role of the dorsal premammillary nucleus in unconditioned and conditioned anti-predatory defensive behavior. Eur J Neurosci 28: 1003-1015.

DeFelipe J, Alonso-Nanclares L, Arellano JI. 2002. Microstructure of the neocortex: comparative aspects. J Neurocytol 31: 299-316.

Dhar SS, Liang HL, Wong-Riley MT. 2009. Transcriptional coupling of synaptic transmission and energy metabolism: role of nuclear respiratory factor 1 in coregulating neuronal nitric oxide synthase and cytochrome c oxidase genes in neurons. Biochim. Biophys. Acta 1793: 1604-1613. .

Eshkind LG, Leube RE. 1995. Mice lacking synaptophysin reproduce and form typical synaptic vesicles. Cell Tissue Res. 282: 423-433. .

Ferris CF, Gold L, De Vries GJ, Potegal M. 1990. Evidence for a functional and anatomical relationship between the lateral septum and the hypothalamus in the control of flank marking behavior in Golden hamsters. J Comp Neurol 293: 476-485.

Flores-Otero J, Xue HZ, Davis RL. 2007. Reciprocal regulation of presynaptic and postsynaptic proteins in bipolar spiral ganglion neurons by neurotrophins. J. Neurosci. 27: 14023-14034. .

Fong AY, Stornetta RL, Foley CM, Potts JT. 2005. Immunohistochemical localization of GAD67-expressing neurons and processes in the rat brainstem: subregional distribution in the nucleus tractus solitarius. J. Comp. Neurol. 493: 274-290. .

Freund TF, Antal M. 1988. GABA-containing neurons in the septum control inhibitory interneurons in the hippocampus. Nature 336: 170-173.

Freund TF, Gulyas AI. 1997. Inhibitory control of GABAergic interneurons in the hippocampus. Can J Physiol Pharmacol 75: 479-487.

Goto M, Swanson LW, Canteras NS. 2001. Connections of the nucleus incertus. J Comp Neurol 438: 86-122.

Gray EG. 1959. Axo-somatic and axo-dendritic synapses of the cerebral cortex: an electron microscope study. J Anat 93: 420-433.

Gritti I, Henny P, Galloni F, Mainville L, Mariotti M, Jones BE. 2006. Stereological estimates of the basal forebrain cell population in the rat, including neurons containing choline acetyltransferase, glutamic acid decarboxylase or phosphate-activated glutaminase and colocalizing vesicular glutamate transporters. Neuroscience 143: 1051-1064. 
Gritti I, Manns ID, Mainville L, Jones BE. 2003. Parvalbumin, calbindin, or calretinin in cortically projecting and GABAergic, cholinergic, or glutamatergic basal forebrain neurons of the rat. J Comp Neurol 458: 11-31.

Haglund L, Swanson LW, Kohler C. 1984. The projection of the supramammillary nucleus to the hippocampal formation: an immunohistochemical and anterograde transport study with the lectin PHA-L in the rat. J Comp Neurol 229: 171-185.

Halpern M. 1987. The organization and function of the vomeronasal system. Annu Rev Neurosci 10: 325-362.

Hangya B, Borhegyi Z, Szilagyi N, Freund TF, Varga V. 2009. GABAergic neurons of the medial septum lead the hippocampal network during theta activity. J Neurosci 29: 80948102.

Haugaard-Kedström LM, Shabanpoor F, Hossain MA, Clark RJ, Ryan PJ, Craik DJ, Gundlach AL, Wade JD, Bathgate RAD, Rosengren KJ. 2011. Design, synthesis, and characterization of a single-chain peptide antagonist for the relaxin-3 receptor RXFP3. J Am Chem Soc 133: 4965-4974.

Haun F, Eckenrode TC, Murray M. 1992. Habenula and thalamus cell transplants restore normal sleep behaviors disrupted by denervation of the interpeduncular nucleus. J Neurosci 12: 3282-3290.

Herkenham M, Nauta WJ. 1977. Afferent connections of the habenular nuclei in the rat. A horseradish peroxidase study, with a note on the fiber-of-passage problem. J Comp Neurol 173: 123-146.

Heusner CL, Beutler LR, Houser CR, Palmiter RD. 2008. Deletion of GAD67 in dopamine receptor-1 expressing cells causes specific motor deficits. Genesis 46: 357-367. .

Holscher C. 1999. Nitric oxide is required for expression of LTP that is induced by stimulation phase-locked with theta rhythm. Eur J Neurosci 11: 335-343.

Jacab RL, Leranth C. 1995. Septum. In The Rat Nervous System, Paxinos G. (ed). Academic Press: 405-442.

Jahn R, Schiebler W, Ouimet C, Greengard P. 1985. A 38,000-dalton membrane protein (p38) present in synaptic vesicles. Proc Natl Acad Sci USA 82: 4137-4141.

Kay RB, Meyer EA, Illig KR, Brunjes PC. 2011. Spatial distribution of neural activity in the anterior olfactory nucleus evoked by odor and electrical stimulation. J. Comp. Neurol. 519: 277-289. .

Kiss J, Borhegyi Z, Csaky A, Szeiffert G, Leranth C. 1997. Parvalbumin-containing cells of the angular portion of the vertical limb terminate on calbindin-immunoreactive neurons 
located at the border between the lateral and medial septum of the rat. Exp Brain Res 113: 48-56.

Kitchigina VF, Kudina TA, Kutyreva EV, Vinogradova OS. 1999. Neuronal activity of the septal pacemaker of theta rhythm under the influence of stimulation and blockade of the median raphe nucleus in the awake rabbit. Neuroscience 94: 453-463.

Kubota Y, Inagaki S, Shiosaka S, Cho HJ, Tateishi K, Hashimura E, Hamaoka T, Tohyama M. 1983. The distribution of cholecystokinin octapeptide-like structures in the lower brain stem of the rat: an immunohistochemical analysis. Neuroscience 9: 587-604.

Kuei C, Sutton S, Bonaventure P, Pudiak C, Shelton J, Zhu J, Nepomuceno D, Wu J, Chen J, Kamme F, Seierstad M, Hack MD, Bathgate RAD, Hossain MA, Wade JD, Atack J, Lovenberg TW, Liu C. 2007. R3(B $\Delta 23-27) R / I 5$ chimeric peptide, a selective antagonist for GPCR135 and GPCR142 over relaxin receptor LGR7: in vitro and in vivo characterization. J Biol Chem 282: 25425-25435.

Leranth C, Carpi D, Buzsaki G, Kiss J. 1999. The entorhino-septo-supramammillary nucleus connection in the rat: morphological basis of a feedback mechanism regulating hippocampal theta rhythm. Neuroscience 88: 701-718.

Leranth C, Vertes RP. 1999. Median raphe serotonergic innervation of medial septum/diagonal band of Broca (MSDB) parvalbumin-containing neurons: possible involvement of the MSDB in the desynchronization of the hippocampal EEG. J Comp Neurol 410: 586-598.

Liu C, Chen J, Kuei C, Sutton S, Nepomuceno D, Bonaventure P, Lovenberg TW. 2005. Relaxin-3/insulin-like peptide 5 chimeric peptide, a selective ligand for $\mathrm{G}$ proteincoupled receptor (GPCR)135 and GPCR142 over leucine-rich repeat-containing G protein-coupled receptor 7. Mol Pharmacol 67: 231-240.

Liu C, Eriste E, Sutton S, Chen J, Roland B, Kuei C, Farmer N, Jornvall H, Sillard R, Lovenberg TW. 2003. Identification of relaxin-3/INSL7 as an endogenous ligand for the orphan G-protein-coupled receptor GPCR135. J Biol Chem 278: 50754-50764.

Ma S, Bonaventure P, Ferraro T, Shen PJ, Burazin TC, Bathgate RA, Liu C, Tregear GW, Sutton SW, Gundlach AL. 2007. Relaxin-3 in GABA projection neurons of nucleus incertus suggests widespread influence on forebrain circuits via G-protein-coupled receptor-135 in the rat. Neuroscience 144: 165-190. .

Ma S, Olucha-Bordonau FE, Hossain MA, Lin F, Kuei C, Liu C, Wade JD, Sutton SW, Nunez A, Gundlach AL. 2009b. Modulation of hippocampal theta oscillations and spatial memory by relaxin-3 neurons of the nucleus incertus. Learn Mem 16: 730-742. 
Ma S, Sang Q, Lanciego JL, Gundlach AL. 2009a. Localization of relaxin-3 in brain of Macaca fascicularis: identification of a nucleus incertus in primate. J Comp Neurol 517: 856-872.

Martin J, Timofeeva E. 2010. Intermittent access to sucrose increases sucrose-licking activity and attenuates restraint stress-induced activation of the lateral septum. Am J Physiol Regul Integr Comp Physiol 298: R1383-1398.

McGowan BMC, Stanley SA, Smith KL, Minnion JS, Donovan J, Thompson EL, Patterson M, Connolly MM, Abbott CR, Small CJ, Gardiner JV, Ghatei MA, Bloom SR. 2006. Effects of acute and chronic relaxin-3 on food intake and energy expenditure in rats. Regul Pept 136: 72-77.

McGowan BMC, Stanley SA, Smith KL, White NE, Connolly MM, Thompson EL, Gardiner JV, Murphy KG, Ghatei MA, Bloom SR. 2005. Central relaxin-3 administration causes hyperphagia in male Wistar rats. Endocrinology 146: 3295-3300.

McGowan BMC, Stanley SA, White NE, Spangeus A, Patterson M, Thompson EL, Smith KL, Donovan J, Gardiner JV, Ghatei MA, Bloom SR. 2007. Hypothalamic mapping of orexigenic action and Fos-like immunoreactivity following relaxin-3 administration in male Wistar rats. Am J Physiol Endocrinol Metab 292: E913-919.

McKenna JT, Vertes RP. 2001. Collateral projections from the median raphe nucleus to the medial septum and hippocampus. Brain Res Bull 54: 619-630.

Miyamoto Y, Watanabe Y, Tanaka M. 2008. Developmental expression and serotonergic regulation of relaxin 3/INSL7 in the nucleus incertus of rat brain. Regul. Pept. 145: 5459.

Morris JL, Konig P, Shimizu T, Jobling P, Gibbins IL. 2005. Most peptide-containing sensory neurons lack proteins for exocytotic release and vesicular transport of glutamate. J. Comp. Neurol. 483: 1-16. .

Motta SC, Goto M, Gouveia FV, Baldo MV, Canteras NS, Swanson LW. 2009. Dissecting the brain's fear system reveals the hypothalamus is critical for responding in subordinate conspecific intruders. Proc Natl Acad Sci USA 106: 4870-4875.

Nerad L, McNaughton N. 2006. The septal EEG suggests a distributed organization of the pacemaker of hippocampal theta in the rat. Eur J Neurosci 24: 155-166.

Nunez A, Cervera-Ferri A, Olucha-Bordonau F, Ruiz-Torner A, Teruel V. 2006. Nucleus incertus contribution to hippocampal theta rhythm generation. Eur J Neurosci 23: 27312738 . 
Nunez A, de Andres I, Garcia-Austt E. 1991. Relationships of nucleus reticularis pontis oralis neuronal discharge with sensory and carbachol evoked hippocampal theta rhythm. Exp Brain Res 87: 303-308.

O'Keefe J. 1993. Hippocampus, theta, and spatial memory. Curr Opin Neurobiol 3: 917-924.

Olucha-Bordonau FE, Ma S, Otero-García M, Martínez-García F, Gundlach AL. 2009.

Distribution of relaxin-3 fibers in the amygdala of the rat. Society for Neuroscience Meeting, Chicago.

Olucha-Bordonau FE, Teruel V, Barcia-Gonzalez J, Ruiz-Torner A, Valverde-Navarro AA, Martinez-Soriano F. 2003. Cytoarchitecture and efferent projections of the nucleus incertus of the rat. J Comp Neurol 464: 62-97.

Peng ZC, Chen S, Bertini G, Schmidt HH, Bentivoglio M. 1994. Co-localization of nitric oxide synthase and NGF receptor in neurons in the medial septal and diagonal band nuclei of the rat. Neurosci. Lett. 166: 153-156. .

Pestche H, Stumpf C. 1962. The origin of theta-rhythm in the rabbit hippocampus. Wien Klin Wochenschr 74: 696-700.

Peters, A. 1987. Synaptic specificity in the cerebral cortex. In Synaptic Function (ed. Edelman, GM, Gall, WE \& Cowan, WM) pp. 373-397. New York: John Wiley.

Raymackers JM, Debaix H, Colson-Van Schoor M, De Backer F, Tajeddine N, Schwaller B, Gailly P, Gillis JM. 2003. Consequence of parvalbumin deficiency in the mdx mouse: histological, biochemical and mechanical phenotype of a new double mutant. Neuromuscul. Disord. 13: 376-387. .

Rico B, Cavada C. 1998. A population of cholinergic neurons is present in the macaque monkey thalamus. Eur J Neurosci 10: 2346-2352.

Risold PY, Canteras NS, Swanson LW. 1994. Organization of projections from the anterior hypothalamic nucleus: a Phaseolus vulgaris-leucoagglutinin study in the rat. J Comp Neurol 348: 1-40.

Risold PY, Swanson LW. 1997a. Connections of the rat lateral septal complex. Brain Res Rev 24: 115-195.

Risold PY, Swanson LW. 1997b. Chemoarchitecture of the rat lateral septal nucleus. Brain Res Rev 24: 91-113.

Ryan MC, Gundlach AL. 1995. Anatomical localisation of preproatrial natriuretic peptide mRNA in the rat brain by in situ hybridisation histochemistry: novel identification in olfactory regions. J Comp Neurol 356: 168-182. 
Ryan PJ, Ma S, Olucha-Bordonau FE, Gundlach AL. 2011. Nucleus incertus - an emerging modulatory role in arousal, stress and memory. Neurosci Biobehav Rev 35: 1326-1341.

Schiffmann SN, Cheron G, Lohof A, d'Alcantara P, Meyer M, Parmentier M, Schurmans S. 1999. Impaired motor coordination and Purkinje cell excitability in mice lacking calretinin. Proc. Natl. Acad. Sci. U. S. A. 96: 5257-5262. .

Simon AP, Poindessous-Jazat F, Dutar P, Epelbaum J, Bassant MH. 2006. Firing properties of anatomically identified neurons in the medial septum of anesthetized and unanesthetized restrained rats. J Neurosci 26: 9038-9046.

Smith CM, Hosken IT, Sutton SW, Lawrence AJ, Gundlach AL. 2011. Relaxin-3 null mutation mice display a circadian hypoactivity phenotype. Genes Brain Behav doi: 10.1111/j.1601-183X.2011.00730.x.

Smith CM, Shen PJ, Banerjee A, Bonaventure P, Ma S, Bathgate RA, Sutton SW, Gundlach AL. 2010. Distribution of relaxin-3 and RXFP3 within arousal, stress, affective, and cognitive circuits of mouse brain. J. Comp. Neurol. 518: 4016-4045. .

Sotty F, Danik M, Manseau F, Laplante F, Quirion R, Williams S. 2003. Distinct electrophysiological properties of glutamatergic, cholinergic and GABAergic rat septohippocampal neurons: novel implications for hippocampal rhythmicity. J Physiol 551: 927-943.

Tanaka M, Iijima N, Miyamoto Y, Fukusumi S, Itoh Y, Ozawa H, Ibata Y. 2005. Neurons expressing relaxin 3/INSL 7 in the nucleus incertus respond to stress. Eur J Neurosci 21: 1659-1670.

Teruel-Marti V, Cervera-Ferri A, Nunez A, Valverde-Navarro AA, Olucha-Bordonau FE, Ruiz-Torner A. 2008. Anatomical evidence for a ponto-septal pathway via the nucleus incertus in the rat. Brain Res 1218: 87-96.

Toth K, Freund TF, Miles R. 1997. Disinhibition of rat hippocampal pyramidal cells by GABAergic afferents from the septum. J Physiol 500: 463-474.

Tulogdi A, Toth M, Halasz J, Mikics E, Fuzesi T, Haller J. 2010. Brain mechanisms involved in predatory aggression are activated in a laboratory model of violent intra-specific aggression. Eur J Neurosci 32: 1744-1753.

Ujfalussy B, Kiss T. 2006. How do glutamatergic and GABAergic cells contribute to synchronization in the medial septum? J Comput Neurosci 21: 343-357.

Valjakka A, Vartiainen J, Tuomisto L, Tuomisto JT, Olkkonen H, Airaksinen MM. 1998. The fasciculus retroflexus controls the integrity of REM sleep by supporting the generation 
of hippocampal theta rhythm and rapid eye movements in rats. Brain Res Bull 47: 171184

Van Pett K, Viau V, Bittencourt JC, Chan RK, Li HY, Arias C, Prins GS, Perrin M, Vale W, Sawchenko PE. 2000. Distribution of mRNAs encoding CRF receptors in brain and pituitary of rat and mouse. J Comp Neurol 428: 191-212.

Veenema AH, Neumann ID. 2007. Neurobiological mechanisms of aggression and stress coping: a comparative study in mouse and rat selection lines. Brain Behav Evol 70: 274285.

Vertes RP, Colom LV, Fortin WJ, Bland BH. 1993. Brainstem sites for the carbachol elicitation of the hippocampal theta rhythm in the rat. Exp Brain Res 96: 419-429.

Vertes RP, Fortin WJ, Crane AM. 1999. Projections of the median raphe nucleus in the rat. J. Comp. Neurol. 407: 555-582.

Vertes RP, Kocsis B. 1997. Brainstem-diencephalo-septohippocampal systems controlling the theta rhythm of the hippocampus. Neuroscience 81: 893-926.

Vertes RP. 1981. An analysis of ascending brain stem systems involved in hippocampal synchronization and desynchronization. J Neurophysiol 46: 1140-1159.

Vertes RP. 1982. Brain stem generation of the hippocampal EEG. Prog Neurobiol 19: 159186.

Vinogradova OS. 1995. Expression, control, and probable functional significance of the neuronal theta-rhythm. Prog Neurobiol 45: 523-583.

Wheeler TC, Chin LS, Li Y, Roudabush FL, Li L. 2002. Regulation of synaptophysin degradation by mammalian homologues of seven in absentia. J. Biol. Chem. 277: 10273-10282.

Wu M, Shanabrough M, Leranth C, Alreja M. 2000. Cholinergic excitation of septohippocampal GABA but not cholinergic neurons: implications for learning and memory. J Neurosci 20: 3900-3908.

Yamamoto T, Watanabe S, Oishi R, Ueki S. 1979. Effects of midbrain raphe stimulation and lesion on EEG activity in rats. Brain Res Bull 4: 491-495.

Yoon T, Otto T. 2007. Differential contributions of dorsal vs. ventral hippocampus to auditory trace fear conditioning. Neurobiol Learn Mem 87: 464-475.

Zimmermann L, Schwaller B. 2002. Monoclonal antibodies recognizing epitopes of calretinins: dependence on $\mathrm{Ca}^{2+}$-binding status and differences in antigen accessibility in colon cancer cells. Cell Calcium 31: 13-25. 


\section{FIGURE LEGENDS}

Figure 1. An example of a camera lucida drawing corresponding to the maps of CB-28kD and RLN3 immunoreactivity in the medial septum (Fig. 5D) and lateral septum (Fig. 7D). (A) Camera lucida drawing of the entire septal area. (B-F) High magnification images of the boxed areas marked in A. Arrows indicate RLN3 fibers. Scale bar, $200 \mu \mathrm{m}(\mathrm{A}), 40 \mu \mathrm{m}(\mathrm{B}-\mathrm{F})$.

Figure 2. Injection points of FG in the hippocampus (A and B) and of miniruby (mR) in the nucleus incertus (C-F). Scale bars in B for A-B and in F for C-F $500 \mu \mathrm{m}$.

Figure 3. Patterns of retrograde labeling in the septal area after anterior hypothalamic or hippocampal Fluorogold (FG) injections. (A) An injection site in the anterior hypothalamus centered in the anterior hypothalamic area that spread into the ventromedial hypothalamic nucleus, tuberal area, lateral hypothalamic and retrochiasmatic area. (B) Retrograde labeling in the septal area following FG injection in the anterior hypothalamus - the LSc-d and the MS are devoid of labeled cells. (C) Higher magnification view of retrograde labeling in the transition region between the vMS and the hMS, illustrating retrograde labeling in a band of cells on the lateral perimeter of the MS (arrows). (D) An injection site in the ventral hippocampus that spread through the subiculum, CA1, CA3 and dentate gyrus. (E) Retrograde labeling in the septal area following a FG injection in the ventral hippocampus - retrograde labeling fills almost the entire medial septum. (F) Higher magnification view of retrograde labeling in the transition region between the vMS and the hMS illustrating retrograde labeling throughout the entire ipsilateral medial septum and some on the contralateral side. Scale bars for A-B, D-E, $500 \mu \mathrm{m}$, for C and F $200 \mu \mathrm{m}$. For abbreviations, see list.

Figure 4. Distribution of anterograde labeling in the septal area following a miniruby $(\mathrm{mR})$ injection into the nucleus incertus, relative to the distribution of ChAT-positive neurons. ChAT-positive cells (blue) and anterograde fibers (red) were mapped in coronal sections using camera lucida and a 20x objective. Septal division boundaries are depicted in black and revectorized. (A) Level 1: a cavity is present in the midline. (B) Level 2: continuity exists between hMS and vMS. (C) Level 3: a clear division is observed between hMS and vMS and the fornix becomes evident in the dorsal tip of the vMS. (D) Level 4: the anterior commissure is interposed between the hMS and vMS. (E) Level 5: the posterior septum is composed of the triangular septal and the septofimbrial nucleus, where sparse ChAT-positive neurons were found between the bundles of the fimbria. At this level, the medial septum is only represented 
by the hMS. The distribution of ChAT-positive neurons correlates with areas containing the densest plexuses of anterograde labeled fibers from the nucleus incertus. Scale bar, $500 \mu \mathrm{m}$. For abbreviations, see list.

Figure 5. Distribution of RLN3-positive fibers in the septal area relative to the distribution of neurons retrogradely labeled following a FG injection into the ventral hippocampus. Immunostaining for FG and RLN3 was mapped as described in Figure 2. (A-E) Levels 1-5: Intense RLN3-labeling was observed within mostly medial septal regions containing retrogradely labeled neurons from the hippocampus including the vMS and hMS. The distribution of RLN3 fibers is similar to that of anterogradely labeling projections from the nucleus incertus (see Fig. 2). Scale bar, $500 \mu \mathrm{m}$. For abbreviations, see list.

Figure 6. Distribution of RLN3-positive fibers in the septal area relative to the distribution of neurons retrogradely labeled following a FG injection into the anterior hypothalamus. Immunostaining for FG and RLN3 was mapped as described in Figure 2. (A-E) Level 1-5: Intense RLN3-labeling was observed within the vertical and horizontal limbs of MS septum, which contained a restricted band of retrogradely labeled neurons on the border with the lateral septum (B-D). RLN3-labeling was also observed in several lateral septum nuclei, which contained very high densities of retrogradely labeled neurons. The dorsal caudal lateral septum was the only region that did not contain retrograde labeling or RLN3-labeled fibers. For abbreviations, see list. Scale bar, $500 \mu \mathrm{m}$.

Figure 7. Distribution of RLN3-positive fibers at level 1 of the septal area in the vertical limb of the medial septum and adjacent lateral septum. (A) Nissl stained section at level 1 is characterized by boundaries with the insula of Calleja Magna. Dorsal aspects of the septum include the dorsal part of the LSc and the septohippocampal nucleus. The central area includes the three divisions of the LSr - dorsolateral, ventrolateral and medial. At this level, two divisions of the medial septum are evident - vMS that contains loosely packed large neurons; and hMS that contains densely packed large neurons. (B-E) Double immunostaining for RLN3 (red) and other septal markers (blue) in the framed region of 'A', mapped using camera lucida. The boundaries of septal divisions are depicted in black and revectorized. Immunostaining for RLN3 mapped with (B) FG following injection into the ventral hippocampus, (C) parvalbumin, (D) calbindin-28kD, and (E) calretinin. Scale bars, $500 \mu \mathrm{m}$ in $\mathrm{A} ; 250 \mu \mathrm{m}$ in B-E. 
Figure 8. Distribution of RLN3-positive fibers at level 2 of the septal area in the vertical limb of the medial septum and adjacent lateral septum. (A) Nissl stained section at level 2 characterized by the presence of the rostral-most level of the fornix, dorsal to the medial septum. Dorsal to the fornix, there is a clear divide between the septohippocampal nucleus and the LSc-d. In the ventral tip of this area, a clearly defined group of dense cells is observed, and identifiable as the LSc-v. The central area includes three divisions of the LSr dorsolateral, ventrolateral and medial, which have no clear boundaries. At this level, there are two divisions of the medial septum, vMS containing loosely packed large neurons, and hMS containing densely packed large neurons. (B-E) Double immunostaining for RLN3 (red) and other septal markers (blue) in framed region of 'A', mapped using camera lucida. Immunostaining for RLN3 combined with (B) FG staining, following injection in the ventral hippocampus, (C) ChAT, (D) nNOS, (E) calretinin, and (F) TH. Scale bars, $500 \mu \mathrm{m}$ in A; 250 $\mu \mathrm{m}$ in B-E.

Figure 9. Distribution of RLN3-positive fibers at level 3 of the septal area in the vertical limb of the medial septum and adjacent lateral septum. (A) A Nissl stained section at level 3 is characterized by fornix bundles occupying the dorsomedial aspects of the septum bordering the medial septum. Capping the fornix dorsolaterally, the LSc contains the dorsal and ventral divisions. Dorsal to the fornix, a clear divide exists between the septohippocampal nucleus and the LSc-d. In the ventral tip of this area, an apparent divide containing densely-packed cells was observed, identified as the LSc-v. The central area includes three divisions of the LSr - dorsolateral, ventrolateral and medial, which have no clear boundaries. At this level, there are two divisions of the medial septum, vMS containing loosely packed large neurons and hMS containing densely packed large neurons. (B-E) Double immunostaining for RLN3 (red) and other septal markers (blue) in framed region of 'A', mapped using camera lucida. Immunostaining for RLN3 combined with (B) FG staining following injection in the anterior hypothalamus, (C) ChAT, (D) PV, (E) CB-28kD, and (F) CR. Scale bars, $500 \mu \mathrm{m}$ in A; 250 $\mu \mathrm{m}$ in B-E.

Figure 10. Distribution of RLN3-positive fibers at level 4 of the septal area in the vertical limb of the medial septum and adjacent posterior septum. (A) A Nissl stained section at level 4, at which the posterior septum appears in the center of the septal area and includes the triangular septal and septofimbral nuclei. Dorsolateral to these nuclei, the fimbrial bundles are 
capped by the LSc-d/v and only the ventral division contained RLN3 fibers. Ventral to the fornix, a group of vMS neurons lie between the fornix and the anterior commissure. Lateral to this cell group, a diagonal band of neurons were observed, corresponding to the LS-v. The hMS appears over the ependymal surface, surrounded by the basal substantia innominata and the anterior dorsal peduncular hypothalamic area. (B-E) Double immunostaining for RLN3 (red) and other septal markers (blue) in framed region of 'A', mapped using camera lucida. Immunostaining for RLN3 combined with (B) nNOS, (C) FG staining following injection into the anterior hypothalamus, (D) calretinin, (E) TH, and (F) calbindin. Scale bars, $500 \mu \mathrm{m}$ in A; $250 \mu \mathrm{m}$ in B-E.

Figure 11. Distribution of RLN3-positive fibers at level 5 of the septal area in the horizontal limb of the medial septum and the lateral septum. (A) A Nissl stained section at level 5, where the posterior septum is composed of the triangular septal and septofimbrial nuclei, which are capped by the dorsal and ventral LSc. Ventrally, the hMS is lateral to the preoptic area of the hypothalamus and is capped dorsally by the basal substantia innominata. (B-E) Double immunostaining for RLN3 (red) and other septal markers (blue) in framed region of 'A', mapped using camera lucida. Immunostaining for RLN3 combined with (B) calretinin, a robust marker for the triangular septal nucleus, (C) FG staining, following FG injection into the anterior hypothalamus, (D) parvalbumin, which delineated the extension of the triangular septal nucleus, (E) parvalbumin in the hMS (note: the SIB contained well-labeled parvalbumin neurons, but sparse RLN3 fibers), (F) nNOS (note: nNOS positive cells occupy different compartments of the hMS), and (F) FG staining, following FG injection into the ventral hippocampus. Scale bars, $500 \mu \mathrm{m}$ in A; $250 \mu \mathrm{m}$ in B-E.

Figure 12. Septal targets of nucleus incertus neurons mapped after injection of the anterograde tracer, miniruby (mR), into the nucleus incertus. (A) Representative photomicrograph of an injection into the nucleus incertus pars compacta, which resulted in little or no spread from the injection site to the contralateral side, posterodorsal tegmental nucleus, or more rostrally located raphe nucleus. (B) Peri-somatic terminal-like labeling of $\mathrm{mR}$ fibers contacting a ChAT-positive cell in the region between the vMS and the hMS. (C) Anterograde terminallike labeling surrounding parvalbumin-positive soma and processes. (D) Terminal-like labeling contacting calbindin-positive soma and processes. (E-G) Confocal images illustrating putative contacts between anterogradely labeled $\mathrm{mR}$ fibers (red) and parvalbumin-positive somata (green) of a hippocampal-projecting neuron (blue), following FG injection into the 
hippocampus. (E) Maximal projection of overlaid images from 10 sections of $0.8 \mu \mathrm{m}$. (F) A single section of $0.8 \mu \mathrm{m}$ illustrating anterogradely-labeled elements and parvalbumin. $(\mathrm{G})$ Retrogradely-labeled FG positive cells and anterogradely-labeled $\mathrm{mR}$ positive elements. Asterisks represent neurons double-labeled for FG and parvalbumin; arrows indicate contacts between anterogradely-labeled fibers and parvalbumin-positive somata or processes. Scale bars, A $200 \mu \mathrm{m}$, B-D $20 \mu \mathrm{m}, \mathrm{E}-\mathrm{G} 40 \mu \mathrm{m}$.

Figure 13. Confocal images illustrating putative contacts between RLN3-positive fibers and (A-D) GAD67-containing neurons; and (E,F) parvalbumin-containing neurons and FG containing neurons, following FG injection into the hippocampus. Neurons containing GAD or parvalbumin are marked by hexagons and neurons double-labeled for GAD and FG are indicated by stars. Arrows indicate possible contacts between RLN3-labeled fibers and labeled neurons or processes. (A) Overlaid maximal projection of $10 \mathrm{scans}, 0.5 \mu \mathrm{m}$ apart through the MS - FG (blue), GAD (red) and RLN3 (green), and (B-D) three single, consecutive scans, $0.5 \mu \mathrm{m}$ apart, represented in A. (E) Maximal projection of 8 sections, 0.8 $\mu \mathrm{m}$ apart - RLN3 (green), FG (blue) and PV (red); and (F) a single section of $0.8 \mu \mathrm{m}$, represented in E. Scale bars, $40 \mu \mathrm{m}$.

Figure 14. Confocal images illustrating putative contacts between RLN3-positive fibers and (A-D) calbindin-28kD-containing neurons or (E-H) calretinin-containing neurons in the medial septum following FG injection into the hippocampus. No colocalization was observed between FG (blue) and CB-28kD or CR (red). (A) Maximal projection of 9 sections, $2 \mu \mathrm{m}$ apart, stained for CB-28kD (red); and (B-D) three single, consecutive sections, $2 \mu \mathrm{m}$ apart, represented in A. (E) Maximal projection of 9 sections, $2 \mu \mathrm{m}$ apart, stained for CR (red), and (F-H) three single, consecutive sections, $2 \mu \mathrm{m}$ apart, represented in A. Solid arrows indicate close contacts between RLN3 (green) and CB-28kD or CR cells. Open arrowheads indicate colocalization of RLN3 and CB 28kD or CR. Scale bars, $40 \mu \mathrm{m}$.

Figure 15. Confocal images illustrating the colocalization of mR- (red) and RLN3- (green) associated immunofluorescence (arrows) in a nerve fiber stained for RLN3 and ChAT (cyan) in the medial septum in a coronal section from a case (\#54) that received a FG injection into the hippocampus and and a $\mathrm{mR}$ injection into the nucleus incertus. Stars indicate doublelabeled FG (blue) and ChAT-positive neurons. Arrowheads indicate putative contacts between $\mathrm{mR} / \mathrm{RLN} 3$ fibers and labeled neurons or processes. Immunofluorescence for (A) 
RLN3 and FG; (B) mR and FG; (C) FG, mR and RLN3 - note overlap of RLN3 and mR labeling in some fibers; (D) triple-labeling for FG, ChAT and $\mathrm{mR}$-note neurons labeled for ChAT and FG); (E) triple-labeling for ChAT, mR and RLN3; and (F) merge of FG, mR, RLN3 and ChAT. Scale bar, $40 \mu \mathrm{m}$.

Figure 16. Confocal images illustrating the colocalization of RLN3 with synaptophysin puncta in regions of the (A-C) medial septum and (D-F) lateral septum (see schematic). Arrows indicate colocalization between RLN3 (red) and Syn (green). Single sections of 0.5 $\mu \mathrm{m}$ illustrating immunofluorescent staining for (A) RLN3, (B) Syn, and (C) RLN3 and Syn images merged. Single sections of $0.5 \mu \mathrm{m}$ in the LSr-vl, illustrating staining for (D) RLN3, (E) Syn, and (F) RLN3 + Syn (merged). Scale bars, $5 \mu \mathrm{m}$.

Figure 17. Confocal images illustrating the colocalization of RLN3 with synaptophysin puncta in the (A-C) caudal LSv and (D-F) septofimbrial nucleus (see schematic). Arrows indicate colocalization between RLN3 (red) and Syn (green). Single sections of $0.5 \mu \mathrm{m}$ in the caudal LSv, illustrating immunofluorescent staining for (A) Syn, (B) RLN3 and (C) RLN3 and Syn images merged. Amongst the high densities of Syn puncta observed, large empty spaces likely correspond to neuronal somata. Single sections of $0.5 \mu \mathrm{m}$ in the septofimbrial nucleus, illustrating immunofluorescent staining for (D) Syn, (E) RLN3, and (F) RLN3 + Syn (merged). The septofimbrial area contains groups of cells between axonal bundles that appear as empty spaces and the majority of RLN3 fibers display Syn staining. Scale bars, $5 \mu \mathrm{m}$.

Figure 18. Electron photomicrographs of sections through the medial septum stained for RLN3 illustrating synaptic contacts between labeled terminals and postsynaptic structures. Most labeled terminals contained large, round dense-vesicles of $\sim 100-150 \mathrm{~nm}$ in diameter (stars). (A) A labeled terminal (ter1) with symmetric contact (arrow) on a dendrite. This dendrite also makes contact with another terminal (ter2) that gives rise to an asymmetric contact (large arrowhead). (B) RLN3-labeled terminal (ter) making symmetric contacts with a soma (so) and a dendrite (de). (C,D) RLN3-labeled terminals making symmetric contacts with dendrites (arrows). Scale bars, $500 \mathrm{~nm}$.

Figure 19. Schematic diagram illustrating two major circuits modulated by RLN3 projections to the septal area. (Upper) Descending projections originating in the medial amygdala and LSr-vl converge on the anterior hypothalamic nucleus, where defensive neural signals are 
channeled to the periaqueductal grey. (Lower) Modulatory inputs arising from the nucleus incertus control the medial septum through two types of projections - those to septohippocampal neurons and local neurons, and those to neurons in the supramammillary nucleus that in turn project to the medial septum and hippocampus. This circuit is responsible for the generation and modulation of hippocampal theta rhythm.
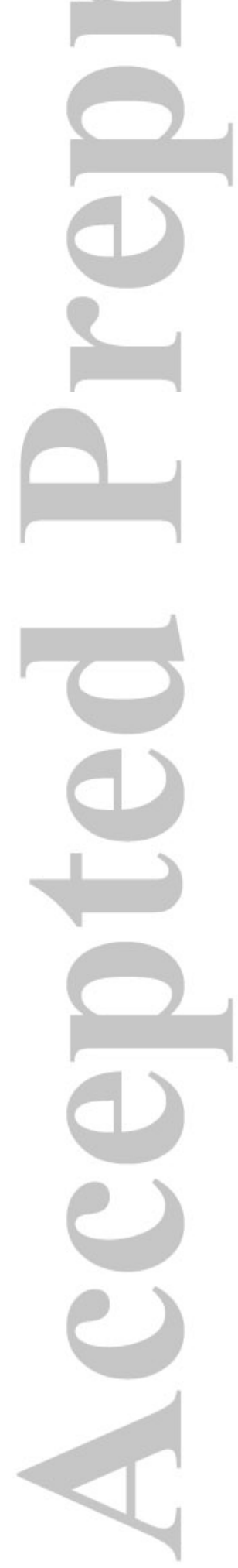


\begin{tabular}{|c|c|}
\hline \multicolumn{2}{|c|}{ LIST OF ABBREVIATIONS USED IN FIGURES } \\
\hline $3 \mathrm{~V}$ & third ventricle \\
\hline ac & anterior commissure \\
\hline Acb & accumbens nucleus shell \\
\hline ADP & anterodorsal preoptic nucleus \\
\hline ax & axon \\
\hline APir & amygdalopiriform transition ares \\
\hline BSTn & bed nucleus of the stria terminalis, medial \\
\hline $\mathrm{CA}$ & field CA1 of hippocampus \\
\hline $\mathrm{CB}$ & calbindin $28 \mathrm{kD}$ \\
\hline ChA & choline acetyltransferase \\
\hline $\mathrm{CR}$ & calretinin \\
\hline DG & dentate gyrus \\
\hline ds & dendritic shaft \\
\hline f & fornix \\
\hline FG & fluorogold \\
\hline GAD & glutamic acid decarboxylase \\
\hline $\mathrm{hM}$ & medial septum, horizontal limb \\
\hline I & intercalated nuclei \\
\hline $\mathrm{ICj}$ & insula of Calleja magna \\
\hline & injection site \\
\hline Lent & lateral entorhinal area \\
\hline LSc- & lateral septum, caudal dorsal \\
\hline & lateral septum, caudal ventral \\
\hline LSr-dl & lateral septum, rostral, dorsolateral division \\
\hline $\mathrm{LSr}$ & lateral septum, rostral, medial division \\
\hline La & lateral septum, rostral, ventrolateral division \\
\hline $\mathrm{LSv}$ & lateral septum, ventral \\
\hline $\mathrm{MnP}$ & median preoptic nucleus \\
\hline & medial preoptic area \\
\hline $\mathrm{mR}$ & miniruby \\
\hline NIc & Nucleus incertus pars compacta \\
\hline NId & Nucleus incertus pars dissipata \\
\hline $\mathrm{nNO}$ & neuronal nitric oxide synthase \\
\hline
\end{tabular}




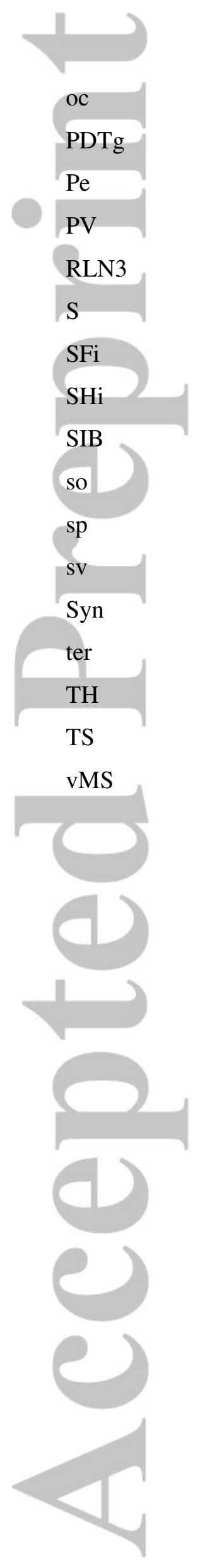

optic chiasma

posterodorsal tegmental nucleus

periventricular hypothalamic nucleus

parvalbumin

relaxin-3

subiculum

septofimbrial nucleus

septohippocampal nucleus

substantia innominata, basal part

soma

dendritic spine

synaptic vesicles

synaptophysin

axon terminal

tyrosine hydroxylase

triangular septal nucleus

medial septum, vertical limb 


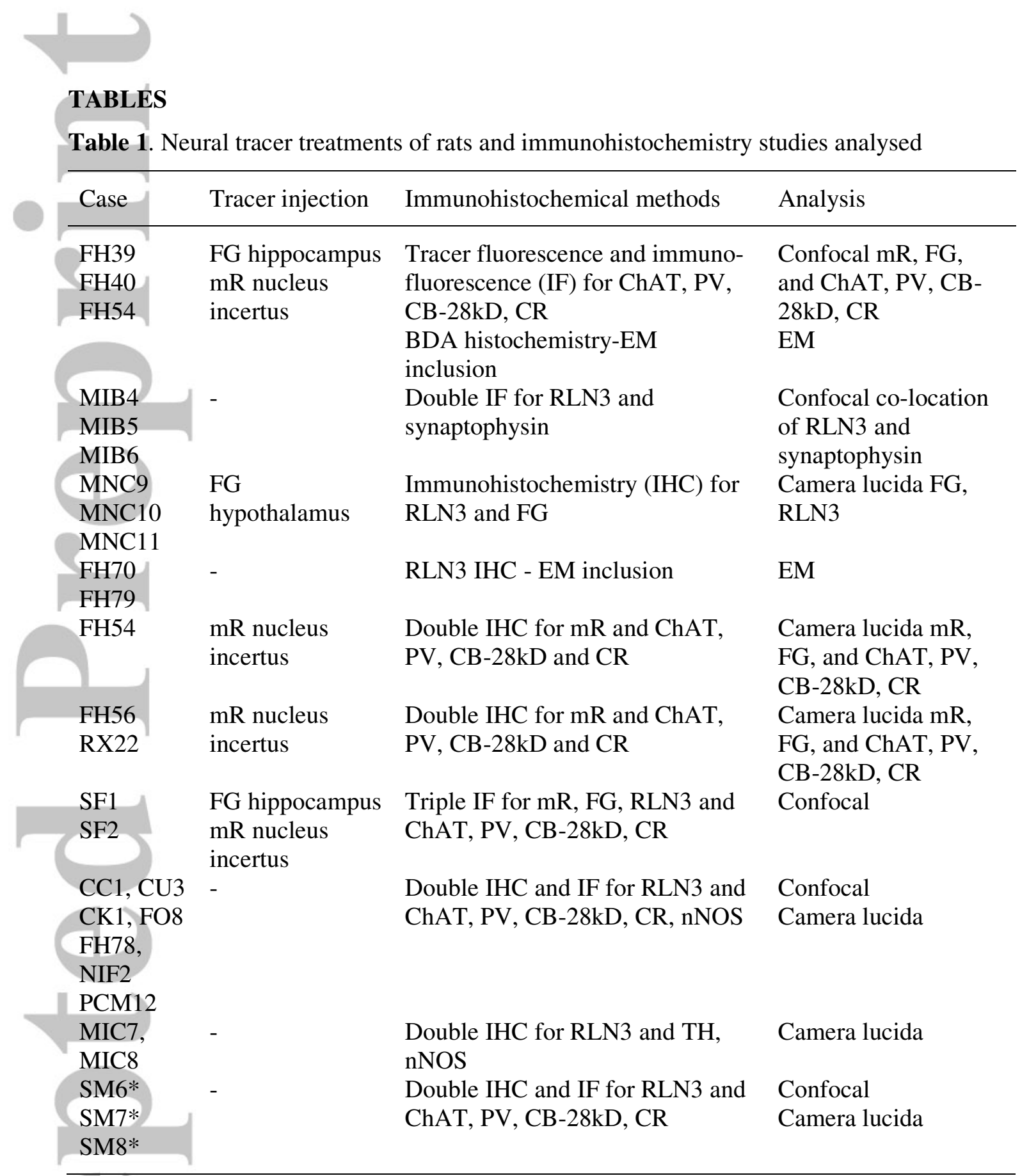

* These rats received a foot shock of $0.6 \mathrm{~mA}$ for $2 \mathrm{sec}, 90 \mathrm{~min}$ prior to processing. 
Table 2. List of Primary Antibodies Used in Immunoperoxidase and Immunofluorescence Staining

\begin{tabular}{|c|c|c|c|}
\hline Antigen & Immunogen (MW) & $\begin{array}{l}\text { Manufacturer, Host } \\
\text { species, Ig isotype, } \\
\text { Catalog number }\end{array}$ & $\begin{array}{l}\text { Dilution used } \\
\text { in } \mathrm{IHC}_{\mathrm{IHF}}\end{array}$ \\
\hline Fluor & $\begin{array}{l}\text { Fluorogold } \\
\text { (5-hydroxystabilamide) }\end{array}$ & $\begin{array}{l}\text { Chemicon, Temacula CA, } \\
\text { USA, rabbit, polyclonal, } \\
\text { AB-153 }\end{array}$ & IHC $1: 3,000$ \\
\hline & $\begin{array}{l}\text { choline acetyltransferase ( } 70 \\
\mathrm{kD})\end{array}$ & $\begin{array}{l}\text { Chemicon, Temacula CA, } \\
\text { USA, goat, polyclonal, } \\
\text { AB-144 }\end{array}$ & $\begin{array}{l}\text { IHC: } 1: 1,000 \\
\text { IF: } 1: 500\end{array}$ \\
\hline $\mathrm{CB}-2$ & $\begin{array}{l}\text { chicken calbindin D-28k ( } 28 \\
\mathrm{kD})\end{array}$ & $\begin{array}{l}\text { Swant, Bellinzona, } \\
\text { Switzerland, mouse, } \\
\text { monoclonal, McAB300 }\end{array}$ & $\begin{array}{l}\text { IHC: } 1: 10,000 \\
\text { IF: } 1: 5,000\end{array}$ \\
\hline & $\begin{array}{l}\text { recombinant human } \\
\text { calretinin-22k }(22 \mathrm{kD})\end{array}$ & $\begin{array}{l}\text { Swant, Bellinzona, } \\
\text { Switzerland, mouse, } \\
\text { monoclonal, McAB6B3 }\end{array}$ & $\begin{array}{l}\text { IHC: } 1: 5,000 \\
\text { IF: } 1: 2,500\end{array}$ \\
\hline & carp parvalbumin $(12 \mathrm{kD})$ & $\begin{array}{l}\text { Swant, Bellinzona, } \\
\text { Switzerland, mouse, } \\
\text { monoclonal, McAB235 }\end{array}$ & $\begin{array}{l}\text { IHC: } 1: 10,000 \\
\text { IF: } 1: 5,000\end{array}$ \\
\hline GAI & $\begin{array}{l}\text { recombinant GAD-67 (67 } \\
\mathrm{kD})\end{array}$ & $\begin{array}{l}\text { Chemicon, Temacula CA, } \\
\text { USA, mouse, monoclonal, } \\
\text { MAB-5406 }\end{array}$ & $\begin{array}{l}\text { IHC: } 1: 300 \\
\text { IF: } 1: 150\end{array}$ \\
\hline & rat tyrosine hydroxylase & $\begin{array}{l}\text { Sigma, St Louis, MO, } \\
\text { USA, mouse, monoclonal, } \\
\text { T1299 }\end{array}$ & IHC: $1: 10,000$ \\
\hline & $\begin{array}{l}\text { recombinant amino acids } 1- \\
181 \text { of nNOS }\end{array}$ & $\begin{array}{l}\text { Sigma, St Louis, MO, } \\
\text { USA, mouse, monoclonal, } \\
\text { N2280 }\end{array}$ & $\begin{array}{l}\text { IHC: } 1: 500 \\
\text { IF: } 1: 250\end{array}$ \\
\hline synaptophysin & $\begin{array}{l}\text { rat retinal synaptosomes } \\
\text { antigen }(38 \mathrm{kD})\end{array}$ & $\begin{array}{l}\text { Sigma, St Louis, MO, } \\
\text { USA, mouse, monoclonal, } \\
\text { S5768 }\end{array}$ & IF: $1: 1,000$ \\
\hline relaxin-3 & $\begin{array}{l}\text { amino acids } 85-101 \text { of pro- } \\
\text { RLN3 peptide conjugated to } \\
\text { KLH }\end{array}$ & $\begin{array}{l}\text { Howard Florey Institute, } \\
\text { Melbourne, Australia, } \\
\text { rabbit, polyclonal }\end{array}$ & $\begin{array}{l}\text { IHC: } 1: 2,500 \\
\text { IF: } 1: 1,250 \\
\text { ICC-EM: } \\
1: 2,500^{2}\end{array}$ \\
\hline
\end{tabular}

IHC/IF incubations were in TBS-Tx100.

${ }^{2} \mathrm{ICC}-\mathrm{EM}$ incubations were in $0.1 \mathrm{M} \mathrm{PB}$. 
Table 3. Semi-quantitative estimates of the distribution of RLN3 immuno-positive fibers relative to neural markers of the medial septum

\begin{tabular}{ccccccccc}
\hline Division & RLN3 & PV & CB & CR & ChAT & nNOS & FG- & FG- \\
& & & & & & & Hyp & Hipp \\
\hline vMS & +++ & +++ & ++ & ++ & +++ & ++ & - & ++++ \\
hMS & +++ & +++ & + & + & +++ & ++ & - & ++ \\
SIB & + & ++ & ++ & + & ++ & + & +++ & - \\
TS & + & ++ & ++++ & ++++ & - & - & + & - \\
\hline
\end{tabular}

Semi-quantitative estimates were made by visual observation of microscopic fields using a $20 \times$ objective: (-) no labelling, (+) 1-4 labeled fibers or cells, (++) 5-8 labeled fibers or cells, (+++) 9-12 labeled fibers or cells, $(+++)$ more than 12 labeled fibers or cells.
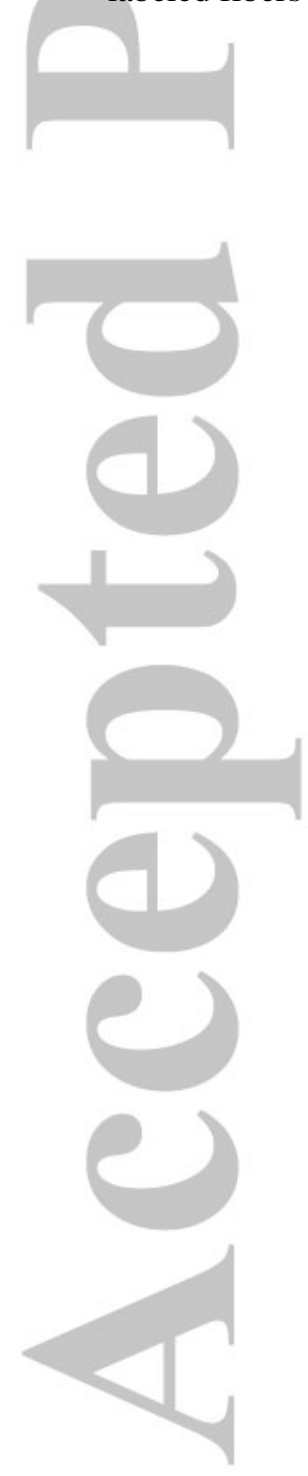
Table 4. Semi-quantitative estimates of the distribution of RLN3 immuno-positive fibers relative to neural markers of the lateral septum

\begin{tabular}{lccccccc}
\hline Division & RLN3 & TH & CB & CR & FG-Hyp & FG-Hipp \\
\hline LSc-d & - & - & + & + & - & - \\
LSc-v & +++ & - & ++ & ++ & +++ & - \\
LSv & + & - & +++ & - & +++ & - \\
LSr-dl & + & + & +++ & - & +++ & - \\
LSr-m & + & ++++ & +++ & ++ & +++ & - \\
LSr-vl & +++ & + & +++ & +++ & +++ & - \\
SHi & - & - & - & - & - & - \\
SFi & +++ & - & +++ & ++++ & ++ & - \\
iCjM & + & - & + & +++ & - & - \\
\hline
\end{tabular}

Semi-quantitative estimates were made by visual observation of microscopic fields using a $20 \times$ objective: (-) no labelling, (+) 1-4 labeled fibers or cells, (++) 5-8 labeled fibers or cells, (+++) 9-12 labeled fibers or cells, (+++) more than 12 labeled fibers or cells.

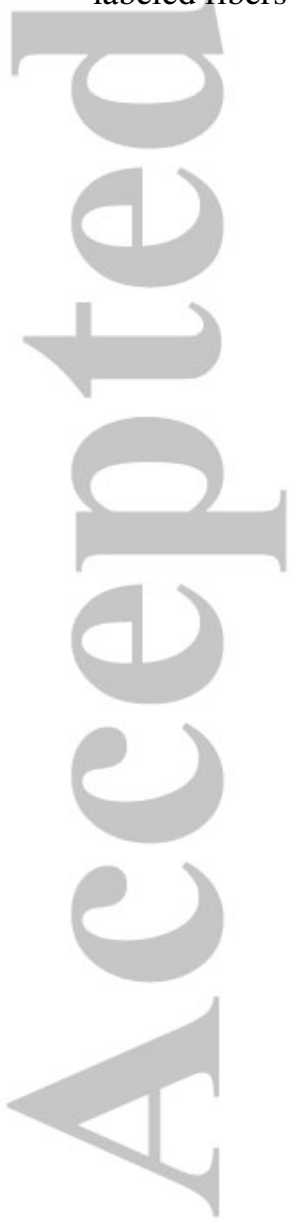



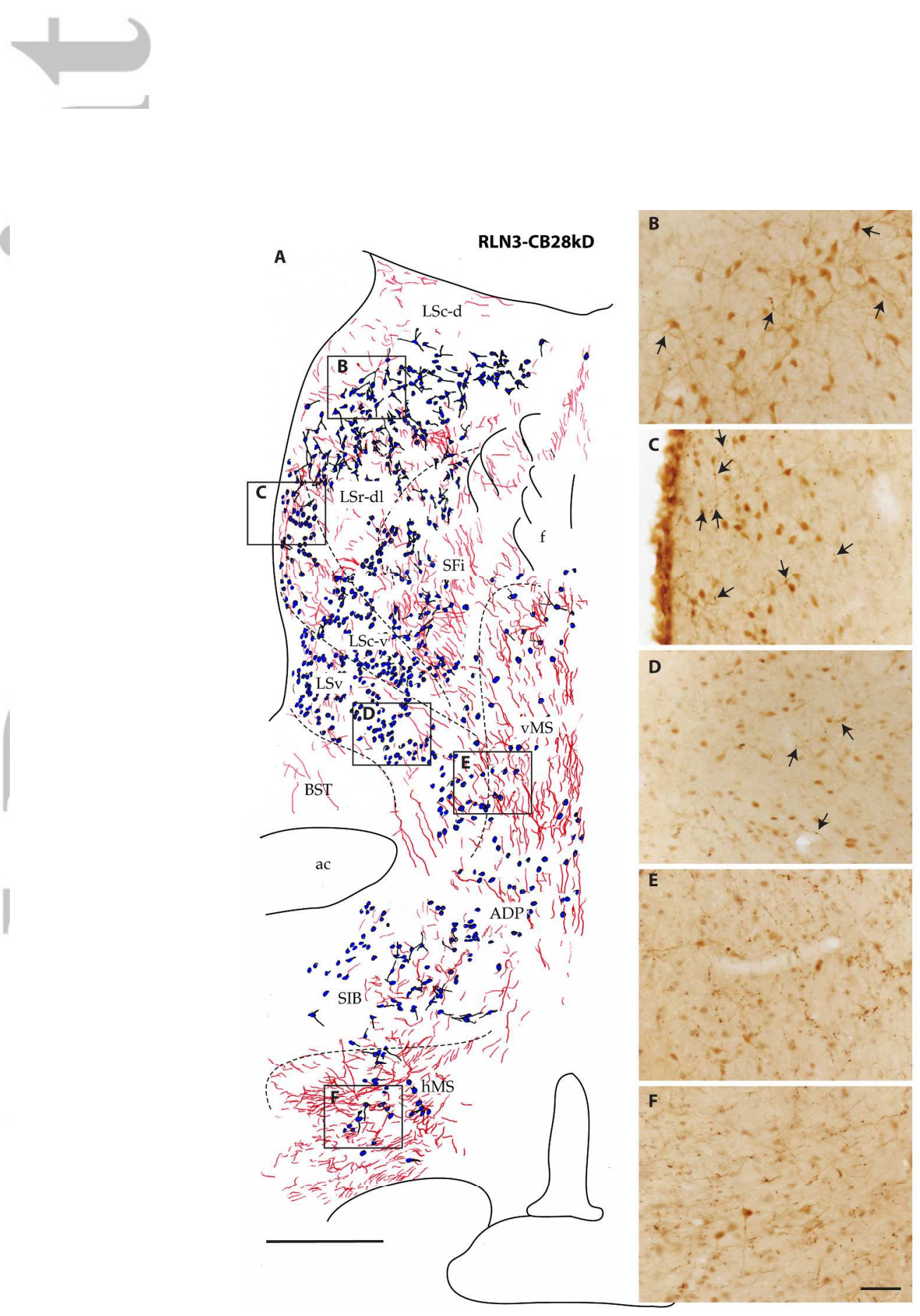

Figure 1. An example of a camera lucida drawing corresponding to the maps of CB-28kD and RLN3 immunoreactivity in the medial septum (Fig. 5D) and lateral septum (Fig. 7D). (A) Camera lucida drawing of the entire septal area. (B-F) High magnification images of the boxed areas marked in A. Arrows indicate RLN3 fibers. Scale bar, $200 \mu \mathrm{m}(\mathrm{A}), 40 \mu \mathrm{m}(\mathrm{B}-\mathrm{F})$.

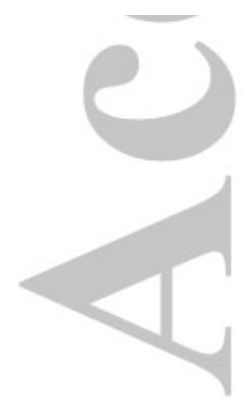
$178 \times 289 \mathrm{~mm}(300 \times 300 \mathrm{DPI})$ 

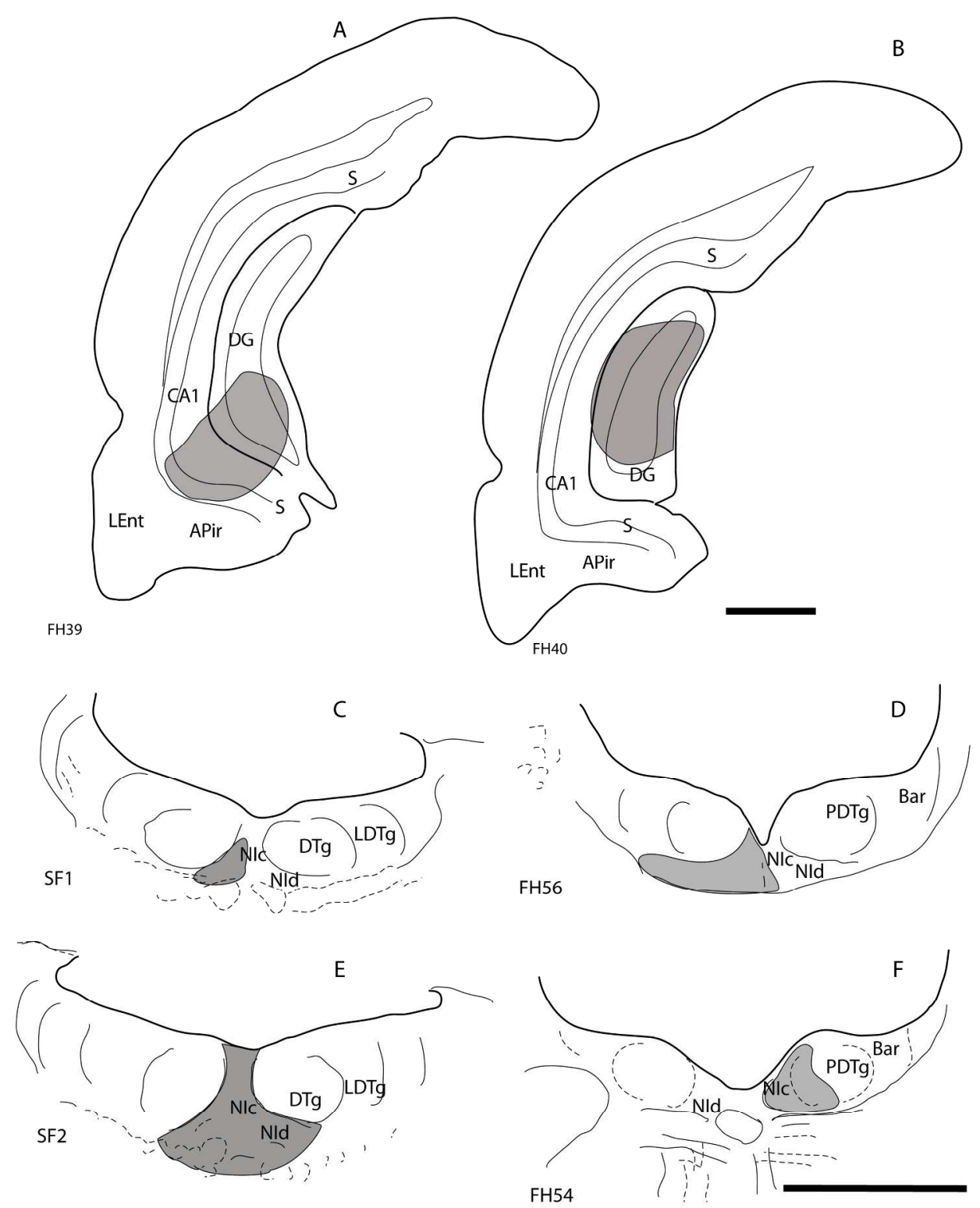

Figure 2. Injection points of $F G$ in the hippocampus ( $A$ and $B$ ) and of miniruby $(m R)$ in the nucleus incertus $(C-F)$. Scale bars in $B$ for $A-B$ and in $F$ for $C-F 500 \mu \mathrm{m}$. $205 \times 255 \mathrm{~mm}(300 \times 300 \mathrm{DPI})$ 

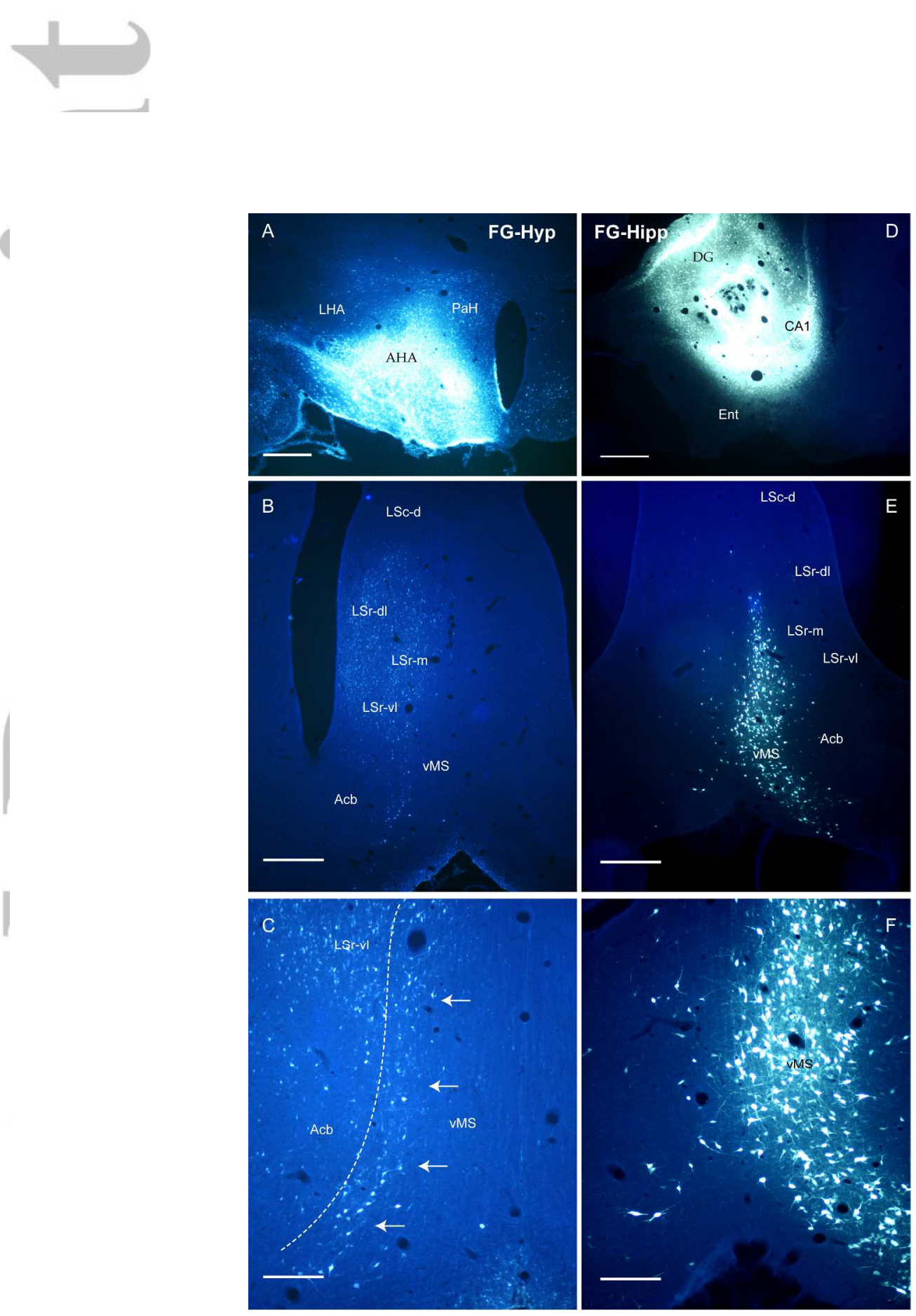

Figure 3. Patterns of retrograde labeling in the septal area after anterior hypothalamic or hippocampal Fluorogold (FG) injections. (A) An injection site in the anterior hypothalamus centered in the anterior

hypothalamic area that spread into the ventromedial hypothalamic nucleus, tuberal area, lateral hypothalamic and retrochiasmatic area. (B) Retrograde labeling in the septal area following FG injection in the anterior hypothalamus - the LSc-d and the MS are devoid of labeled cells. (C) Higher magnification view of retrograde labeling in the transition region between the vMS and the hMS, illustrating retrograde labeling

in a band of cells on the lateral perimeter of the MS (arrows). (D) An injection site in the ventral hippocampus that spread through the subiculum, CA1, CA3 and dentate gyrus. (E) Retrograde labeling in the septal area following a FG injection in the ventral hippocampus - retrograde labeling fills almost the entire medial septum. (F) Higher magnification view of retrograde labeling in the transition region between the vMS and the hMS illustrating retrograde labeling throughout the entire ipsilateral medial septum and some on the contralateral side. Scale bars for A-B, D-E, $500 \mu \mathrm{m}$, for C and F $200 \mu \mathrm{m}$. For abbreviations, see list. 

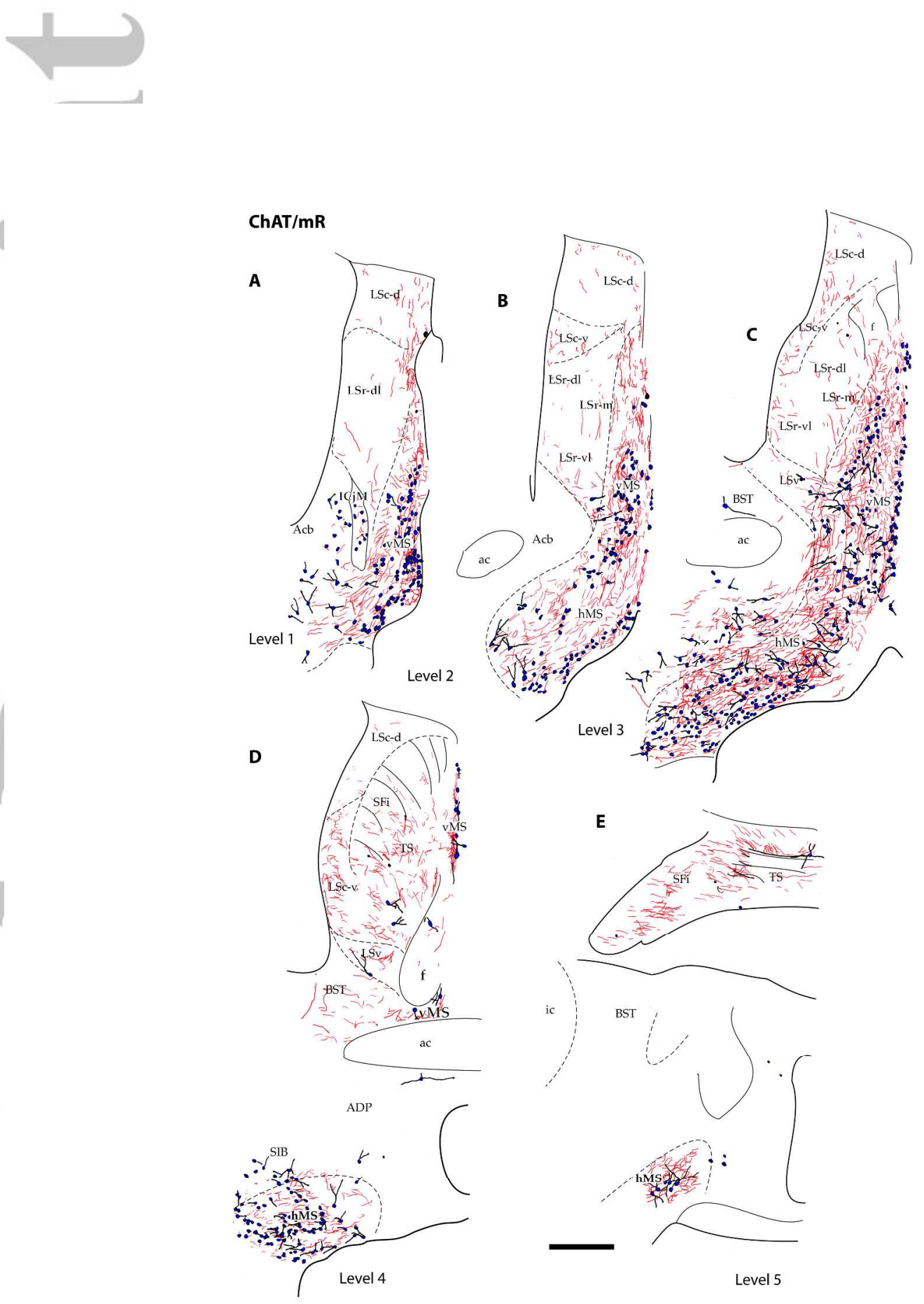

Figure 4. Distribution of anterograde labeling in the septal area following a miniruby $(\mathrm{mR})$ injection into the nucleus incertus, relative to the distribution of ChAT-positive neurons. ChAT-positive cells (blue) and anterograde fibers (red) were mapped in coronal sections using camera lucida and a $20 \times$ objective. Septal division boundaries are depicted in black and revectorized. (A) Level 1: a cavity is present in the midline. (B) Level 2: continuity exists between hMS and VMS. (C) Level 3: a clear division is observed between hMS and vMS and the fornix becomes evident in the dorsal tip of the vMS. (D) Level 4: the anterior commissure is interposed between the hMS and VMS. (E) Level 5: the posterior septum is composed of the triangular septal and the septofimbrial nucleus, where sparse ChAT-positive neurons were found between the bundles of the fimbria. At this level, the medial septum is only represented by the hMS. The distribution of ChATpositive neurons correlates with areas containing the densest plexuses of anterograde labeled fibers from the nucleus incertus. Scale bar, $500 \mu \mathrm{m}$. For abbreviations, see list. $178 \times 286 \mathrm{~mm}(300 \times 300$ DPI) 

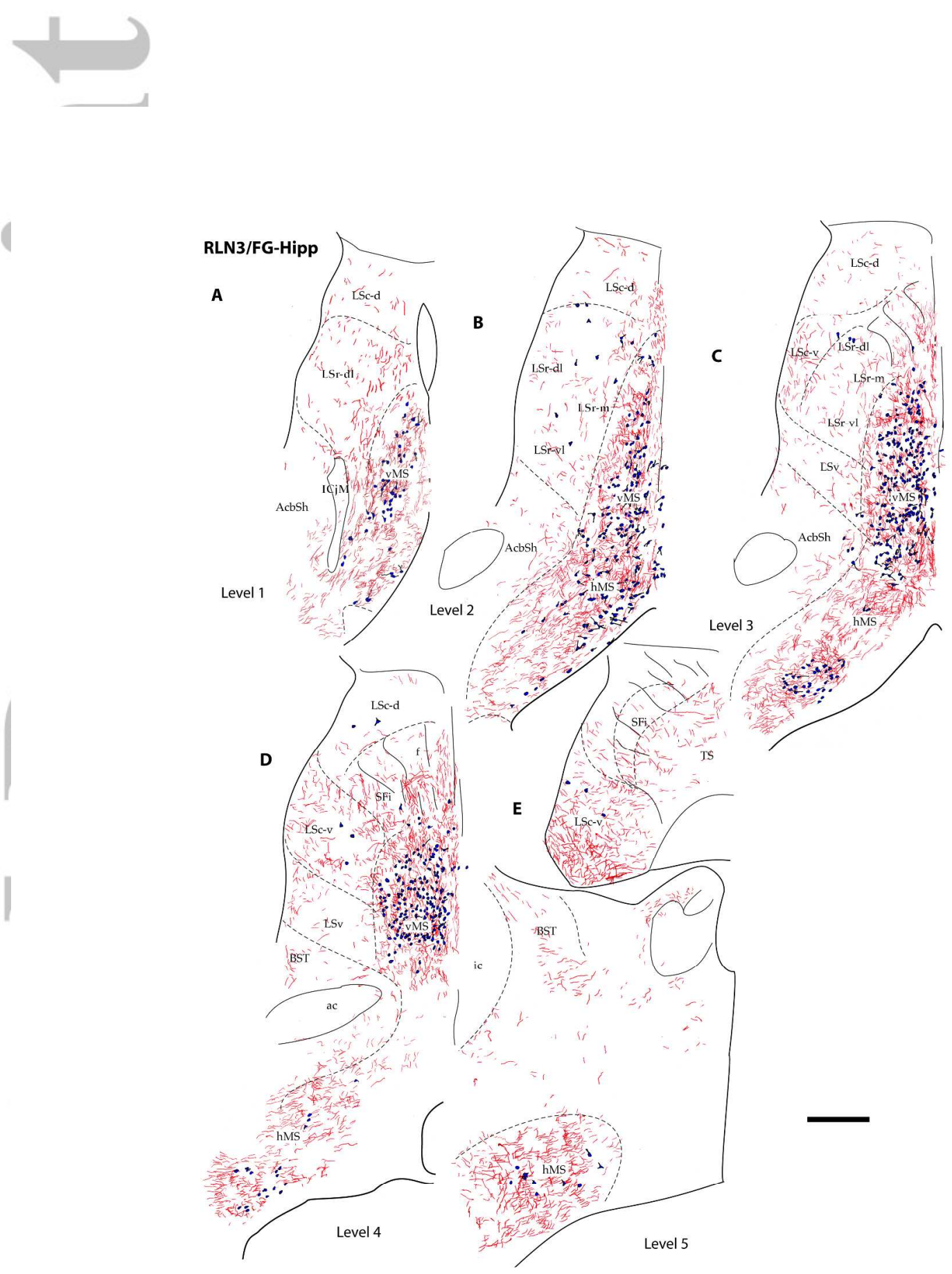

Figure 5. Distribution of RLN3-positive fibers in the septal area relative to the distribution of neurons retrogradely labeled following a FG injection into the ventral hippocampus. Immunostaining for FG and RLN3 was mapped as described in Figure 2. (A-E) Levels 1-5: Intense RLN3-labeling was observed within mostly medial septal regions containing retrogradely labeled neurons from the hippocampus including the vMS and hMS. The distribution of RLN3 fibers is similar to that of anterogradely labeling projections from the nucleus incertus (see Fig. 2). Scale bar, $500 \mu \mathrm{m}$. For abbreviations, see list.

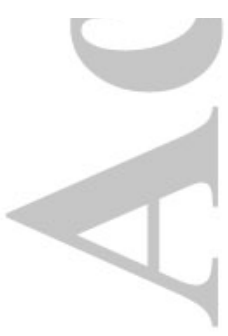

$209 \times 296 \mathrm{~mm}(300 \times 300$ DPI $)$ 


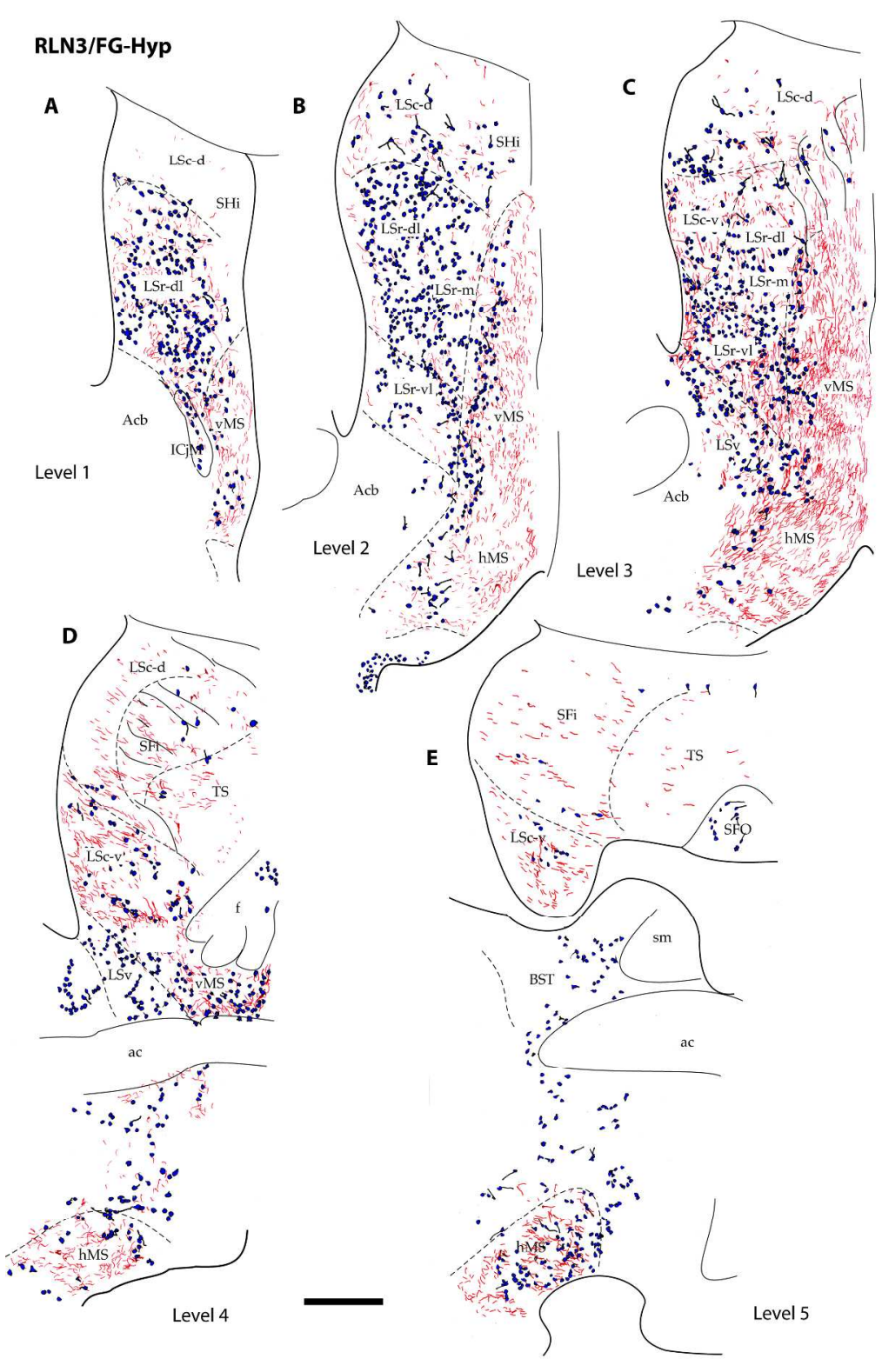

Figure 6. Distribution of RLN3-positive fibers in the septal area relative to the distribution of neurons retrogradely labeled following a FG injection into the anterior hypothalamus. Immunostaining for FG and RLN3 was mapped as described in Figure 2. (A-E) Level 1-5: Intense RLN3-labeling was observed within the vertical and horizontal limbs of MS septum, which contained a restricted band of retrogradely labeled neurons on the border with the lateral septum (B-D). RLN3-labeling was also observed in several lateral septum nuclei, which contained very high densities of retrogradely labeled neurons. The dorsal caudal lateral septum was the only region that did not contain retrograde labeling or RLN3-labeled fibers. For abbreviations, see list. Scale bar, $500 \mu \mathrm{m}$.

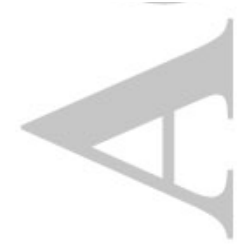
$188 \times 292 \mathrm{~mm}(300 \times 300 \mathrm{DPI})$ 

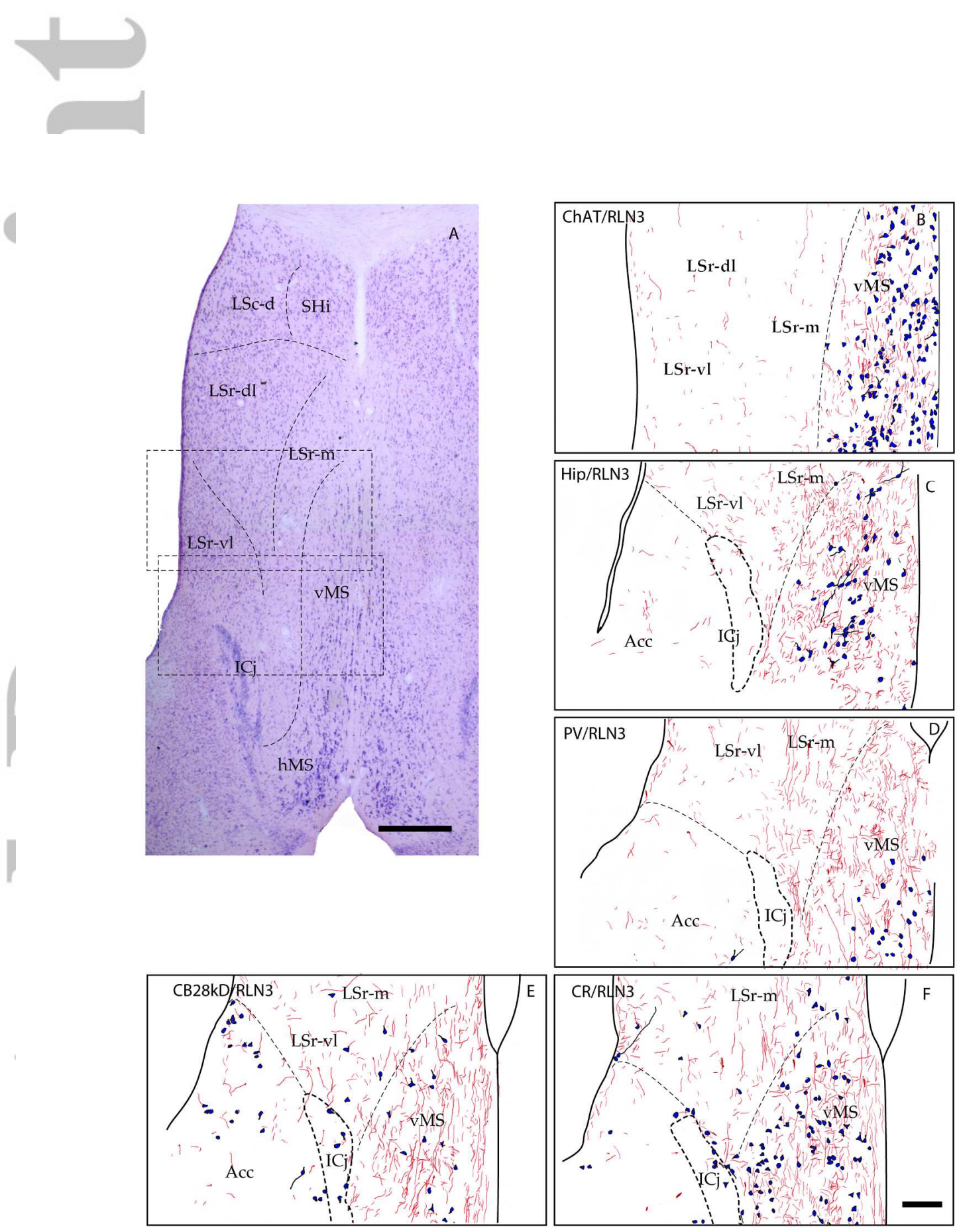

Figure 7. Distribution of RLN3-positive fibers at level 1 of the septal area in the vertical limb of the medial septum and adjacent lateral septum. (A) Nissl stained section at level 1 is characterized by boundaries with the insula of Calleja Magna. Dorsal aspects of the septum include the dorsal part of the LSc and the septohippocampal nucleus. The central area includes the three divisions of the LSr - dorsolateral, ventrolateral and medial. At this level, two divisions of the medial septum are evident - vMS that contains loosely packed large neurons; and hMS that contains densely packed large neurons. (B-E) Double immunostaining for RLN3 (red) and other septal markers (blue) in the framed region of ' $A$ ', mapped using camera lucida. The boundaries of septal divisions are depicted in black and revectorized. Immunostaining for RLN3 mapped with (B) FG following injection into the ventral hippocampus, (C) parvalbumin, (D) calbindin$28 \mathrm{kD}$, and $(E)$ calretinin. Scale bars, $500 \mu \mathrm{m}$ in $\mathrm{A} ; 250 \mu \mathrm{m}$ in B-E.

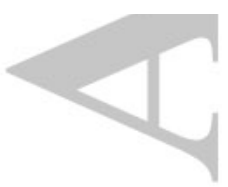
$201 \times 252 \mathrm{~mm}(300 \times 300$ DPI $)$ 

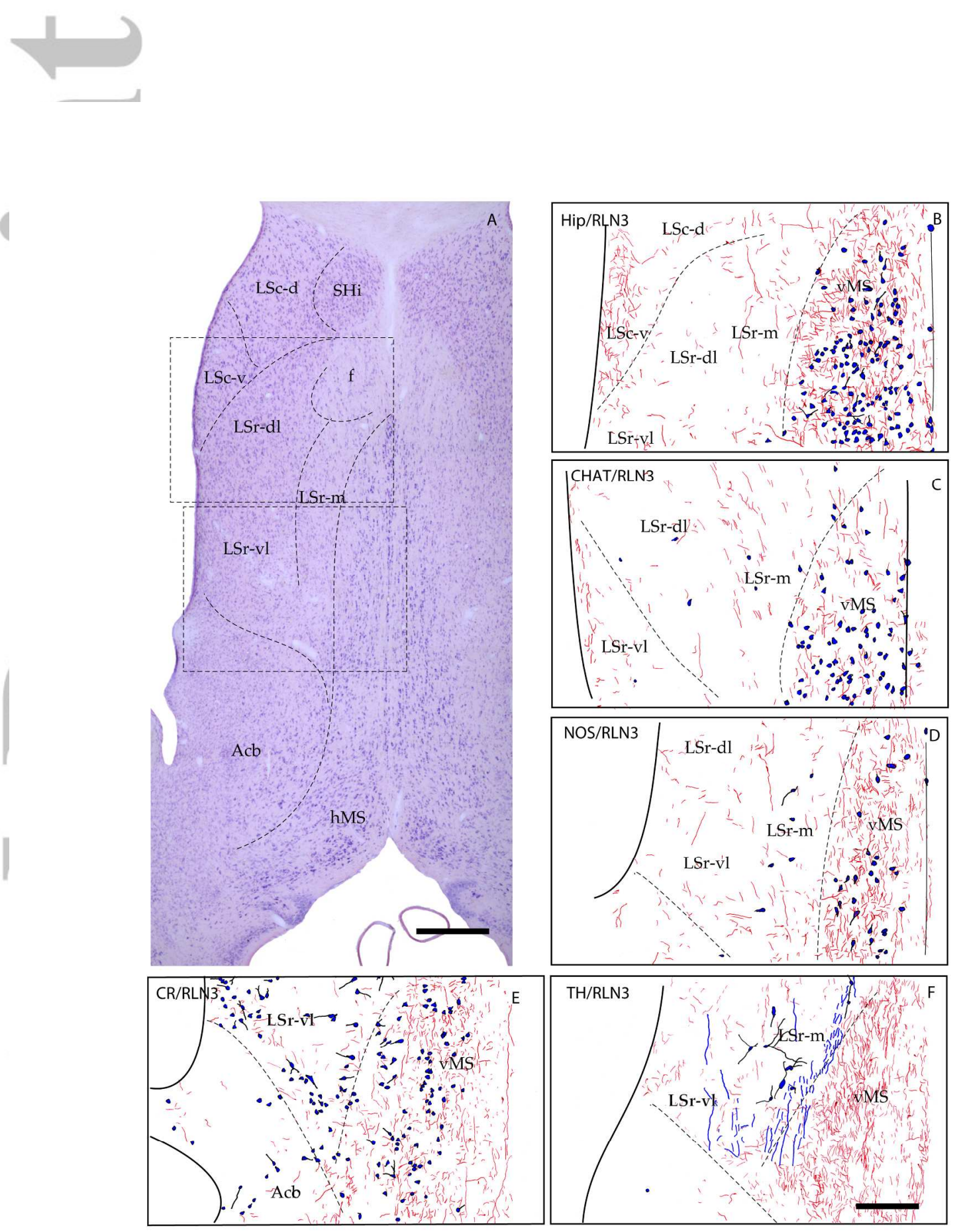

Figure 8. Distribution of RLN3-positive fibers at level 2 of the septal area in the vertical limb of the medial septum and adjacent lateral septum. (A) Nissl stained section at level 2 - characterized by the presence of the rostral-most level of the fornix, dorsal to the medial septum. Dorsal to the fornix, there is a clear divide between the septohippocampal nucleus and the LSc-d. In the ventral tip of this area, a clearly defined group of dense cells is observed, and identifiable as the LSc-v. The central area includes three divisions of the LSr

- dorsolateral, ventrolateral and medial, which have no clear boundaries. At this level, there are two divisions of the medial septum, vMS containing loosely packed large neurons, and hMS containing densely packed large neurons. (B-E) Double immunostaining for RLN3 (red) and other septal markers (blue) in framed region of ' $A$ ', mapped using camera lucida. Immunostaining for RLN3 combined with (B) FG staining, following injection in the ventral hippocampus, (C) ChAT, (D) nNOS, (E) calretinin, and (F) TH. Scale bars, $500 \mu \mathrm{m}$ in $\mathrm{A} ; 250 \mu \mathrm{m}$ in $\mathrm{B}-\mathrm{E}$. $199 \times 254 \mathrm{~mm}(300 \times 300 \mathrm{DPI})$ 


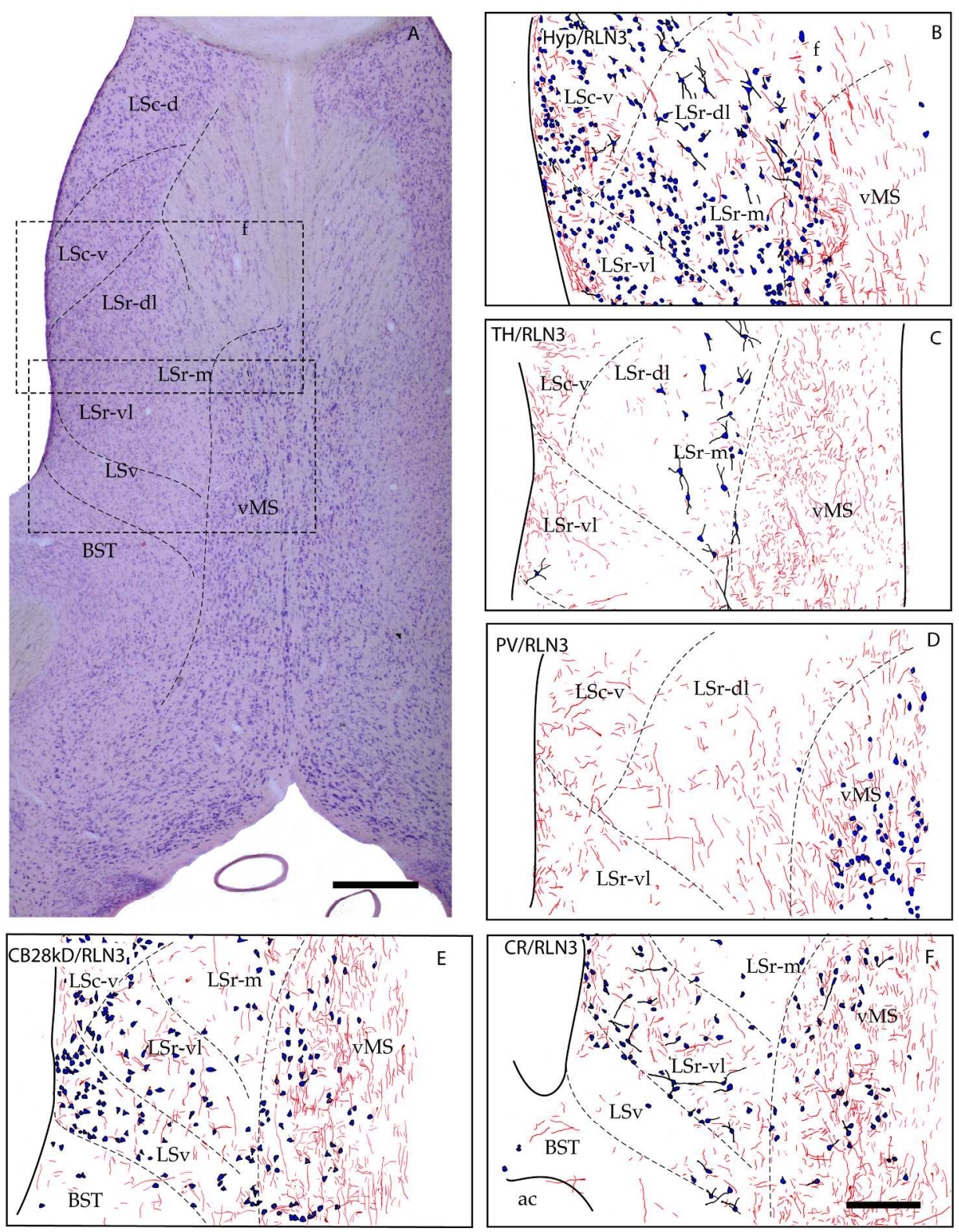

Figure 9. Distribution of RLN3-positive fibers at level 3 of the septal area in the vertical limb of the medial septum and adjacent lateral septum. (A) A Nissl stained section at level 3 is characterized by fornix bundles occupying the dorsomedial aspects of the septum bordering the medial septum. Capping the fornix dorsolaterally, the LSc contains the dorsal and ventral divisions. Dorsal to the fornix, a clear divide exists between the septohippocampal nucleus and the LSc-d. In the ventral tip of this area, an apparent divide containing densely-packed cells was observed, identified as the LSc-v. The central area includes three divisions of the LSr - dorsolateral, ventrolateral and medial, which have no clear boundaries. At this level, there are two divisions of the medial septum, vMS containing loosely packed large neurons and hMS containing densely packed large neurons. (B-E) Double immunostaining for RLN3 (red) and other septal markers (blue) in framed region of ' $A$ ', mapped using camera lucida. Immunostaining for RLN3 combined with (B) FG staining following injection in the anterior hypothalamus, (C) ChAT, (D) PV, (E) CB-28kD, and (F) CR. Scale bars, $500 \mu \mathrm{m}$ in A; $250 \mu \mathrm{m}$ in B-E. $199 \times 255 \mathrm{~mm}(300 \times 300 \mathrm{DPI})$ 

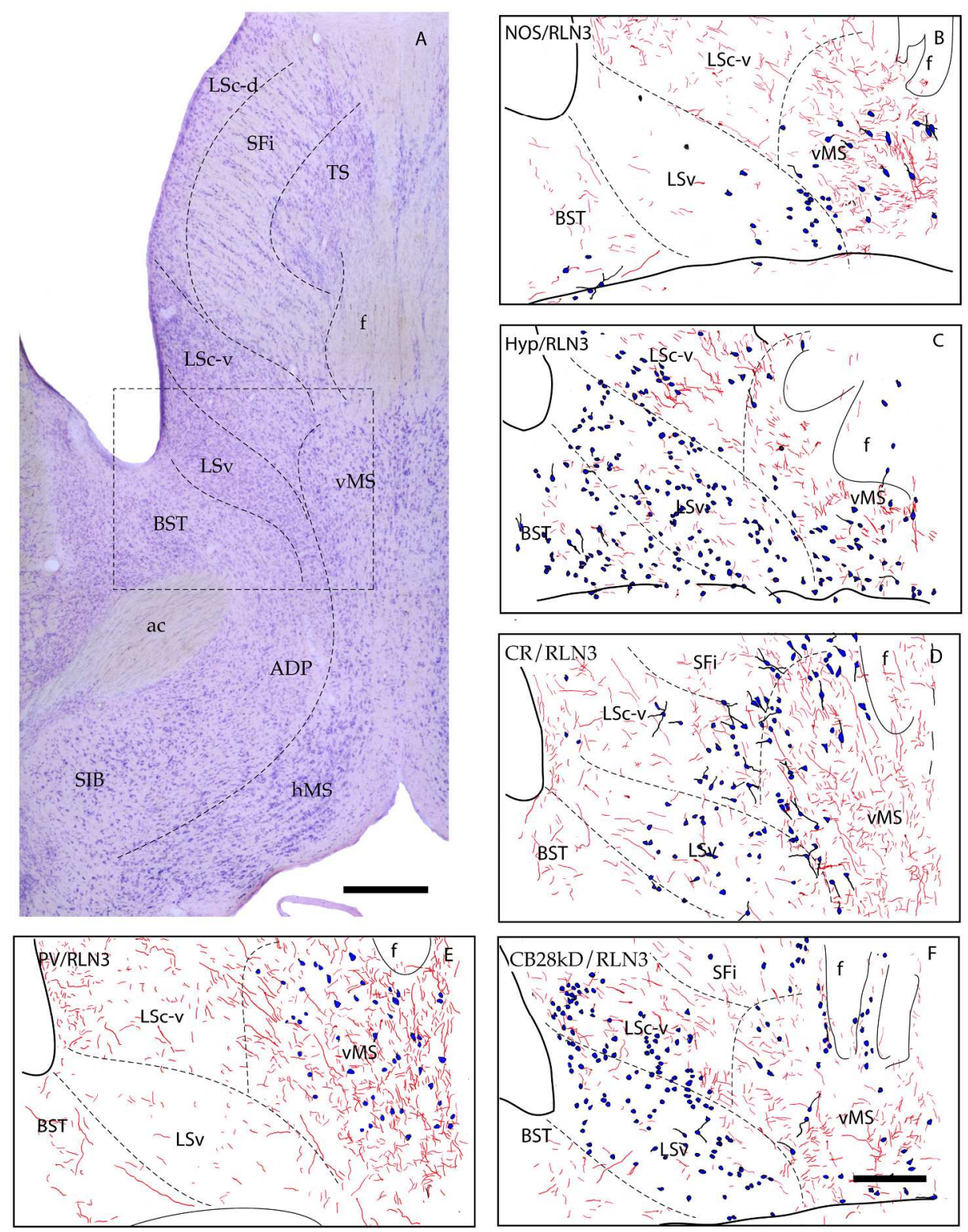

Figure 10. Distribution of RLN3-positive fibers at level 4 of the septal area in the vertical limb of the medial septum and adjacent posterior septum. (A) A Nissl stained section at level 4, at which the posterior septum appears in the center of the septal area and includes the triangular septal and septofimbral nuclei.

Dorsolateral to these nuclei, the fimbrial bundles are capped by the LSc-d/v and only the ventral division contained RLN3 fibers. Ventral to the fornix, a group of VMS neurons lie between the fornix and the anterior commissure. Lateral to this cell group, a diagonal band of neurons were observed, corresponding to the LSv. The hMS appears over the ependymal surface, surrounded by the basal substantia innominata and the anterior dorsal peduncular hypothalamic area. (B-E) Double immunostaining for RLN3 (red) and other septal markers (blue) in framed region of ' $A$ ', mapped using camera lucida. Immunostaining for RLN3 combined with (B) nNOS, (C) FG staining following injection into the anterior hypothalamus, (D) calretinin, (E) TH, and (F) calbindin. Scale bars, $500 \mu \mathrm{m}$ in $\mathrm{A} ; 250 \mu \mathrm{m}$ in $\mathrm{B}-\mathrm{E}$. $201 \times 260 \mathrm{~mm}(300 \times 300 \mathrm{DPI})$ 


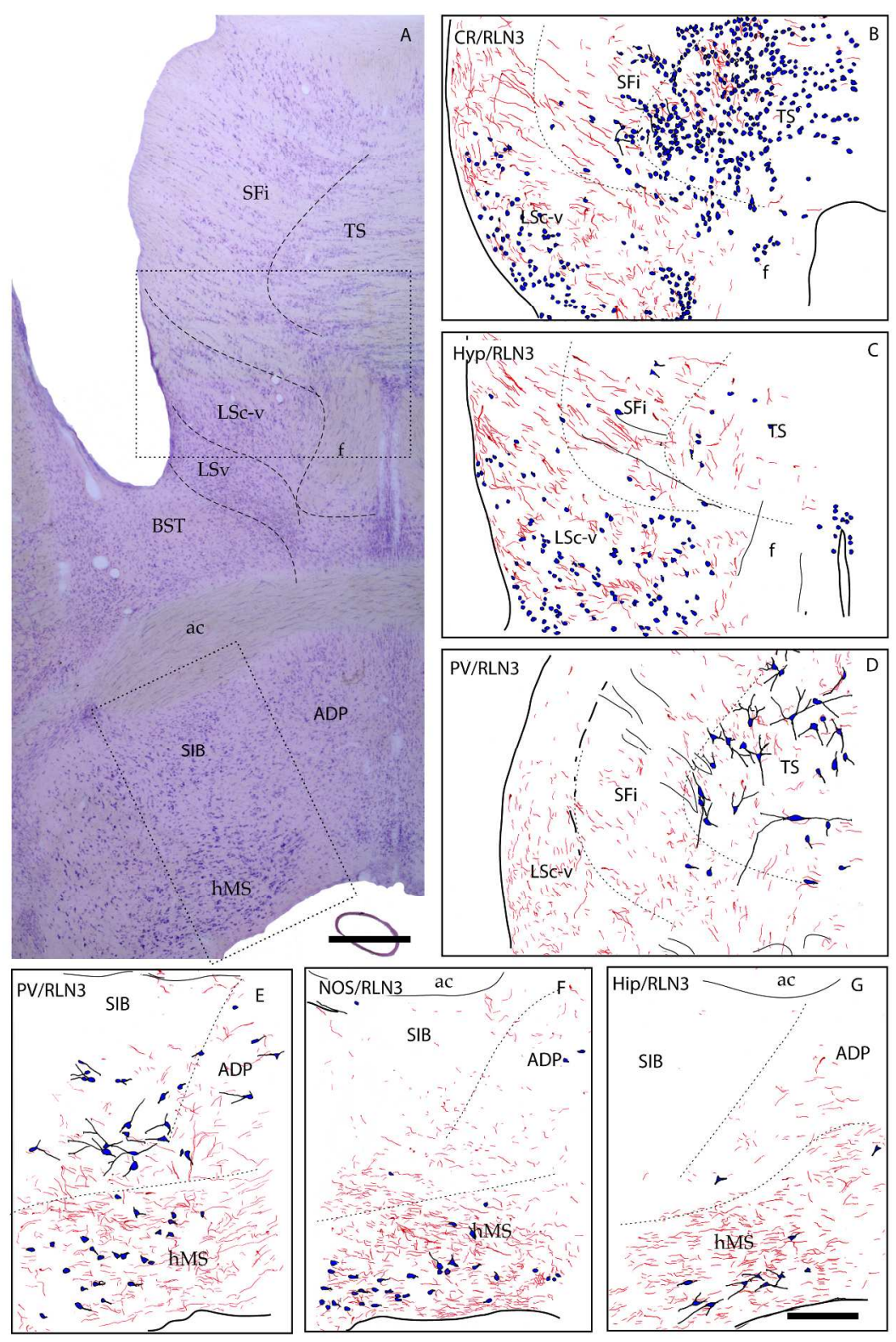

Figure 11. Distribution of RLN3-positive fibers at level 5 of the septal area in the horizontal limb of the medial septum and the lateral septum. (A) A Nissl stained section at level 5, where the posterior septum is composed of the triangular septal and septofimbrial nuclei, which are capped by the dorsal and ventral LSc. Ventrally, the hMS is lateral to the preoptic area of the hypothalamus and is capped dorsally by the basal substantia innominata. (B-E) Double immunostaining for RLN3 (red) and other septal markers (blue) in framed region of ' $A$ ', mapped using camera lucida. Immunostaining for RLN3 combined with (B) calretinin, a robust marker for the triangular septal nucleus, (C) FG staining, following FG injection into the anterior hypothalamus, (D) parvalbumin, which delineated the extension of the triangular septal nucleus, (E) parvalbumin in the hMS (note: the SIB contained well-labeled parvalbumin neurons, but sparse RLN3 fibers), (F) nNOS (note: nNOS positive cells occupy different compartments of the hMS), and (F) FG staining, following FG injection into the ventral hippocampus. Scale bars, $500 \mu \mathrm{m}$ in A; $250 \mu \mathrm{m}$ in B-E. $194 \times 289 \mathrm{~mm}(300 \times 300 \mathrm{DPI})$ 

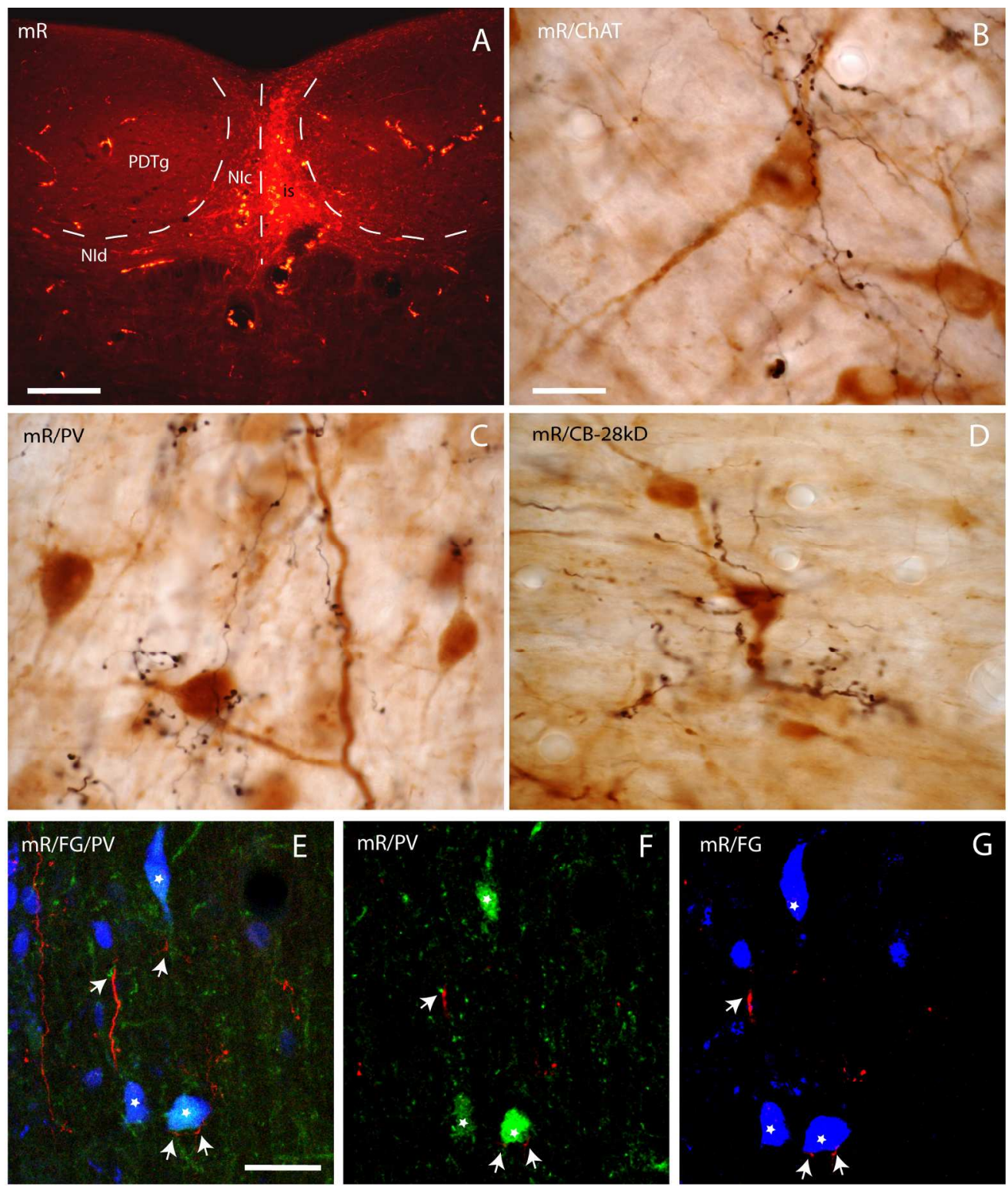

Figure 12. Septal targets of nucleus incertus neurons mapped after injection of the anterograde tracer, miniruby ( $m R$ ), into the nucleus incertus. (A) Representative photomicrograph of an injection into the nucleus incertus pars compacta, which resulted in little or no spread from the injection site to the contralateral side, posterodorsal tegmental nucleus, or more rostrally located raphe nucleus. (B) Perisomatic terminal-like labeling of $\mathrm{mR}$ fibers contacting a ChAT-positive cell in the region between the vMS and the hMS. (C) Anterograde terminal-like labeling surrounding parvalbumin-positive soma and processes.

(D) Terminal-like labeling contacting calbindin-positive soma and processes. (E-G) Confocal images illustrating putative contacts between anterogradely labeled $\mathrm{mR}$ fibers (red) and parvalbumin-positive somata (green) of a hippocampal-projecting neuron (blue), following FG injection into the hippocampus. (E) Maximal projection of overlaid images from 10 sections of $0.8 \mu \mathrm{m}$. (F) A single section of $0.8 \mu \mathrm{m}$ illustrating anterogradely-labeled elements and parvalbumin. (G) Retrogradely-labeled FG positive cells and anterogradely-labeled $\mathrm{mR}$ positive elements. Asterisks represent neurons double-labeled for FG and parvalbumin; arrows indicate contacts between anterogradely-labeled fibers and parvalbumin-positive somata or processes. Scale bars, A $200 \mu \mathrm{m}$, B-D $20 \mu \mathrm{m}, \mathrm{E}-\mathrm{G} 40 \mu \mathrm{m}$. 

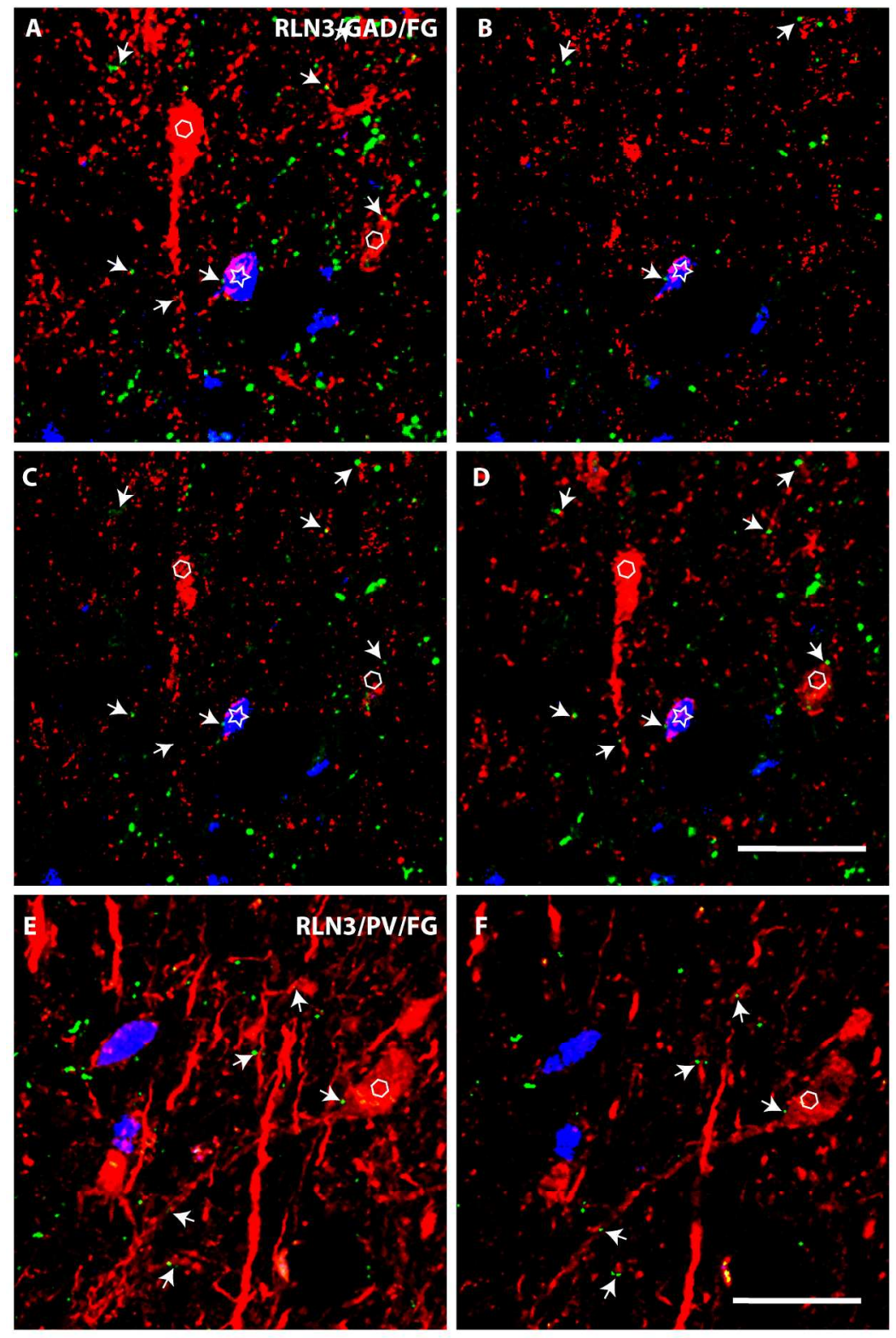

Figure 13. Confocal images illustrating putative contacts between RLN3-positive fibers and (A-D) GAD67containing neurons; and $(E, F)$ parvalbumin-containing neurons and FG containing neurons, following FG injection into the hippocampus. Neurons containing GAD or parvalbumin are marked by hexagons and neurons double-labeled for GAD and FG are indicated by stars. Arrows indicate possible contacts between RLN3-labeled fibers and labeled neurons or processes. (A) Overlaid maximal projection of $10 \mathrm{scans}, 0.5 \mu \mathrm{m}$ apart through the MS - FG (blue), GAD (red) and RLN3 (green), and (B-D) three single, consecutive scans, $0.5 \mu \mathrm{m}$ apart, represented in A. (E) Maximal projection of 8 sections, $0.8 \mu \mathrm{m}$ apart - RLN3 (green), FG

(blue) and PV (red); and (F) a single section of $0.8 \mu \mathrm{m}$, represented in E. Scale bars, $40 \mu \mathrm{m}$. $166 \times 251 \mathrm{~mm}(300 \times 300 \mathrm{DPI})$

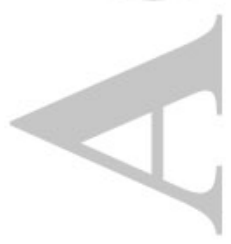



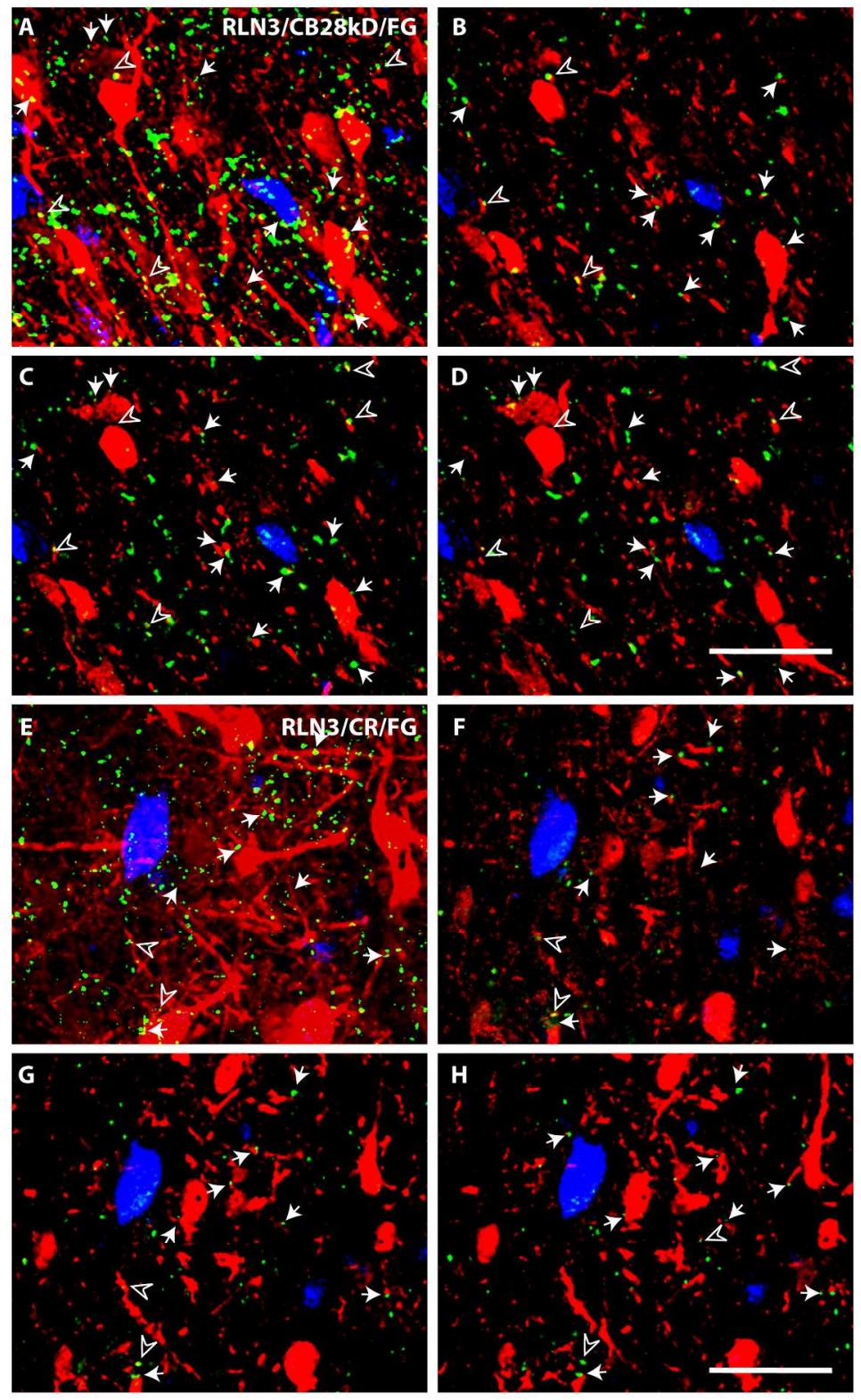

Figure 14. Confocal images illustrating putative contacts between RLN3-positive fibers and (A-D) calbindin$28 \mathrm{kD}$-containing neurons or $(\mathrm{E}-\mathrm{H})$ calretinin-containing neurons in the medial septum following $\mathrm{FG}$ injection into the hippocampus. No colocalization was observed between FG (blue) and CB-28kD or CR (red). (A)

Maximal projection of 9 sections, $2 \mu \mathrm{m}$ apart, stained for CB-28kD (red); and (B-D) three single, consecutive sections, $2 \mu \mathrm{m}$ apart, represented in A. (E) Maximal projection of 9 sections, $2 \mu \mathrm{m}$ apart, stained for CR (red), and (F-H) three single, consecutive sections, $2 \mu \mathrm{m}$ apart, represented in A. Solid arrows indicate close contacts between RLN3 (green) and CB-28kD or CR cells. Open arrowheads indicate colocalization of RLN3 and CB 28kD or CR. Scale bars, $40 \mu \mathrm{m}$. $167 \times 273 \mathrm{~mm}(300 \times 300 \mathrm{DPI})$

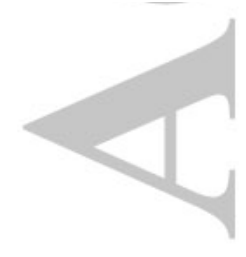



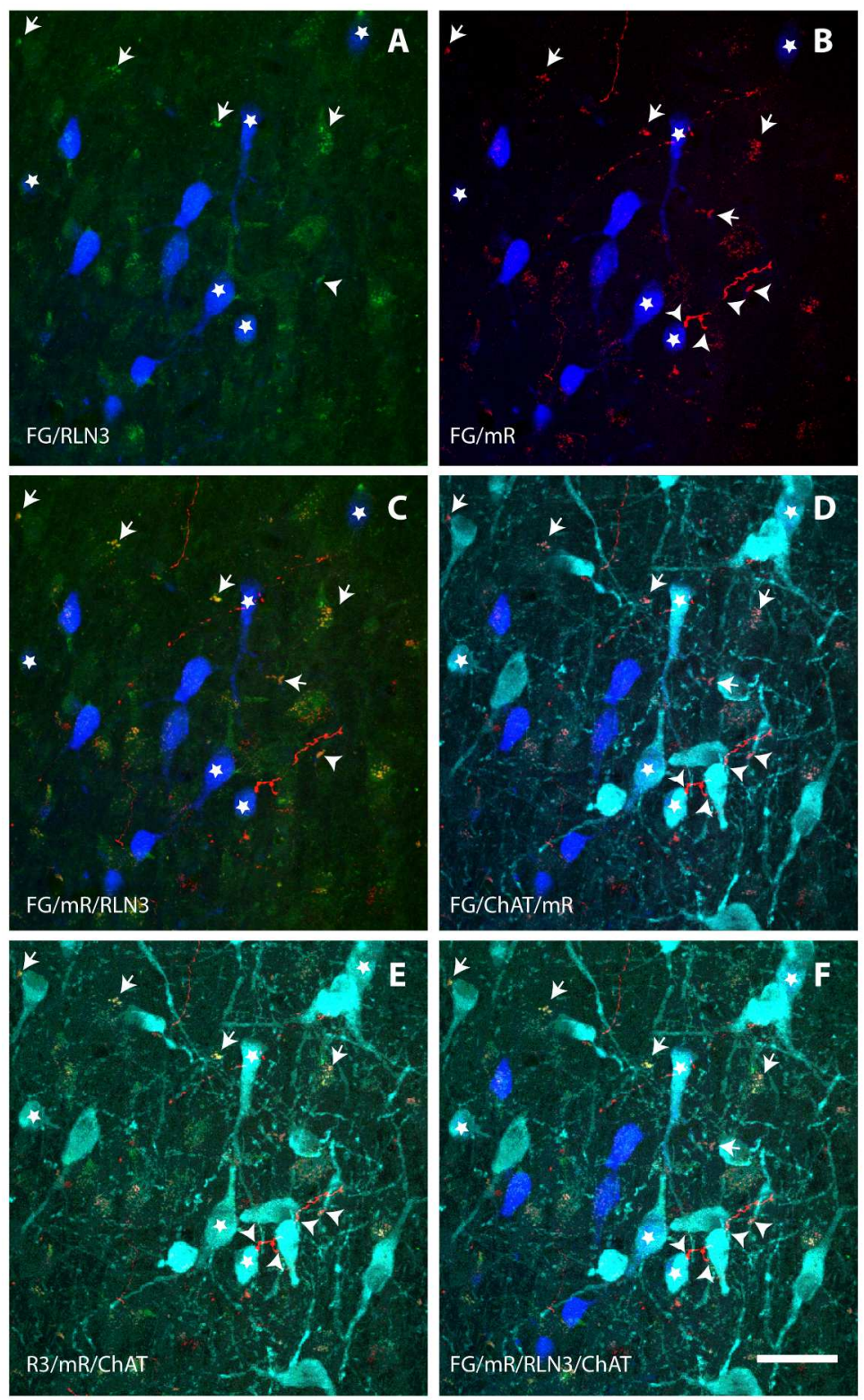

Figure 15. Confocal images illustrating the colocalization of mR- (red) and RLN3- (green) associated immunofluorescence (arrows) in a nerve fiber stained for RLN3 and ChAT (cyan) in the medial septum in a coronal section from a case (\#54) that received a FG injection into the hippocampus and and a mR injection into the nucleus incertus. Stars indicate double-labeled FG (blue) and ChAT-positive neurons. Arrowheads indicate putative contacts between $\mathrm{mR} / \mathrm{RLN} 3$ fibers and labeled neurons or processes. Immunofluorescence for (A) RLN3 and FG; (B) mR and FG; (C) FG, mR and RLN3 - note overlap of RLN3 and mR labeling in some fibers; (D) triple-labeling for FG, ChAT and $\mathrm{mR}$-note neurons labeled for ChAT and FG); (E) triple-labeling for ChAT, $m R$ and RLN3; and (F) merge of FG, mR, RLN3 and ChAT. Scale bar, $40 \mu \mathrm{m}$.

$157 \times 256 \mathrm{~mm}(300 \times 300 \mathrm{DPI})$

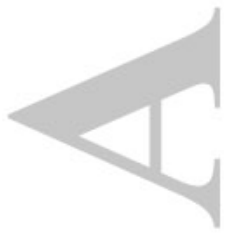



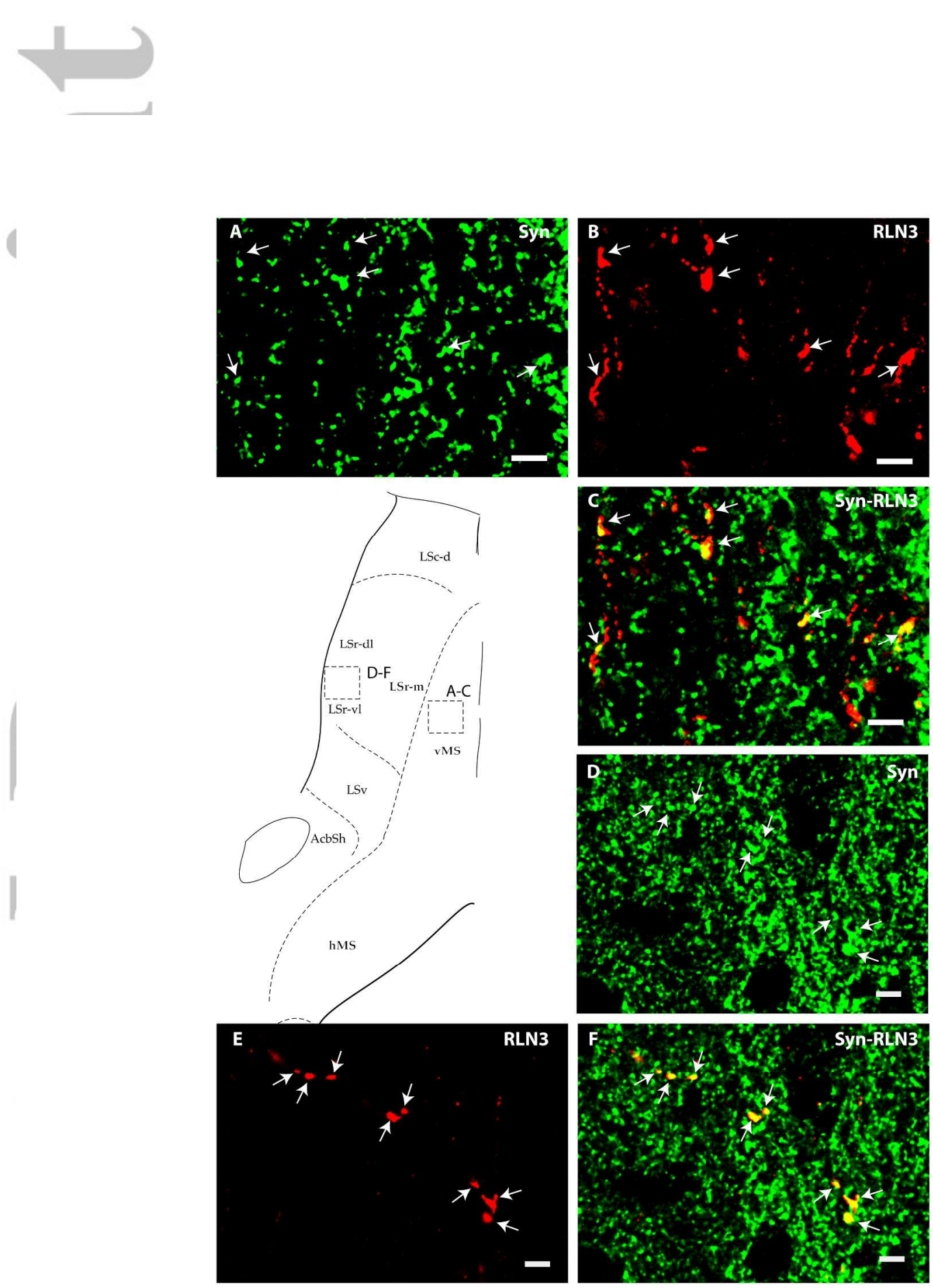

Figure 16. Confocal images illustrating the colocalization of RLN3 with synaptophysin puncta in regions of the (A-C) medial septum and (D-F) lateral septum (see schematic). Arrows indicate colocalization between RLN3 (red) and Syn (green). Single sections of $0.5 \mu \mathrm{m}$ illustrating immunofluorescent staining for (A) RLN3, (B) Syn, and (C) RLN3 and Syn images merged. Single sections of $0.5 \mu \mathrm{m}$ in the LSr-vl, illustrating staining for (D) RLN3, (E) Syn, and (F) RLN3 + Syn (merged). Scale bars, $5 \mu \mathrm{m}$. $182 \times 271 \mathrm{~mm}(300 \times 300 \mathrm{DPI})$

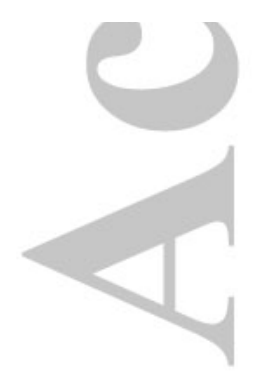



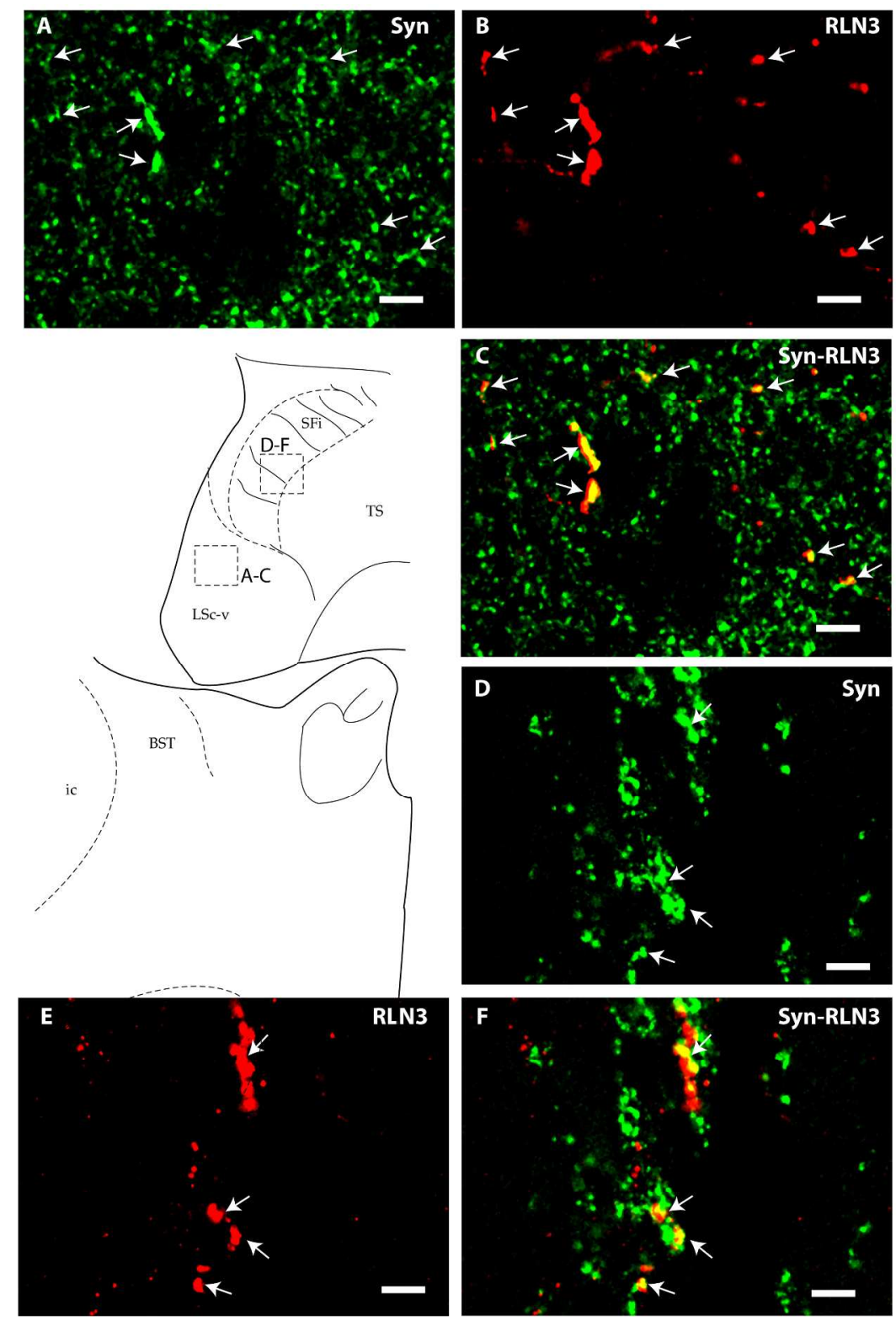

Figure 17. Confocal images illustrating the colocalization of RLN3 with synaptophysin puncta in the (A-C) caudal LSv and (D-F) septofimbrial nucleus (see schematic). Arrows indicate colocalization between RLN3 (red) and Syn (green). Single sections of $0.5 \mu \mathrm{m}$ in the caudal LSv, illustrating immunofluorescent staining for (A) Syn, (B) RLN3 and (C) RLN3 and Syn images merged. Amongst the high densities of Syn puncta observed, large empty spaces likely correspond to neuronal somata. Single sections of $0.5 \mu \mathrm{m}$ in the septofimbrial nucleus, illustrating immunofluorescent staining for (D) Syn, (E) RLN3, and (F) RLN3 + Syn (merged). The septofimbrial area contains groups of cells between axonal bundles that appear as empty spaces and the majority of RLN3 fibers display Syn staining. Scale bars, $5 \mu \mathrm{m}$. $183 \times 271 \mathrm{~mm}(300 \times 300 \mathrm{DPI})$

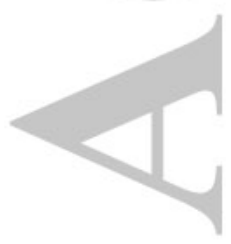



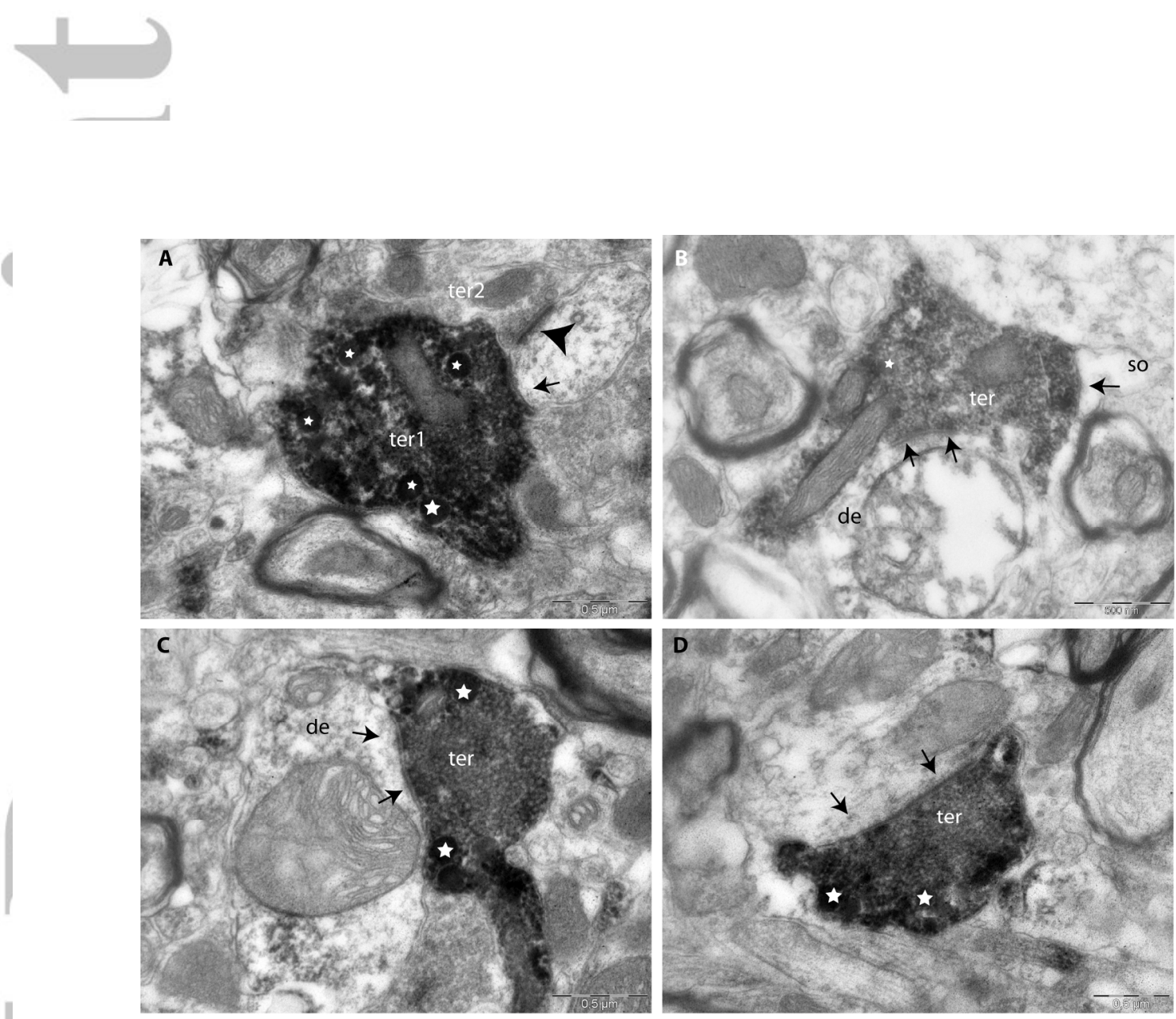

Figure 18. Electron photomicrographs of sections through the medial septum stained for RLN3 illustrating synaptic contacts between labeled terminals and postsynaptic structures. Most labeled terminals contained

large, round dense-vesicles of $\sim 100-150 \mathrm{~nm}$ in diameter (stars). (A) A labeled terminal (ter1) with symmetric contact (arrow) on a dendrite. This dendrite also makes contact with another terminal (ter2) that gives rise to an asymmetric contact (large arrowhead). (B) RLN3-labeled terminal (ter) making symmetric contacts with a soma (so) and a dendrite (de). (C,D) RLN3-labeled terminals making symmetric contacts with dendrites (arrows). Scale bars, $500 \mathrm{~nm}$.

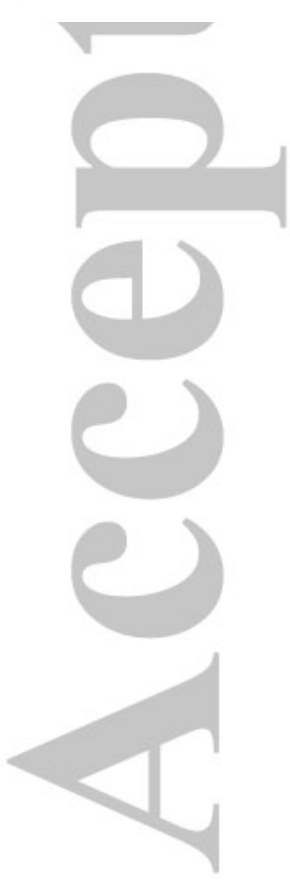
$194 \times 146 \mathrm{~mm}$ ( $300 \times 300$ DPI) 


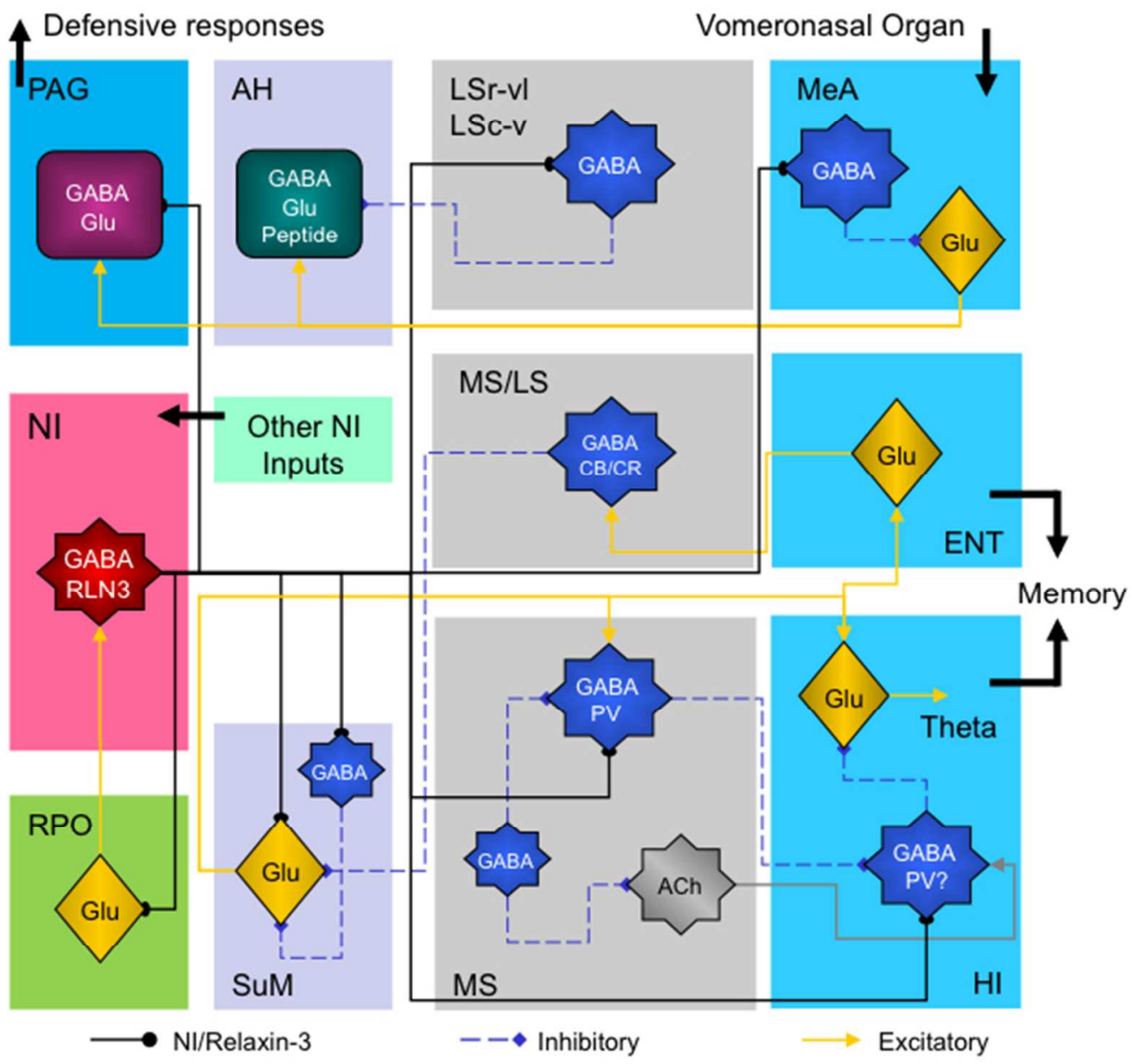

Figure 19. Schematic diagram illustrating two major circuits modulated by RLN3 projections to the septal area. (Upper) Descending projections originating in the medial amygdala and LSr-vl converge on the anterior hypothalamic nucleus, where defensive neural signals are channeled to the periaqueductal grey. (Lower) Modulatory inputs arising from the nucleus incertus control the medial septum through two types of projections - those to septohippocampal neurons and local neurons, and those to neurons in the supramammillary nucleus that in turn project to the medial septum and hippocampus. This circuit is responsible for the generation and modulation of hippocampal theta rhythm.

$$
218 \times 205 \mathrm{~mm}(72 \times 72 \mathrm{DPI})
$$




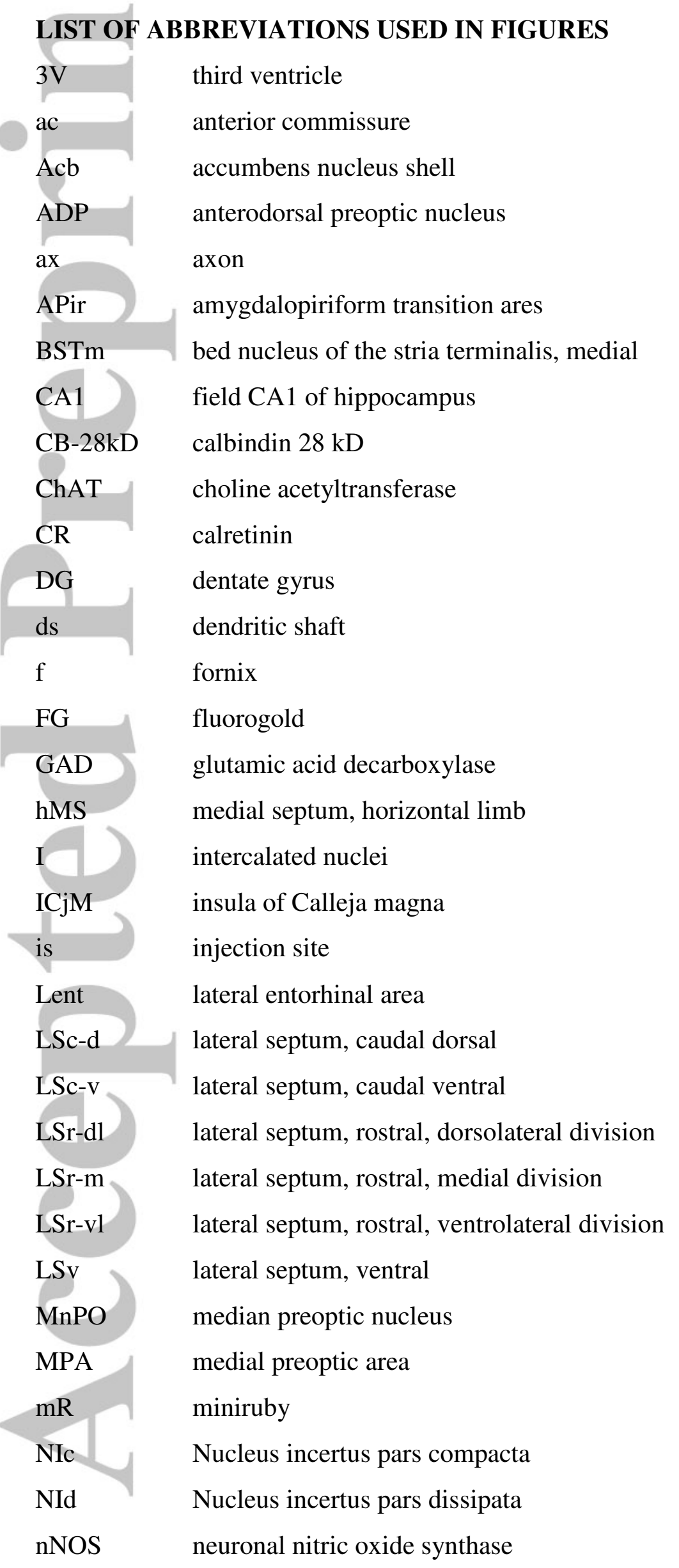




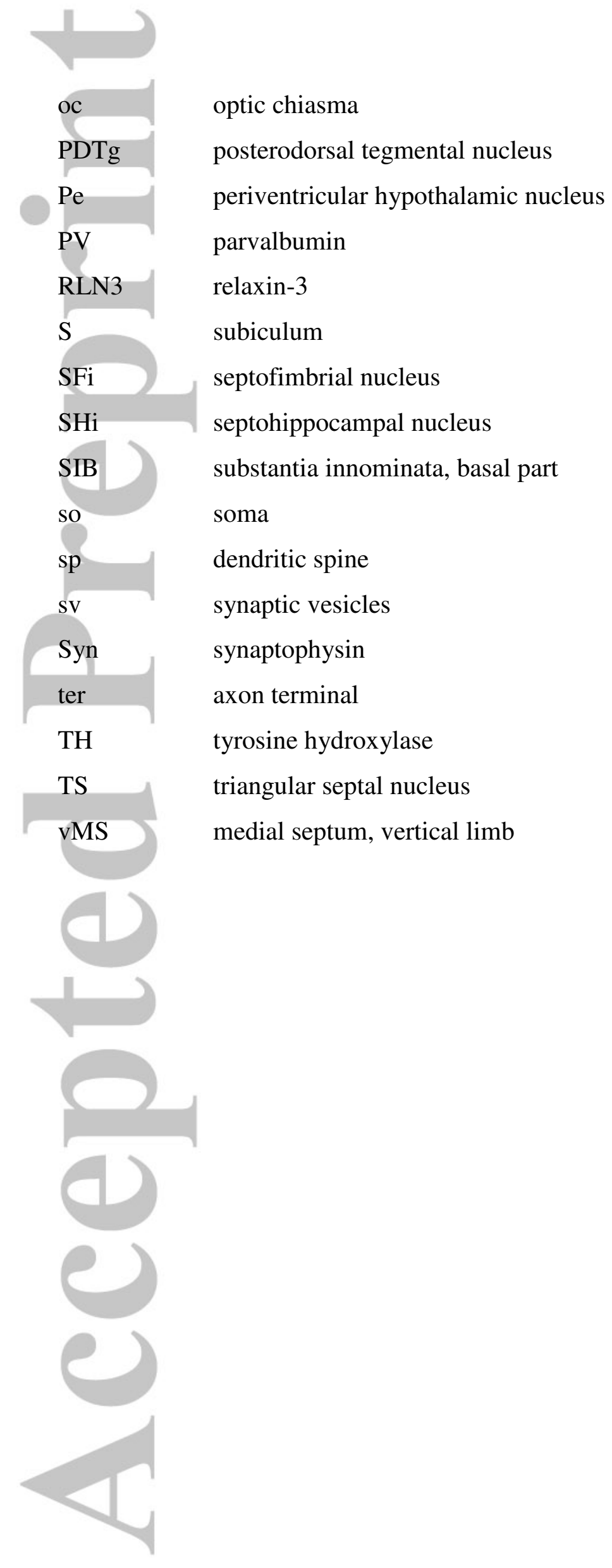



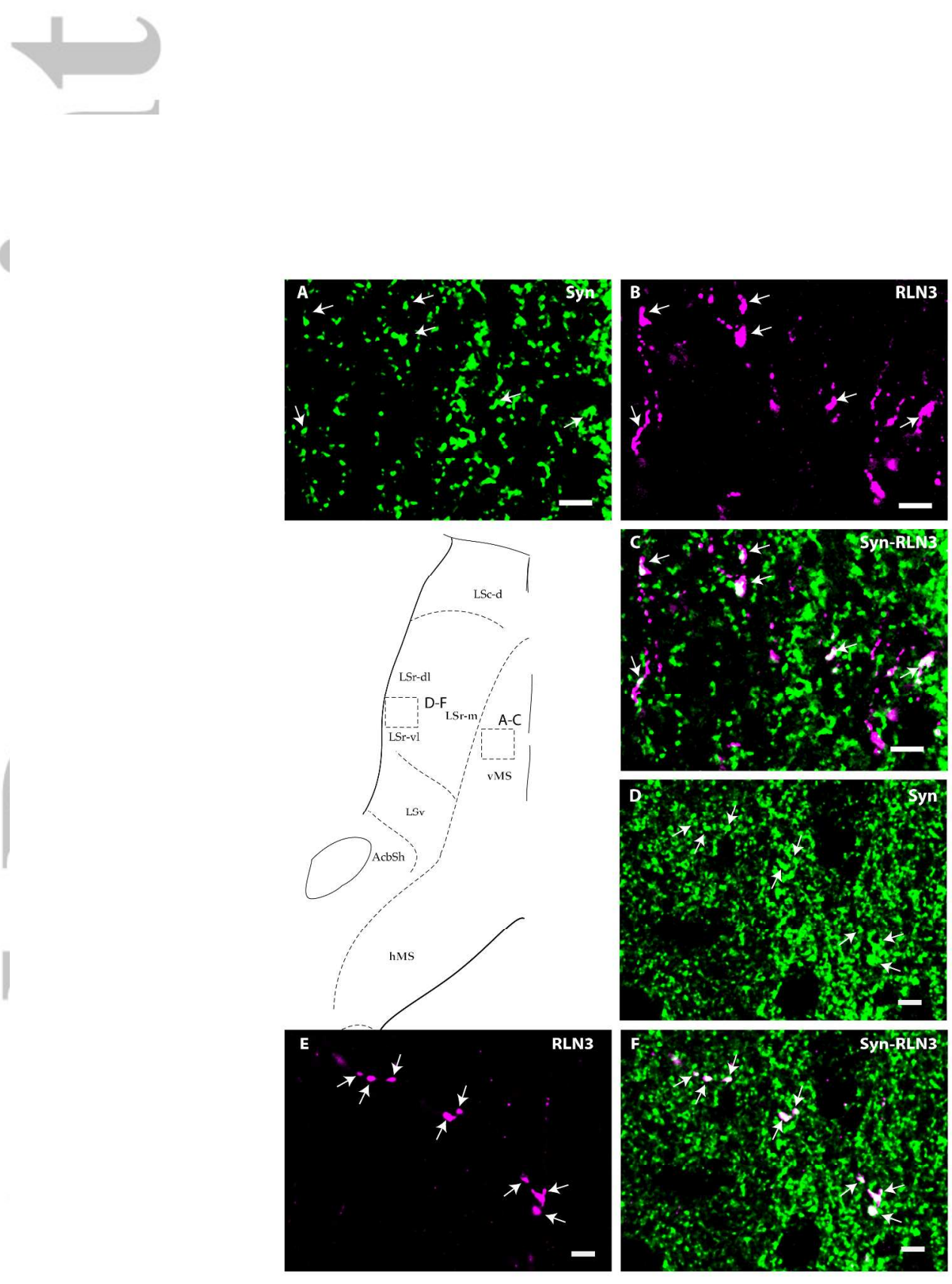

Supplementary figure 1. Confocal images illustrating the colocalization of RLN3 with synaptophysin puncta in regions of the $(A-C)$ medial septum and $(D-F)$ lateral septum (see schematic). Arrows indicate colocalization between RLN3 (magenta) and Syn (green). Single sections of $0.5 \mu \mathrm{m}$ illustrating immunofluorescent staining for (A) RLN3, (B) Syn, and (C) RLN3 and Syn images merged. Single sections of $0.5 \mu \mathrm{m}$ in the LSr-vl, illustrating staining for (D) RLN3, (E) Syn, and (F) RLN3 + Syn (merged). Scale bars, $5 \mu \mathrm{m}$. $229 \times 319 \mathrm{~mm}(300 \times 300 \mathrm{DPI})$

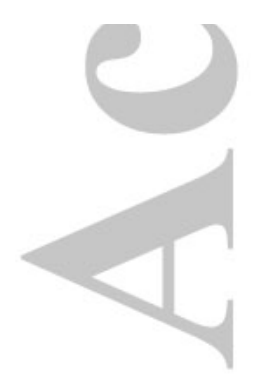



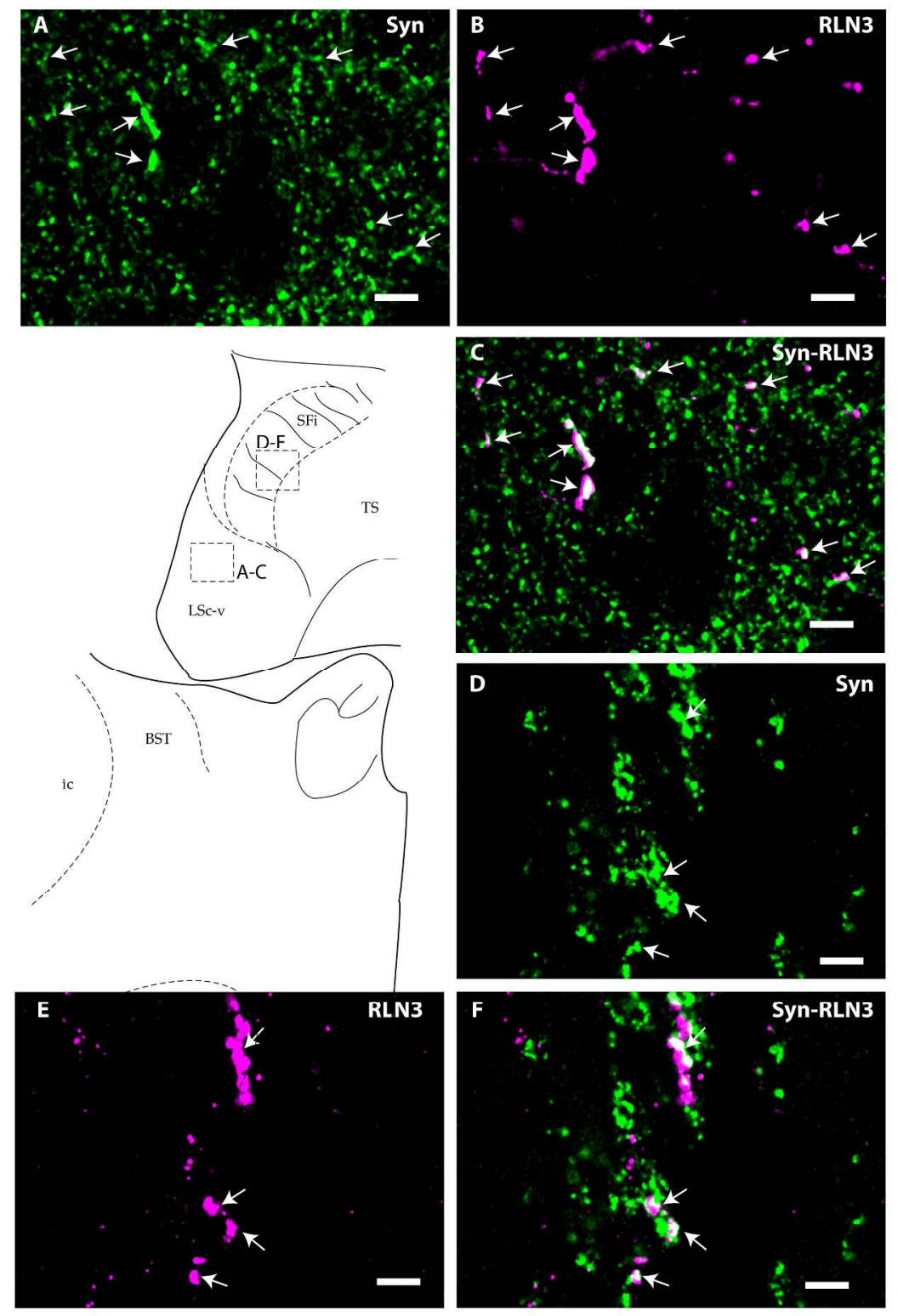

Supplementary figure 2. Confocal images illustrating the colocalization of RLN3 with synaptophysin puncta in the (A-C) caudal LSv and (D-F) septofimbrial nucleus (see schematic). Arrows indicate colocalization between RLN3 (magenta) and Syn (green). Single sections of $0.5 \mu \mathrm{m}$ in the caudal LSv, illustrating immunofluorescent staining for (A) Syn, (B) RLN3 and (C) RLN3 and Syn images merged. Amongst the high densities of Syn puncta observed, large empty spaces likely correspond to neuronal somata. Single sections of $0.5 \mu \mathrm{m}$ in the septofimbrial nucleus, illustrating immunofluorescent staining for (D) Syn, (E) RLN3, and

(F) RLN3 + Syn (merged). The septofimbrial area contains groups of cells between axonal bundles that appear as empty spaces and the majority of RLN3 fibers display Syn staining. Scale bars, $5 \mu \mathrm{m}$. $227 \times 275 \mathrm{~mm}(300 \times 300 \mathrm{DPI})$

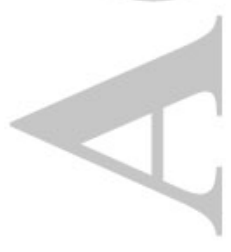




\section{SUPPLEMENTARY FILES:}

Supplementary figure 1. Confocal images illustrating the colocalization of RLN3 with synaptophysin puncta in regions of the (A-C) medial septum and (D-F) lateral septum (see schematic). Arrows indicate colocalization between RLN3 (magenta) and Syn (green). Single sections of $0.5 \mu \mathrm{m}$ illustrating immunofluorescent staining for (A) RLN3, (B) Syn, and (C) RLN3 and Syn images merged. Single sections of $0.5 \mu \mathrm{m}$ in the LSr-vl, illustrating staining for (D) RLN3, (E) Syn, and (F) RLN3 + Syn (merged). Scale bars, 5 $\mu \mathrm{m}$.

Supplementary figure 2. Confocal images illustrating the colocalization of RLN3 with synaptophysin puncta in the (A-C) caudal LSv and (D-F) septofimbrial nucleus (see schematic). Arrows indicate colocalization between RLN3 (magenta) and Syn (green). Single sections of $0.5 \mu \mathrm{m}$ in the caudal LSv, illustrating immunofluorescent staining for (A) Syn, (B) RLN3 and (C) RLN3 and Syn images merged. Amongst the high densities of Syn puncta observed, large empty spaces likely correspond to neuronal somata. Single sections of $0.5 \mu \mathrm{m}$ in the septofimbrial nucleus, illustrating immunofluorescent staining for (D) Syn, (E) RLN3, and (F) RLN3 + Syn (merged). The septofimbrial area contains groups of cells between axonal bundles that appear as empty spaces and the majority of RLN3 fibers display Syn staining. Scale bars, $5 \mu \mathrm{m}$. 